\title{
A KINETIC STUDY OF METHANOL SYNTHESIS IN A SLURRY REACTOR \\ USING a $\mathrm{CuO} / \mathrm{ZnO} / \mathrm{Al}_{2} \mathrm{O}_{3}$ CATALYST
}

DOE/PC/89787-T4

DE92 016818

A thesis

by

HAMAD ABDULWAHAB AL-ADWANI

Submitted to the Office of the Graduate Studies of

Texas A\&M University

in partial fulfillment of the requirements for the degree of

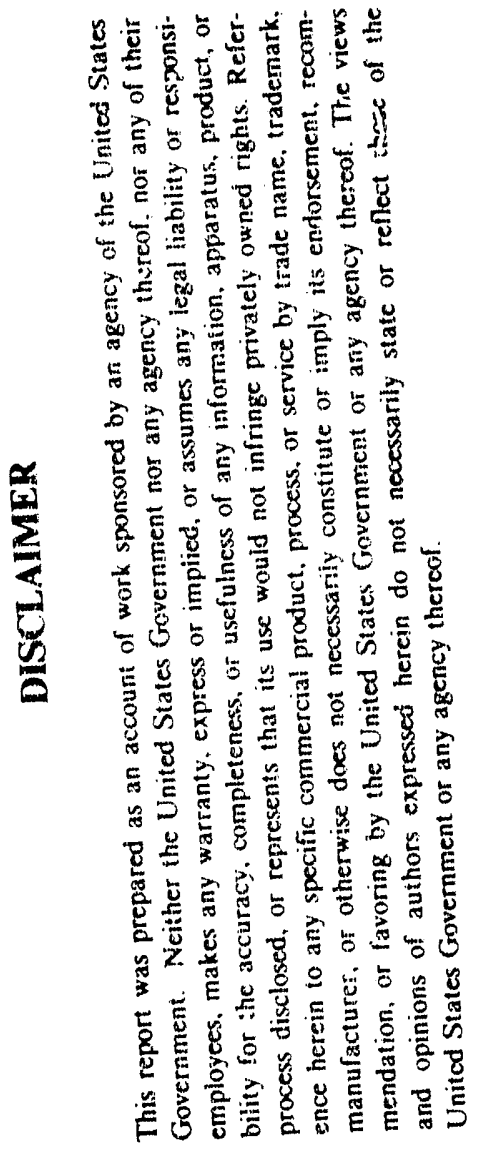

MASTER OF SCIENCE

FG22-89PC89787

May 1992

Major Subject: Chemical Engineering

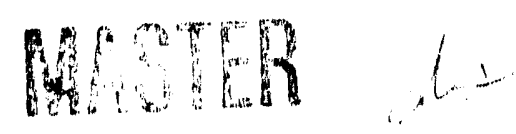

DISTRBBUTION OF THIS DOCUMENT IS UNLIMITED 


\title{
A KINETIC STUDY OF METHANOL SYNTHESIS IN A SLURRY REACTOR USING a $\mathrm{CuO} / \mathrm{ZnO} / \mathrm{Al}_{2} \mathrm{O}_{3}$ CATALYST
}

\author{
A thesis \\ by \\ HAMAD ABDULWAHAB AL-ADWANI
}

Approved as to style and content by:

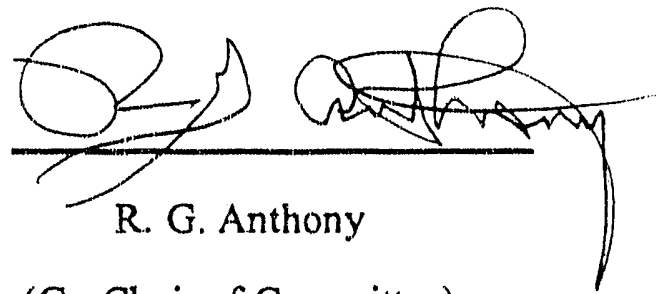

(Co-Chair of Committee)

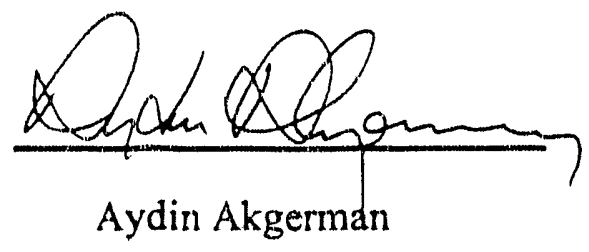

(Co-Chair of Committee)

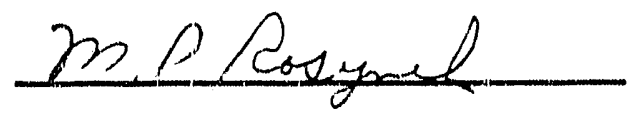

Michael P. Rosynek.

(Member)

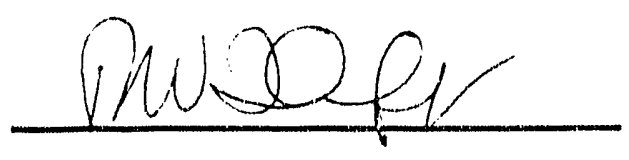

Raymond W. Flumerfelt

(Head of Department) 


\begin{abstract}
A Kinetic Study of Methanol Synthesis in a Slurry Reactor Using a $\mathrm{CuO} / \mathrm{ZnO} / \mathrm{Al}_{2} \mathrm{O}_{3}$ Catalyst. (May 1992)

Hamad Abdulwahab Al-Adwani, B.S., Kuwait University

Co-Chair Of Advisory Committee: Dr. R. G. Anthony

Co-Chair Of Advisory Committee: Dr. A. Akgerman
\end{abstract}

A kinetic model that describes the methanol production rate over a $\mathrm{CuO} / \mathrm{ZnO} / \mathrm{Al}_{2} \mathrm{O}_{3}$ catalyst (United Catalyst L-951) at typical industrial operating conditions is developed using a slurry reactor. Different experiments are conducted in which the $\mathrm{H}_{2} /\left(\mathrm{CO}+\mathrm{CO}_{2}\right)$ ratio is equal to 2,1 , and 0.5 , respectively, while the $\mathrm{CO} / \mathrm{CO}_{2}$ ratio is held constant at 9. At each $\mathrm{H}_{2} /\left(\mathrm{CO}+\mathrm{CO}_{2}\right)$ ratio the space velocity is set at four different values in the range of $3000-13000 \mathrm{l} / \mathrm{hr} \mathrm{kg}$ cat.

The effect of $\mathrm{H}_{2} /\left(\mathrm{CO}+\mathrm{CO}_{2}\right)$ ratio and space velocity on methanol production rate, conversions, and product composition is further investigated. The results indicate that the highest methanol production rate can be achieved at $\mathrm{H}_{2} /\left(\mathrm{CO}+\mathrm{CO}_{2}\right)$ ratio of 1 followed by $\mathrm{H}_{2} /\left(\mathrm{CO}+\mathrm{CO}_{2}\right)$ ratio of 0.5 and 2 respectively. The hydrogen and carbon monoxide conversions decrease with increasing space velocity for all $\mathrm{H}_{2} /\left(\mathrm{CO}+\mathrm{CO}_{2}\right)$ ratios tested. Carbon monoxide hydrogenation appears to be the main route to methanol at $\mathrm{H}_{2} /\left(\mathrm{CO}+\mathrm{CO}_{2}\right)$ ratio of 0.5 and 2 . On the other hand, carbon dioxide hydrogenation appears to be the main route to methanol at $\mathrm{H}_{2} /\left(\mathrm{CO}+\mathrm{CO}_{2}\right)$ ratio of 1 . At all $\mathrm{H}_{2} /\left(\mathrm{CO}+\mathrm{CO}_{2}\right)$ ratios, the extent of the reverse water gas shift reaction decreases with increasing space velocity.

The effect of temperature on the kinetics is examined by using the same experimental approach at $508 \mathrm{~K}$. It is found that a different reaction sequence takes place at each temperature. 
Also, a time on stream stuciy is conducted simultaneously in order to investigate the characteristic of catalyst deactivation with time on stream. During the first 150 hours of time on stream, the catalyst loses approximately $2 / 3$ of its initial activity before reaching a steady state activity. 
DEDICATION

to my mother with love 


\section{ACKNOWLEDGMENTS}

I would like to express my deepest appreciation to my co-advisors, Dr. Rayford G. Anthony, and Dr. Aydin Akgerman for their sincere guidance and motivation throughout the course of this research. I am thankful to Dr. Michael P. Rosynek for serving on my committee.

I would like to thank my professors in the Department of Chemical Engineering of Kuwait University for their confidence and for giving me the chance to seek higher degrees in my field of interest.

I would also like to thank Walter Postula for the help he gave me.

Finally, I am grateful to my parents and to my younger brothers, Mohammed and Ahmed, whom I hope will accomplish higher academic achievements than myself. 
TABLE OF CONTENTS

Page

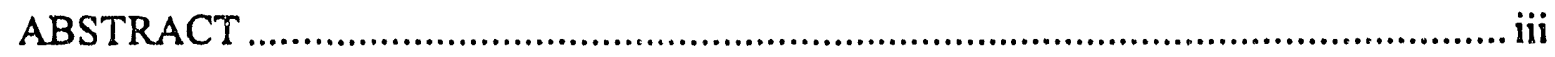

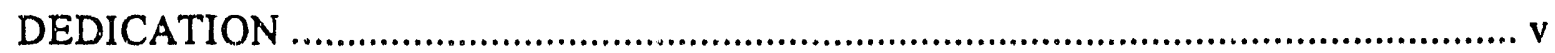

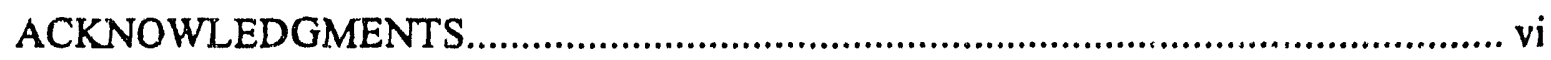

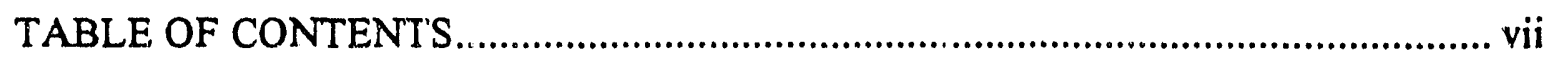

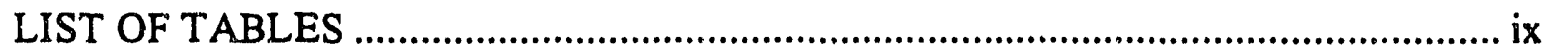

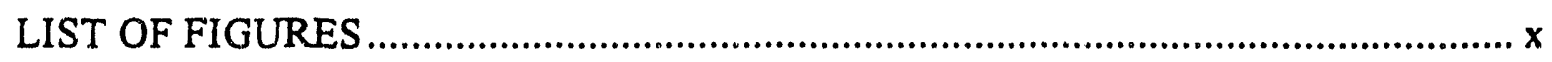

CHAPTER

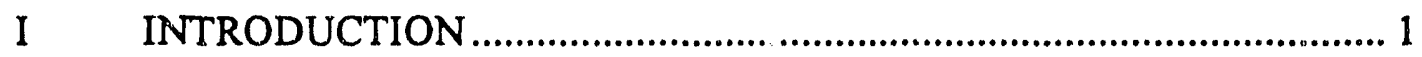

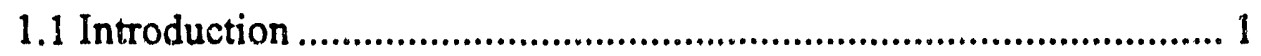

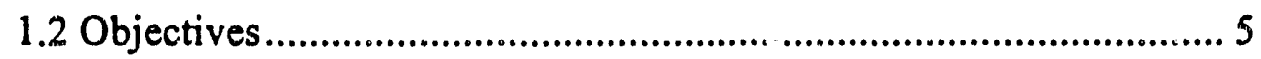

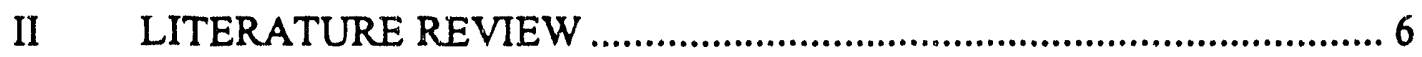

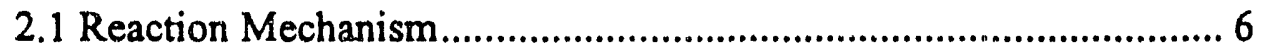

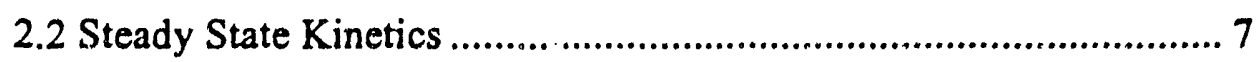

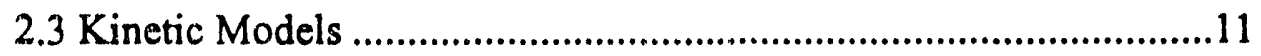

2.4 The $\mathrm{CuO} / \mathrm{ZnO} / \mathrm{Al}_{2} \mathrm{O}_{3}$ Catalyst......................................................18

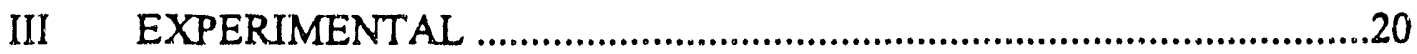

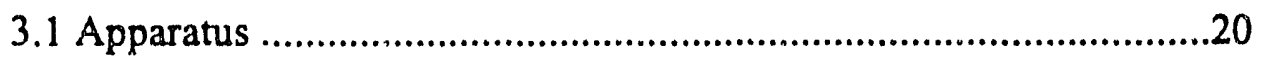

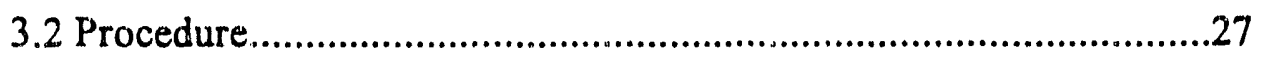

3.2.1 Catalyst loading ......................................................................27

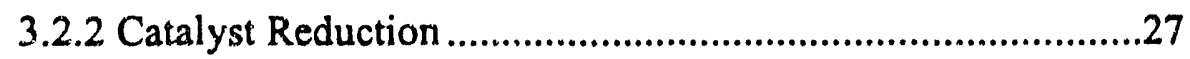

3.2.3 Reaction Procedure .................................................................28

3.2.4 Kinetic data Gathering .........................................................29

3.2.5 Analytical procedure ............................................................. 
TABLE OF CONTENTS (continued)

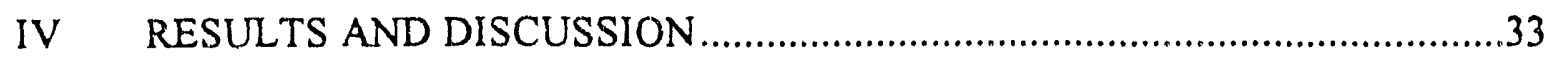

4.1 Time on Stream Study ..................................................................33

4.2 Effect of Space Velocity and $\mathrm{H}_{2} /\left(\mathrm{CO}+\mathrm{CO}_{2}\right)$ Ratio .........................48

4.3 Effect of Temperature ......................................................................

4.4 Comparison with Other Studies......................................................66

4.5 Role of Carbon Dioxide ..................................................................

4.6 Pore Diffusional Limitations..........................................................77

4.7 Equilibrium Calculations ............................................................... 80

4.8 Rate Equation Development.............................................................84

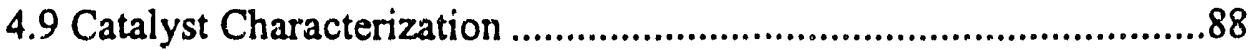

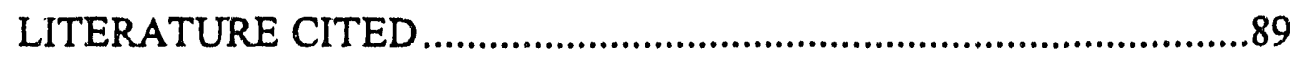

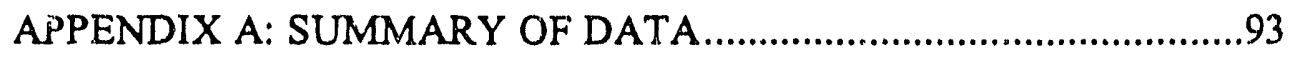

APPENDIX B: EQUILIBRIUM CALCULATIONS PROGRAM ........101

APPENDIX C: PROCESS SIMULATION PROGRAM ........................104

VITA 


\section{LIST OF TABLES}

Table page

1. Response factors for the Carie and Gow Mac gas chromatographs................... 32

2. Effect of $\mathrm{H}_{2} /\left(\mathrm{CO}+\mathrm{CO}_{2}\right)$ ratio on the ratio of carbon moles reacted to oxygen moles reacted

3. Comparison between experimental methanol and water production rates with these obtained by equilibrium calculations.

4. Comparison between experimental hydrogen and carbon monoxide conversions with these obtained by equilibrium calculations

5. Comparison of the average error percent of models proposed

by several researchers

6. Comparison between methanol production rates obtained by process simulation and experimental methanol production rates

A1. Effect of time on stream on condensate production rate and composition

at $50001 / \mathrm{hr} \mathrm{kg}$ cat, $523 \mathrm{~K}$, and $\mathrm{H}_{2} /\left(\mathrm{CO}+\mathrm{CO}_{2}\right)=2$

A.2. Effect of time on stream on conversions at $50001 / \mathrm{hr} \mathrm{kg}$ cat,

$523 \mathrm{~K}$, and $\mathrm{H}_{2} /\left(\mathrm{CO}+\mathrm{CO}_{2}\right)=2$

A3. Effect of space velocity on condensate production rate and composition at $523 \mathrm{~K}$ and different $\mathrm{H}_{2} /\left(\mathrm{CO}+\mathrm{CO}_{2}\right)$ ratios

A4. Effect of space velocity on conversions at $523 \mathrm{~K}$ and

different $\mathrm{H}_{2} /\left(\mathrm{CO}+\mathrm{CO}_{2}\right)$ ratios

A5. Effect of space velocity on condensate production rate and composition at different temperatures and at $\mathrm{H}_{2} /\left(\mathrm{CO}+\mathrm{CO}_{2}\right)=2$

A6. Effect of space velocity on conversions at different temperatures and at $\mathrm{H}_{2} /\left(\mathrm{CO}+\mathrm{CO}_{2}\right)=2$

A7. Percent error of the proposed equation. 100 


\section{LIST OF FIGURES}

Figure

page

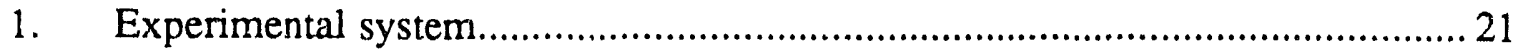

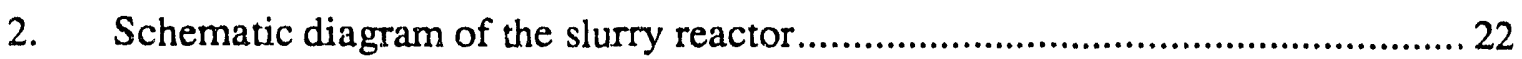

3. Hydrogen mass flow controller calibration line........................................ 24

4. $\mathrm{CO} / \mathrm{CO}_{2}$ mass flow controller calibration line ............................................. 25

5. Effect of time on stream on methanol production rate at

$5000 \mathrm{l} / \mathrm{hr} \mathrm{kg}$ cat, $523 \mathrm{~K}$, and $\mathrm{H}_{2} /\left(\mathrm{CO}+\mathrm{CO}_{2}\right)=2$

6. Effect of time on stream on water production rate at

$5000 \mathrm{l} / \mathrm{hr} \mathrm{kg}$ cat, $523 \mathrm{~K}$, and $\mathrm{H}_{2} /\left(\mathrm{CO}+\mathrm{CO}_{2}\right)=2$

7. Effect of time on stream on methanol and water mole fractions in

condensate at $5000 \mathrm{l} / \mathrm{hr} \mathrm{kg}$ cat, $523 \mathrm{~K}$, and $\mathrm{H}_{2} /\left(\mathrm{CO}+\mathrm{CO}_{2}\right)=2$

8. Effect of time on stream on $\% \mathrm{H}_{2}$ conversion at $5000 \mathrm{l} / \mathrm{hr} \mathrm{kg}$ cat,

$523 \mathrm{~K}$, and $\mathrm{H}_{2} /\left(\mathrm{CO}+\mathrm{CO}_{2}\right)=2$

9. Effect of time on stream on \% CO conversion at $5000 \mathrm{l} / \mathrm{hr} \mathrm{kg}$ cat,

$523 \mathrm{~K}$, and $\mathrm{H}_{2} /\left(\mathrm{CO}+\mathrm{CO}_{2}\right)=$

10. Effect of time on stream on \% conversion of hydrogen and $\mathrm{CO}$ at

$5000 \mathrm{l} / \mathrm{hr} \mathrm{kg}$ cat, $523 \mathrm{~K}$, and $\mathrm{H}_{2} /\left(\mathrm{CO}+\mathrm{CO}_{2}\right)=2$

11. Effect of time on stream on $\% \mathrm{CO}_{2}$ conversion at $5000 \mathrm{l} / \mathrm{hr} \mathrm{kg}$ cat,

$523 \mathrm{~K}$, and $\mathrm{H}_{2} /\left(\mathrm{CO}+\mathrm{CO}_{2}\right)=2$

12. Effect of time on stream on $\%$ conversion of $\mathrm{CO}$ to $\mathrm{CO}_{2}$ at

$50001 / \mathrm{hr} \mathrm{kg}$ cat, $523 \mathrm{~K}$, and $\mathrm{H}_{2} /\left(\mathrm{CO}+\mathrm{CO}_{2}\right)=2$

13. Effect of time on stream on total carbon \% conversion at

$50001 / \mathrm{hr} \mathrm{kg}_{\text {cat }}, 523 \mathrm{~K}$, and $\mathrm{H}_{2} /\left(\mathrm{CO}+\mathrm{CO}_{2}\right)=2$

14. Effect of time on stream on \% conversion of $\mathrm{CO}$ to methanol at

$50001 / \mathrm{hr} \mathrm{kg}_{\text {cat }}, 523 \mathrm{~K}$, and $\mathrm{H}_{2} /\left(\mathrm{CO}+\mathrm{CO}_{2}\right)=2$ 


\section{LIST OF FIGURES (Continued)}

15. Effect of time on stream on \% conversion of carbon to methanol at $5000 \mathrm{l} / \mathrm{hr} \mathrm{kg}$ cat, $523 \mathrm{~K}$, and $\mathrm{H}_{2} /\left(\mathrm{CO}+\mathrm{CO}_{2}\right)=2$

16. Effect of time on stream on \% conversion of hydrogen to methanol at $5000 \mathrm{l} / \mathrm{hr} \mathrm{kg}$ cat, $523 \mathrm{~K}$, and $\mathrm{H}_{2} /\left(\mathrm{CO}+\mathrm{CO}_{2}\right)=2$

17. Comparison between the effect of time on stream on \% conversions of $\mathrm{CO}$ to methanol and $\mathrm{C}$ to methanol at $5000 \mathrm{1} / \mathrm{hr} \mathrm{kg}$ cat, $523 \mathrm{~K}$, and $\mathrm{H}_{2} /\left(\mathrm{CO}+\mathrm{CO}_{2}\right)=2 . .47$

18. Effect of space velocity on methanol production rate at $523 \mathrm{~K}$ and different $\mathrm{H}_{2} /\left(\mathrm{CO}+\mathrm{CO}_{2}\right)$ ratios.

19. Effect of space velocity on water production rate at $523 \mathrm{~K}$ and different $\mathrm{H}_{2} /\left(\mathrm{CO}+\mathrm{CO}_{2}\right)$ ratios

20. Effect of space velocity on DME production rate at $523 \mathrm{~K}$ and different $\mathrm{H}_{2} /\left(\mathrm{CO}+\mathrm{CO}_{2}\right)$ ratios

21. Effect of space velocity on methanol mole fraction in condensate at $523 \mathrm{~K}$ and different $\mathrm{H}_{2} /\left(\mathrm{CO}+\mathrm{CO}_{2}\right)$ ratios

22. Effect of space velocity on water mole fraction in condensate

at $523 \mathrm{~K}$ and different $\mathrm{H}_{2} /\left(\mathrm{CO}+\mathrm{CO}_{2}\right)$ ratios

23. Effect of space velocity on hydrogen \% conversion

at $523 \mathrm{~K}$ and different $\mathrm{H}_{2} /\left(\mathrm{CO}+\mathrm{CO}_{2}\right)$ ratios

24. Effect of space velocity on $\mathrm{CO}_{2} \%$ conversion at $523 \mathrm{~K}$

and different $\mathrm{H}_{2} /\left(\mathrm{CO}+\mathrm{CO}_{2}\right)$ ratios

25. Effect of space velocity on $\mathrm{CO} \%$ conversion at $523 \mathrm{~K}$ and different $\mathrm{H}_{2} /\left(\mathrm{CO}+\mathrm{CO}_{2}\right)$ ratios

26. Effect of space velocity on $\mathrm{CO}$ conversion to $\mathrm{CO}_{2}$ at $523 \mathrm{~K}$ and different $\mathrm{H}_{2} /\left(\mathrm{CO}+\mathrm{CO}_{2}\right)$ ratios

27. Effect of space velocity on methanol production rate at $\mathrm{H}_{2} /\left(\mathrm{CO}+\mathrm{CO}_{2}\right)=2$ and different temperatures. 


\section{LIST OF FIGURES (Continued)}

28. Effect of space velocity on $\%$ hydrogen conversion at $\mathrm{H}_{2} /\left(\mathrm{CO}+\mathrm{CO}_{2}\right)=2$ and different temperatures

29. Effect of space velocity on $\mathrm{CO} \%$ conversion at $\mathrm{H}_{2} /\left(\mathrm{CO}+\mathrm{CO}_{2}\right)=2$ and different temperatures

30. Effect of space velocity on total carbon \% conversion at $\mathrm{H}_{2} /\left(\mathrm{CO}+\mathrm{CO}_{2}\right)=2$ and different temperatures

31. Effect of space velocity on total carbon $\%$ conversion to methanol at $\mathrm{H}_{2} /\left(\mathrm{CO}+\mathrm{CO}_{2}\right)=2$ and different temperatures.

32. Effect of space velocity on hydrogen $\%$ conversion to methanol at $\mathrm{H}_{2} /\left(\mathrm{CO}+\mathrm{CO}_{2}\right)=2$ and different temperatures.

33. Comparison between methanol productivity as a function of space velocity for a slurry reactor at $523 \mathrm{~K}$ and $\mathrm{H}_{2} /\left(\mathrm{CO}+\mathrm{CO}_{2}\right)$ ratio of 0.5 to 0.6

34. Comparison between methanol productivity as a function of space velocity for a slurry reactor at $523 \mathrm{~K}$ and $\mathrm{H}_{2} /\left(\mathrm{CO}+\mathrm{CO}_{2}\right)$ ratio of 1

35. Comparison between methanol productivity as a function of space velocity for a slurry reactor at $523 \mathrm{~K}$ and $\mathrm{H}_{2} /\left(\mathrm{CO}+\mathrm{CO}_{2}\right)$ ratio of 2 to 2.3 .

36. Effect of mole percent $\mathrm{CO}_{2}$ in the feed on methanol production rate at $5.2 \mathrm{MPa}, 523 \mathrm{~K}$, and $8000 \mathrm{~V} / \mathrm{hr} \mathrm{kg}$ cat

37. Comparison between the effect of mole percent $\mathrm{CO}_{2}$ in the feed on methanol production rate at 5.2 to $7 \mathrm{MPa}, 523 \mathrm{~K}$, and space velocity range from 6200 to $8700 \mathrm{l} / \mathrm{hr} \mathrm{kg}$ cat

38. The $(\mathrm{H} / \mathrm{C})_{\text {reacted }}$ mole ratio at different time on stream experiments at $5.2 \mathrm{MPa}, 523 \mathrm{~K}$, space velocity of $5000 \mathrm{l} / \mathrm{hr} \mathrm{kg}$ cat , and $\mathrm{H}_{2} /\left(\mathrm{CO}+\mathrm{CO}_{2}\right)=2 \ldots \ldots \ldots .74$

39. The $(\mathrm{C} / \mathrm{O})_{\text {reacted }}$ mole ratio at different time on stream experiments at $5.2 \mathrm{MPa}, 523 \mathrm{~K}$, space velocity of $5000 \mathrm{lhr} \mathrm{kg}$ cat , and $\mathrm{H}_{2} /\left(\mathrm{CO}+\mathrm{CO}_{2}\right)=2$ .75 


\section{LIST OF FIGURES (Continued)}

40 The $(\mathrm{C} / \mathrm{O})_{\text {reacted }}$ mcle ratio as a function of space velocity at $523 \mathrm{~K}$ and different $\mathrm{H}_{2} /\left(\mathrm{CO}+\mathrm{CO}_{2}\right)$ ratios...................................................................... 76

41. Effect of time on stream on methanol production rate using two different catalyst particle sizes at $523 \mathrm{~K}$ and $\mathrm{H}_{2} /\left(\mathrm{CO}+\mathrm{CO}_{2}\right)=2$ 78

42. Effect of catalyst particle size on methanol production rate as a function of time on stream at $523 \mathrm{~K}, 5000 \mathrm{l} / \mathrm{hr} \mathrm{kg}$ cat and $\mathrm{H}_{2} /\left(\mathrm{CO}+\mathrm{CO}_{2}\right)=2$

43. Scatter plot showing the validation of the rate equation developed in this study 


\section{CHAPTER I \\ INTRODUCTION}

\subsection{Introduction}

'Methanol is one of the basic feed stocks in the chemical industry and its demand is increasing on a regular basis. Studies are being conducted for building new methanol plants in different locations around the globe. It is being used as a fuel additive and as a clean burning fuel. Moreover, methanol is the starting point for formaldehyde, methyl tetr-butyl ether (MTBE) and other solvents.

Worldwide, most methanol is produced directly from synthesis gas, a mixture of $\mathrm{H}_{2}, \mathrm{CO}$, and $\mathrm{CO}_{2}$, in a gas phase fixed bed reactor over a $\mathrm{CuO} / \mathrm{ZnO} / \mathrm{Al}_{2} \mathrm{O}_{3}$ catalyst. Being the only oxygenate produced directly from synthesis gas in high selectivity, methanol provides a single carbon feed stock for synthesizing higher oxygenate chemicals that cannot be produced directly from synthesis cas in high selectivities, (King and Grate, 1985). Nevertheless, methanol synthesis kinetics are complex and disagreed upon by different researchers. In 1991, the international annual production of methanol reached about 22. Million tons (Crocco, 1991), which makes it a 4 Billion dollar business. Therefore, a good understanding of the kinetics of methanol synthesis will increase profits and improve energy conservation.

Methanol is produced from synthesis gas over a $\mathrm{CuO} / \mathrm{ZnO}$, a $\mathrm{CuO} / \mathrm{ZnO} / \mathrm{Cr}_{2} \mathrm{O}_{3}$, or a $\mathrm{CuO} / \mathrm{ZnO} / \mathrm{Al}_{2} \mathrm{O}_{3}$ catalyst. The later is considered of industrial importance. The three principal reactions that occur during methanol synthesis are:

$$
\begin{array}{lc}
\mathrm{CO}+2 \mathrm{H}_{2} \Leftrightarrow \mathrm{CH}_{3} \mathrm{OH} & \Delta \mathrm{H}_{298 \mathrm{R}}=-2.1 .7 \mathrm{kcal} / \mathrm{mol} \\
\mathrm{CO}_{2}+3 \mathrm{H}_{2} \Leftrightarrow \mathrm{CH}{ }_{3} \mathrm{OH}+\mathrm{H}_{2} \mathrm{O} & \Delta \mathrm{H}_{298 \mathrm{R}}=-11.9 \mathrm{kcal} / \mathrm{mol} \\
\mathrm{CO}_{2}+\mathrm{H}_{2} \Leftrightarrow \mathrm{CO}+\mathrm{H}_{2} \mathrm{O} & \Delta \mathrm{H}_{298 \mathrm{R}}=+9.8 \mathrm{kcal} / \mathrm{mol}
\end{array}
$$

${ }^{1}$ This thesis follows the style and format of the AJChEJournal. 
The literature is divided on which of the above reactions actually contribute to methanol synthesis. A study by Liu et al. (1985) indicates that methanol synthesis is best represented by the carbon monoxide hydrogenation reaction. On the other hand, Lee et al. (1989) assert that carbon dioxide hydrogenation to methanol is the dominant reaction. However, Schack at al. (1989) suggest that carbon monoxide hydrogenation is the main route to methanol at typical industrial conditions while carbon dioxide is the main route under lower temperatures and pressures

The oil crisis in the early 1970's accelerated the need to find alternative fuel sources. Methanol has a potential as a clean burning fuel that can be produced from coal derived synthesis gas. Unfortunately, The coal derived synthesis gas is characterized by low $\mathrm{H}_{2} / \mathrm{CO}$ ratios that make the majority of methanol synthesis catalysts susceptible to poisoning by coke deposition causing the catalyst activity to decrease.

Most methanol production plants employ the same chemical process in which a purified synthesis gas with the $\mathrm{H}_{2} / \mathrm{CO}$ ratio of 5 to 8 is passed through a fixed bed reactor over a $\mathrm{Cw} / \mathrm{ZnO}$ catalyst at pressures and temperatures ranging from 5 to $10 \mathrm{MPa}$ and 500 to $575 \mathrm{~K}$. Methanol is then collected by condensation and purified while the unreacted synthesis gas is recycled. The Lurgi, ICI, and Linde companies are all utilizing fixed bed reactors in their methanol synthesis processes. In the Linde's process, the reactor has a shell and tube configuration in which the shell side is filled with the catalyst and the heat generated by the reaction is removed by injecting boiler feed water into the tubes. The Lurgi's process is completely the opposite to the of Linde's. Fixed bed reactors operate at near plug flow conditions and endure high space velocities. The later characteristic is of great importance in methanol synthesis in order to minimize synthesis of side products (Natta, 1955). Fixed bed reactors are used extensively in the chemical industry because of their simplicity and low cost of construction, operation, and maintenance. One of the important features of the fixed bed reactor is that, unlike slurry 
and fluidized bed reactors, there are no difficulties in separating the catalyst particles from the reactor effluent stream (Hill, 1977).

Liquid phase methanol synthesis processes are also being developed by industry. Air Products and Chemicals company with funding from the Department of Energy built a 5 ton/day plant employing the liquid phase methanol process technique where the catalyst is slurried with a mineral oil. The type of mineral oil used in that plant is the same as of that used in this study. A wide range of $\mathrm{H}_{2} / \mathrm{CO}$ ratios can be handled in this process. Slurry reactors are used in order to avoid the main drawback of the fixed bed reactors which is non isothermal conditions when conducing exothermic reactions like the methanol synthesis reaction. Slurry reactors provide good heat recovery and isothermal conditions because of the high heat capacity of the slurry liquid. Also, fine particles of the catalyst in the slurry increases the intraparticle effectiveness, and therefore provide a high rate of production of methanol per unit weigh of catalyst.

Pass et al. (1990) studied methanol synthesis in a trickle bed reactor where the feed gas and the oil flow cocurrently over a $\mathrm{CuO} / \mathrm{ZnO} / \mathrm{Al}_{2} \mathrm{O}_{3}$ catalyst at $523 \mathrm{~K}$ and 7.1 $\mathrm{MPa}$ under a wide range of space velocities and at a $\mathrm{H}_{2} /\left(\mathrm{CO}+\mathrm{CO}_{2}\right)$ ratio of 1 . Substantially high methanol productivities and conversions where achieved compared to those achieved in a slurry reactor at similar space velocities due to plug flow conditions encountered in the trickle bed reactor compared to back mixing conditions in the slurry reactor.

Along with the $\mathrm{CuO} / \mathrm{ZnO}, \mathrm{CuO} / \mathrm{ZnO} / \mathrm{Cr}_{2} \mathrm{O}_{3}$ and $\mathrm{CuO} / \mathrm{ZnO} / \mathrm{Al}_{2} \mathrm{O}_{3}$ catalysts, other catalysts are being investigated for practical use. Maj et al. (1985) prepared and characterized $\mathrm{Na}-\mathrm{ThO}_{2}$ and $\mathrm{NH}_{4}-\mathrm{ThO}_{2}$ catalysts for methanol production that produced $\mathrm{CO}$ conversions of $3 \%$ with high selectivities. $\mathrm{Pd} / \mathrm{SiO}_{2}$ and $\mathrm{Rh} / \mathrm{TiO}{ }_{2}$ catalysts were investigated by (Poutsma et al., 1978 ; Kelly et al., 1986) showed lower activities than an $\mathrm{CuO} / \mathrm{ZnO}, \mathrm{CuO} / \mathrm{ZnO} / \mathrm{Cr}_{2} \mathrm{O}_{3}$, and $\mathrm{CuO} / \mathrm{ZnO} / \mathrm{Al}_{2} \mathrm{O}_{3}$ catalysts. Intermetalic catalysts like $\mathrm{Cu} / \mathrm{Ce}_{\mathrm{X}}$ and $\mathrm{Cu} / \mathrm{Th}_{\mathrm{x}}$ were reported to demonstrate activity towards methanol synthesis. 
Recently, Stiles et al. (1991) prepared a catalyst system $(\mathrm{Cu} / \mathrm{Mn} / \mathrm{Zn} / \mathrm{Co} / \mathrm{Cr} /(\mathrm{K}+\mathrm{Cs})=$ $4 / 3 / 1 / 0.028 /(15$ wt. $\%+4.0$ wt $\%))$ with high activity for producing higher alcohols. 


\subsection{Objectives}

The aim of this work is to develop a kinetic model that describes the methanol production rate over a $\mathrm{CuO} / \mathrm{ZnO} / \mathrm{Al}_{2} \mathrm{O}_{3}$ catalyst (United Catalyst L-951) at typical industrial operating conditions of $523 \mathrm{~K}$, and $5.2 \mathrm{MP}$ ? using a slurry reactor. Different experiments will be conducted in which the $\mathrm{H}_{2} /\left(\mathrm{CO}+\mathrm{CO}_{2}\right)$ ratio is adjusted at 2,1 , and 0.5 , respectively, while the $\mathrm{CO} / \mathrm{CO}_{2}$ ratio is held constant at 9. At each $\mathrm{H}_{2} /\left(\mathrm{CO}+\mathrm{CO}_{2}\right)$ ratio the space velocity is set at four different values in the range of $3000-13000$ $\mathrm{L}_{\mathrm{hr}} \mathrm{kg}_{\text {cat }}$. A slurry reactor is used in this study to eliminate variables such as wetting efficiency, flow irregularities, and heat temperature profiles that usually occur in trickle bed reactors.

The advantage of the proposed work is that the wide ranges of $\mathrm{H}_{2} /\left(\mathrm{CO}+\mathrm{CO}_{2}\right)$ ratio and space velocity will provide experimental data sufficient enough to produce a general power law kinetic model that best describes methanol production using a $\mathrm{CuO} / \mathrm{ZnO} / \mathrm{Al}_{2} \mathrm{O}_{3}$ catalyst and to obtain information about the effects of $\mathrm{H}_{2} /\left(\mathrm{CO}+\mathrm{CO}_{2}\right)$ ratio and space velocity on methanol production rate, conversions, and product composition.

The effect of temperature on the above mentioned parameters is investigated by using the same experimental approach at $508 \mathrm{~K}$.

Also, a time on stream study will be conducted simultaneously in order to investigate the characteristic of catalyst deactivation with time on stream. The reaction is operated continuously in order to simulate pilot plant conditions and avoid secondary reactions. 


\section{CHAPTER II \\ LITERATURE REVIEW}

\subsection{Reaction Mechanism}

No universal methanol synthesis reaction mechanism has been determined by researchers yet due to the complex nature of methanol synthesis, the different types of catalysts used in these studies, and the different apparent rate controlling steps of these catalysts. Rase (1990) describes the following mechanism for methanol synthesis over a $\mathrm{CuO} / \mathrm{ZnO} / \mathrm{Al}_{2} \mathrm{O}_{3}$ catalyst:

1. Adsorption of $\mathrm{H}_{2}$ on an active site.

2. Adsorption of $\mathrm{CO}$ on an electron deficient active site which in turn reacts with the oxygen end of $\mathrm{CO}$, forming a strongly bonded activated complex.

3. The migration of the adsorbed $\mathrm{H}_{2}$ to the adsorbed $\mathrm{CO}$ in order to form a surface formyl species.

4. The surface formyl species is hydrogenated to form a surface methoxide.

5. The surface methoxide in turn is hydrogenated to methanol which is desorbed yielding the original catalyst site.

Aharoni et al., (1974) suggest different reaction steps are to be taken as the rate determining stage over a $\mathrm{CuO} / \mathrm{ZnO} / \mathrm{Al}_{2} \mathrm{O}_{3}$ catalyst, among these are:

1. Adsorption of $\mathrm{H}_{2}$ and $\mathrm{CO}$ on active sites.

2. Trimolecular reaction between adsorbed $\mathrm{H}_{2}$ and adsorbed $\mathrm{CO}$.

3. Reaction between the adsorbed hydrogen atom and the adsorbed surface compound $\mathrm{CH}_{3} \mathrm{O}$.

4. Reaction between gaseous $\mathrm{H}_{2}$ and the surface compound.

5. Two stage hydrogenation of adsorbed $\mathrm{CO}$ by adsorbed hydrogen. 


\subsection{Steady State Kinetics}

The roles of carbon dioxide and carbon monoxide in the methanol synthesis are surrounded by controversy. This controversy is hindering the development and optimization of methanol synthesis industrial processes, (Lee et al.,1989).

Schack et al. (1989) studied methanol synthesis over a $\mathrm{CuO} / \mathrm{ZnO} / \mathrm{Al}_{2} \mathrm{O}_{3}$ catalyst supplied by $\mathrm{BASF}$ in a Berty reactor with a $\mathrm{H}_{2} / \mathrm{CO} / \mathrm{CO}_{2}$ feed gas ratio range of $70 / 30 / 0$ to $70 / 22 / 8$. The pressure and temperature were in the range of 2.89 to $4.38 \mathrm{MPa}$ and 483 to $513 \mathrm{~K}$ respectively. The space velocity was kept constant at $9500 \mathrm{l} / \mathrm{hr} \mathrm{kg}$ cat. The catalyst was reduced in-situ. Schack determined that the optimum methanol production rate occurred at a carbon dioxide concentration of 2 mole percent in the gas feed with a constant $\mathrm{CO} / \mathrm{H}_{2}$ ratio of $1.0 / 3.9$. When the carbon dioxide mole percent in the feed was held constant at $2 \%$ while increasing the mole percent of carbon monoxide in the feed with the balance being hydrogen, a maximum methanol production rate occurred in the range of carbon monoxide mole percent of 20 to $29 \%$ depending on the pressure at $488 \mathrm{~K}$. When carbon monoxide was replaced with helium in the feed, methanol production rate dropped drastically and more water was produced. Schack concluded that carbon dioxide concentrations above 2 mole percent prevents the carbon monoxide hydrogenation reaction, and when carbon monoxide exists in the feed, the water-gas shift reaction proceed in the forward direction and vise versa. Schack indicated that carbon dioxide acts as a catalyst promoter and a methanol producer. Finally Schack concluded that carbon monoxide hydrogenation is the main reaction in methanol synthesis under usual industrial conditions while carbon dioxide is the main source of methanol at lower temperatures and pressures.

On the other hand, Chinchen et al. (1990) used isotopic labeling to determine the main reaction that occurs in the methanol synthesis under the typical industrial conditions of $523 \mathrm{~K}$ and $5.2 \mathrm{MPa}$. Chinchen found that the methanol produced had the same ${ }^{14} \mathrm{C}$ as that of carbon dioxide used in the feed gas. Therefore, he points out that methanol is 
directly produced from carbon dioxide immediately whereas carbon monoxide is first converted to carbon dioxide via the reverse water gas shift reaction, and carbon dioxide remains the principal source of methanol. The distribution rate of ${ }^{14} \mathrm{C}$ was slow enough to identify the following reactions:

$$
\begin{gathered}
{ }^{14} \mathrm{CO}+{ }^{12} \mathrm{CO}_{2} \Leftrightarrow{ }^{14} \mathrm{CO}_{2}+{ }^{12} \mathrm{CO} \\
\mathrm{H}_{2} \mathrm{O}+{ }^{14} \mathrm{CO} \Leftrightarrow{ }^{14} \mathrm{CO}_{2}+\mathrm{H}_{2} \\
{ }^{12} \mathrm{CO}+\mathrm{O}_{(a)} \Leftrightarrow{ }^{12} \mathrm{CO}_{2}
\end{gathered}
$$

The catalyst used by Chinchen was a $\mathrm{CuO} / \mathrm{ZnO} / \mathrm{Al}_{2} \mathrm{O}_{3}$ catalyst manufactured by ICI and had a composition of $60 \% \mathrm{CuO}, 30 \% \mathrm{ZnO}$, and $10 \% \mathrm{Al}_{2} \mathrm{O}_{3}$ by weight, (Chinchen et al. 1987). The experiments were conducted in a fixed bed reactor and the space velocity was varied between 15000 and $120000 \mathrm{hr}^{-1}$ while the $\mathrm{CO}$ and $\mathrm{CO}_{2}$ mole percent in the feed was varied between 9.2 to $21.7 \%$ and 0.01 to $10 \%$ respectively with the balance being hydrogen. The reactor volume along with the catalyst loading were not given.

Lee et al. (1989) investigated the kinetics of methanol synthesis in a one liter slurry reactor using Witco-40 mineral oil and a catalyst with particle size of 106 microns as slurry. The pressure was set at $6.5 \mathrm{MPa}$ while the temperature was varied between 478 and $523 \mathrm{~K}$. Two types of catalysts where used, the first catalyst investigated was a BASF $\mathrm{CuO} / \mathrm{ZnO} / \mathrm{Al}_{2} \mathrm{O}_{3}$ catalyst and the second was a United Catalyst $\mathrm{CuO} / \mathrm{ZnO} / \mathrm{Al}_{2} \mathrm{O}_{3} / \mathrm{SiO}_{2}$ catalyst. Only methanol and water were detected at the reactor effluent strearn. Three different sets of experiments were conducted. In the first experiment, the gas feed composition was set at carbon monoxide free synthesis gas, while in the second carbon dioxide free synthesis gas was introduced, and in the third set, the $\mathrm{H}_{2} / \mathrm{CO}$ ratio was held at 0.656 while the $\mathrm{CO}_{2} /\left(\mathrm{CO}+\mathrm{H}_{2}\right)$ ratio was varied between 0.047 and 0.264 at five different levels. Lee, in agreement with Schack et al. (1989), concluded that methanol production rate reaches a maximum as the mole percent of carbon dioxide in the feed increases. After reaching the maximum value, methanol 
productivity decreases as the mole percent of carbon dioxide increases. The location of the maximum is a function of temperature. The hydrogenation of carbon dioxide was found to best describe methanol synthesis.

The third set of experiments was conducted to investigate the catalyst activity, which was found to decrease remarkably when no carbon dioxide was used in the feed. Lee suggests that this drop in the catalyst activity is due to the deposition of carbon on the catalyst by the Boudouard reaction, and not due to the absence of $\mathrm{CO}_{2}$ as a catalyst promoter by maintaining the catalyst in the proper state of oxidation through the following reaction:

$$
\mathrm{Cu}+\mathrm{CO}_{2} \Leftrightarrow \mathrm{CuO}+\mathrm{CO}
$$

Natta (1955) studied methanol synthesis kinetics in a fixed bed reactor over a $\mathrm{ZnO} / \mathrm{Cr}_{2} \mathrm{O}_{3}$ catalyst and a $\mathrm{Cu} / \mathrm{ZnO}_{-} / \mathrm{Cr}_{2} \mathrm{O}_{3}$ catalyst. The temperature measured over $90 \%$ of the reactor length was at a constant value $( \pm 1 \mathrm{~K})$. The temperature and pressure were in the range of 573 to $633 \mathrm{~K}$ and 20.3 to $3.04 \mathrm{MPa}$. Carbon dioxide was not used in the feed, while the $\mathrm{H}_{2} / \mathrm{CO}$ ratio was varied between 2 and 10 at different space velocities. Natta indicates that equilibrium can be reached at $\mathrm{H}_{2} / \mathrm{CO}$ ratios greater than 10 , because hydrogen adsorption rate occurs at a much slower rate than the adsorption rate of carbon monoxide on the catalyst surface. Therefore, it is suggested to operate at $\mathrm{H}_{2} / \mathrm{CO}$ ratio greater than 10 in order to achieve stoichiometric $\mathrm{H}_{2} / \mathrm{CO}$ ratio of 2 in the adsorbed phase. The role of carbon dioxide in methanol synchesis was discussed by Natta as well. He suggests that carbon dioxide has a favorable significance on methanol production because it decreases the mole fraction of dimethyl ether in the gas effluent stream, inhibits the conversion of carbon monoxide to carbon dioxide if water is present, and provide a better temperature control, because the heat evolved from the carbon dioxide hydrogenation reaction is lower than that of carbon monoxide hydrogenation reaction. However, Natta did not discuss the effect of carbon dioxide on the catalyst activity. 
Klier et al. (1982) studied methanol synthesis in a fixed bed reactor using a $\mathrm{CuO} / \mathrm{ZnO}$ catalyst. The temperature was in the range of 498 to $523 \mathrm{~K}$, while the pressure and the space velocity were held constant at $7.6 \mathrm{MPa}$ and $6100 \mathrm{l} / \mathrm{hr} \mathrm{kg}_{\text {cat }}$ respectively. The hydrogen mole fraction in the feed was held constant while the $\mathrm{CO} / \mathrm{CO}_{2}$ ratio was varied in order to find the role of carbon dioxide in methanol synthesis. The maximum methanol production rate was found at $\mathrm{H}_{2} / \mathrm{CO} / \mathrm{CO}_{2}$ ratio of $70 / 28 / 2$ indicating that the optimal mole fraction of carbon dioxide in the feed gas is 0.02 at $523 \mathrm{~K}$. This value agrees with the results obtained by Schack et al.(1989). Klier concluded that carbon dioxide mainly plays the role of catalyst promoter. He came to this conclusion by observing that a conversion to methanol of $47 \%$ was achieved using a gas feed with a carbon dioxide mole fraction of 0.06 . On the other hand, when using a carbon dioxide free gas feed, 51 to $61 \%$ conversion to methanol were achieved.

Liu et al.(1984) extensively studied the effect of the feed composition on methanol synthesis. The investigation was conducted using a constant volume batch reactor and a $\mathrm{CuO} / \mathrm{ZnO}$ catalyst. The temperature was in the range of 468 to $498 \mathrm{~K}$ while the pressure was held constant at 17.2 MPa. The catalyst was reduced using an $\mathrm{N}_{2} / \mathrm{H}_{2}$ mixture with a ratio of $98 / 2$. Liu observed that methanol production rate increased with increasing $\mathrm{CO}_{2} / \mathrm{CO}$ ratio. Methanol production rate reached a maximum when carbon monoxide free gas was used as feed. Water had an inhibiting effect on methanol production, because water is strongly adsorbed on the catalyst surface. However, Liu found that small amounts of carbon dioxide or water keep the catalyst active. Due to the inhibiting effect of water and the favorable effect of carbon dioxide on methanol production, Liu reached the conclusion that carbon dioxide hydrogenation is the main route to methanol production.

Graaf et al. (1988) found that the water produced was more than what was accounted for thermodynamically, and suggests that the extent of the water gas shift reaction is negligible because the water gas shift reaction is relatively slow compared to 
the methanol synthesis reaction. Therefore, the carbon dioxide hydrogenation reaction must be the main route to water production. Graaf calculated the rate of production of methanol from carbon monoxide and carbon dioxide respectively, and found that both carbon monoxide and carbon dioxide contribute significantly to methanol production.

The study was performed in a spinning basket reactor using a commercial $\mathrm{CuO} / \mathrm{ZnO} / \mathrm{Al}_{2} \mathrm{O}_{3}$ catalyst supplied by Haldc $r$ Inc. The temperature and pressure were in the range of 483 to $517 \mathrm{~K}$ and 1.5 to $5.2 \mathrm{MPa}$, respectively. The gas feed composition was adjusted at different values where the hydrogen mole fraction was between 0.625 and 0.90 and that of carbon monoxide between 0 and 0.22 with the balance being carbon dioxide.

\subsection{Kinetic Models}

Chemical kinetics that describe the reaction rate will still be valid and appreciated even if their mechanisms were proven to be incorrect. For methanol synthesis reaction, developing a mechanistic kinetic model is not an easy task because of the controversial results given by previous researchers.

Methanol production rate is usually described by a power law or a LangmuirHinshelwood expression. Agny and Takoudis (1985) proposed the following twoparameter kinetic model using the Langmuir-Hinshelwood approach:

$$
r_{\text {methanol }}=k\left(p_{C O} p_{H_{2}}^{2}-\frac{p_{C H, O H}}{K_{\text {eql }}}\right)\left(p_{C O} p_{H_{2}}^{0.5}\right)^{n}
$$

Where $\mathrm{k}$ is the reaction rate constant and $\mathrm{K}_{\text {eql }}$ is the equilibrium constant of carbon monoxide hydrogenation reaction. The value of the pre-exponential factor and the overall activation energy at $523 \mathrm{~K}$ are $13600 \mathrm{~mol} /\left(\mathrm{s}\right.$ atm $\mathrm{gcat}_{\mathrm{cat}}$ and $34000 \mathrm{cal} / \mathrm{g}_{\mathrm{mol}}$ respectively. Agny and Takoudis postulated that the adsorbed CO molecule 
dissocaitively adsorbs a hydrogen molecule to form the formyl intermediate CHO- with $\mathrm{H}_{2} / \mathrm{CO}$ ratio of $0.5 / 1$ which is represented in the $\left(p_{\mathrm{Co}} p_{\mathrm{H}_{2}}^{0.5}\right)^{n}$ term where $\mathrm{n}$ was determined as -1.3 empirically. The $\mathrm{CHO}$ - intermediate was postulated to be the abundant surface intermediate while the rate determining step was the surface reaction between the adsorbed hydrogen and the methoxy intermediate $\mathrm{CH}_{3} \mathrm{O}$-. Carbon dioxide was detected at the reaction effluent stream with concentrations between trace amounts to 0.51 percent. They suggested that carbon dioxide is produced from the water gas shift reaction and the redox reaction from the oxidized state to the reduced state of the catalyst. The study was conducted using a $U$ shaped fixed bed reactor and a $\mathrm{CuO} / \mathrm{ZnO} / \mathrm{Al}_{2} \mathrm{O}_{3}$ catalyst supplied by United Catalyst. The pressure and temperature where maintained in the range of 0.3 to $1.5 \mathrm{MPa}$ and 523 to $563 \mathrm{~K}$ respectively. A carbon dioxide free synthesis gas was used as feed, therefore, no term corresponding the carbon dioxide was incorporated in the rate equation. The $\mathrm{H}_{2} / \mathrm{CO}$ ratio was maintained between 2.1 and 2.4 .

Klier et al. (1982) assumed that $\mathrm{CH}_{3} \mathrm{OH}$ and $\mathrm{H}_{2} \mathrm{O}$ are weakly adsorbed on the active sites and $\mathrm{CO}_{2}$ competes with $\mathrm{H}_{2}$ and $\mathrm{CO}$ for active sites. As a result, Klier et al. developed the following kinetic model based on two synthesis route terms. The first describes methanol synthesis from $\mathrm{CO}$ hydrogenation while the second describes methanol synthesis from $\mathrm{CO}_{2}$ hydrogenation. Unlike Agny et al.(1985), Klier et al. took into consideration the effect of carbon dioxide as a catalyst promoter and a source of methanol in the rate equation:

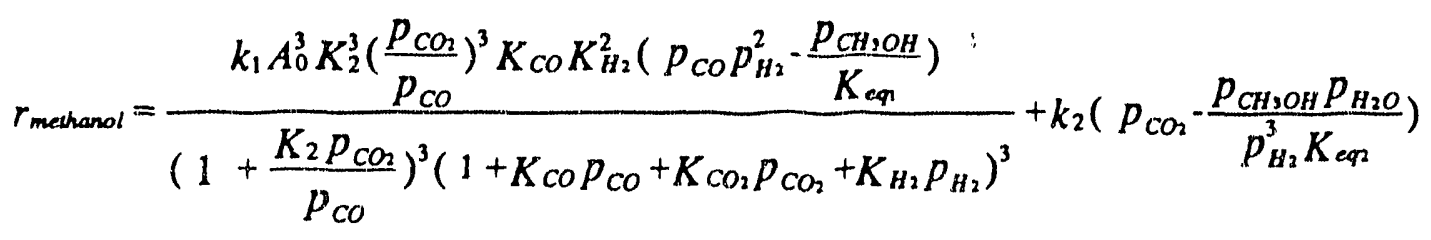


Where $\mathrm{K}_{\text {eq }}$ and $\mathrm{K}_{\text {eq2 }}$, are the equilibrium constants for $\mathrm{CO}$ and $\mathrm{CO}_{2}$ hydrogenation reactions respectively and $\left(\mathrm{k}_{1} \mathrm{~A}_{0}{ }^{3}\right), \mathrm{K}_{\mathrm{CO}}, \mathrm{K}_{\mathrm{H}_{2}}, \mathrm{~K}_{\mathrm{CO}_{2}}, \mathrm{~K}_{2}, \mathrm{k}_{2}$ are the desorption and adsorption parameters The values of these parameters at $523 \mathrm{~K}$ are 4.095 , $2.625,1.584,5.00,1.00,9.00,90.00$, and 3.75 respectively, where the partial pressures are given in atmospheres.

Graaf et al. (1988) studied methanol synthesis in a spinning basket reactor over a commercial $\mathrm{CuO} / \mathrm{ZnO} / \mathrm{Al}_{2} \mathrm{O}_{3}$ catalyst at pressures between 1.5 and $5.2 \mathrm{MPa}$ and temperatures between 483 and $518 \mathrm{~K}$. The $\mathrm{H}_{2} / \mathrm{CO} / \mathrm{CO}_{2}$ ratio was varied between 67.4/26.1/6.5 and 88.5/11.5/0. Graaf indicates that methanol is directly produced from both carbon monoxide and carbon dioxide hydrogenation reactions. Surplus amounts of water were collected during the experiment relative to the amount predicted by equilibrium calculations. Graaf assumed that the hydrogen molecule is dissociativly adsorbed on the catalyst surface. After testing 48 different kinetic models based on different mechanisms, the following dual site Langmuir Hinshelwood rate expression is given by Graaf:

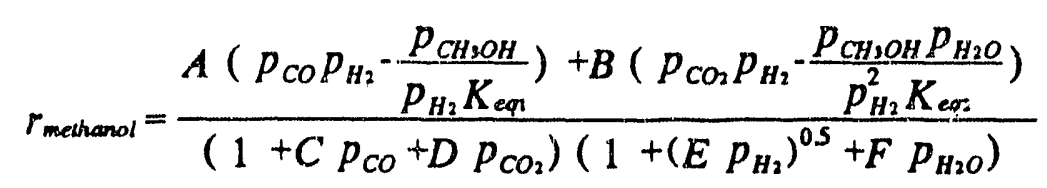

Where the rate controlling step is the surface reaction between the adsorbed $\mathrm{H}_{2}$ molecule and the formyl species. The kinetic parameters A, B, C, D, E, and F were fit from data, and the equilibrium constants, $\mathrm{K}_{\text {eq } 1}$ and $\mathrm{K}_{\text {eq } 2}$ were determined from thermodynamic correlations. The kinetic parameters values are given as functions of reaction temperature.

McNeil et al. (1989) used a Berty reactor to investigate the kinetics of methanol synthesis over a wide range of $\mathrm{H}_{2} / \mathrm{CO} / \mathrm{CO}_{2}$ ratios using a commercial $\mathrm{CuO} / \mathrm{ZnO} / \mathrm{Al}_{2} \mathrm{O}_{3}$ 
catalyst supplied by BASF. The temperature and pressure were maintained in the range of 483 to 513 and 2.89 to $4.38 \mathrm{MPa}$, respectively. This model takes into consideration both carbon monoxide and carbon dioxide hydrogenation reactions. It also includes the role of carbon dioxide as a methanol production inhibitor.

In developing the kinetic model, the following assumptions were made

1. The hydrogen molecule is dissociatively adsorbed.

2. The number of sites that contain hydrogen molecules is constant.

3. The rate determining step for the carbon monoxide reaction is the surface reaction between the hydrogen atom and the methoxy intermediate which is the most abundant reaction intermediate for the carbon monoxide hydrogenation reaction.

4. The rate determining step for the carbon dioxide reaction is the surface reaction between the hydrogen atom and the formate intermediate which is the most abundant reaction intermediate for the carbon dioxide hydrogenation reaction.

5. Hydrogen is adsorbed on $\mathrm{ZnO}$ while the carbon monoxide and carbon dioxide are adsorbed on copper, where the $\mathrm{CO}_{2}$ is adsorbed on $\mathrm{Cu}^{0}$ sites and $\mathrm{CO}$ is adsorbed on $\mathrm{Cu}^{+1}$ sites.

With these assumptions, McNeil proposed the following rate equation:

$$
r_{\text {mechanol }}=\left(\frac{p_{C O} p_{H 2}^{2}-\frac{p_{C H 3 O H}}{K_{e q 1}}}{A_{1} p_{C O} p_{H 2}^{3 / 2}+B_{1} p_{H 2}+C_{1} p_{C O 2}}\right)+\left(\frac{p_{C O 2} p_{H 2}-\frac{p_{C H 3 O H} p_{H 2 O}}{K_{e q 2} p_{H 2}^{2}}}{A_{2} p_{C O 2} p_{H 2}^{1 / 2}+B_{2} p_{C O 2}^{2}+C_{2} p_{H 2 O}^{3}}\right)
$$

The values of the equation parameters, $A_{1}, A_{2}, B_{1}, B_{2}, C_{1}$, and $C_{2}$ were derived from the experimental data, while $\mathrm{K}_{\text {eq }} 1$ and $\mathrm{K}_{\text {eq } 2}$ are the equilibrium constants for the carbon monoxide and carbon dioxide hydrogenation reactions respectively. The parameter values at $513 \mathrm{~K}$ are $\mathrm{A}_{1}=3.762 * 10^{5}, \mathrm{~A}_{2}=8.939 * 10^{5}, \mathrm{~B}_{1}=1.536 * 10^{7}$, 
$B_{2}=2.368 * 10^{6}, C_{1}=2.993 * 10^{7}$, and $C_{2}=7.702 * 10^{6}$, where the partial pressures are given in Mpa.

Natta (1955) used a fixed bed reactor to study methanol synthesis in the gas phase over $\mathrm{ZnO} / \mathrm{Cr}_{2} \mathrm{O}_{3}$ and $\mathrm{CuO} / \mathrm{ZnO} / \mathrm{Cr}_{2} \mathrm{O}_{3}$ catalysts using a carbon dioxide free synthesis gas. The pressure was set at $30 \mathrm{MPa}$ while the temperature was varied between 573 and $633 \mathrm{~K}$.

It was found that the adsorption and desorption steps of hydrogen and carbon monoxide are faster than their reaction on the catalyst surface. The reaction is trimolecular involving two Hydrogen molecules and one carbon monoxide molecule. With these assumptions, the following kinetic model was proposed:

$$
r_{\text {mathanol }}=\frac{\gamma_{C O} p_{C O}\left(\gamma_{H_{2}} p_{H_{2}}\right)^{2}-\frac{\gamma_{C H, O H} p_{C H, O H}}{K_{\text {aq1 }}}}{\left(A+B \gamma_{C O} p_{C O}+C \gamma_{H_{2}} p_{H_{2}}+D \gamma_{C H, O H} p_{C H, O H}\right)^{3}}
$$

The parameters $A, B, C$, and D were regressed from experimental data and the values of the parameters are different for each of the two catalysts used and depend also on the temperature. $K_{\text {eq } 1}$ is the thermodynamic equilibrium constant for the carbon monoxide hydrogenation reaction and $\gamma_{i}$ is the fugacity coefficient of each component. Natta reported that the agreement between the calculated values and the experimental data were best at low $\mathrm{CO} / \mathrm{H}_{2}$ ratios.

A Langmuir-Hinshelwood rate equation was derived by Villa et al. (1985) in which it was assumed that the rate determining step is the carbon monoxide hydrogenation surface reaction between the adsorbed hydrogen and carbon monoxide molecules. The study was conducted in a Berty reactor over a $\mathrm{CuO} / \mathrm{ZnO} / \mathrm{Al}_{2} \mathrm{O}_{3}$ catalyst at the remperature and pressure ranges of 488 to $518 \mathrm{~K}$ and 3.0 to $9.5 \mathrm{MPa}$. Villa proposed the following model: 


$$
r_{\text {meahanol }}=\frac{p_{\mathrm{CO}} p_{\mathrm{H}_{2}}^{2}-\frac{p_{\mathrm{CH} 3 \mathrm{OH}}}{K_{\mathrm{CQ} 1}}}{\left(A+B p_{\mathrm{CO}}+C p_{\mathrm{CO}_{2}}+D p_{\mathrm{CH}, \mathrm{OH}}\right)}
$$

Where $\mathrm{K}_{\text {eq1 } 1}$ is the equilibrium constant for the carbon monoxide hydrogenation reaction and the prarameters $A, B, C$, and $D$ where regressed from experimental data.

Dybkjaer et al. (1981) devised the following Langmuir-Hinshelwood rate expression for methanol synthesis assuming that the sites that adsorb carbon monoxide and carbon dioxide are different from the one that adsorb hydrogen and water:

$$
r_{\text {mevianol }}=\frac{k p_{\mathrm{H}_{2}}\left(1-\frac{p_{\mathrm{CH}, \mathrm{OH}}}{K_{\text {eq }} p_{C O} p_{\mathrm{H}_{2}}^{2}}\right)}{\left(1+A p_{\mathrm{H}_{2}}^{0.5}+\frac{B p_{\mathrm{H}_{2} \mathrm{O}}}{p_{\mathrm{H}_{2}}^{0.5}}\right)}
$$

Where Keql is the thermodynamic equilibrium constant of the carbon monoxide hydrogenation reaction and the parameters $A, B$, and $k$ were empirically regressed from kinetic data. The investigation was performed in a fixed bed reactor over a $\mathrm{CuO} / \mathrm{ZnO} / \mathrm{Cr}_{2} \mathrm{O}_{3}$ catalyst.

Leonov et al. (1973) studied methanol synthesis in a fixed bed reactor over a $\mathrm{CuO} / \mathrm{ZnO} / \mathrm{Al}_{2} \mathrm{O}_{3}$ catalyst using a carbon dioxide free synthesis gas. The temperature and pressure were set in the range of 493 to $533 \mathrm{~K}$ and 4.0 to $5.5 \mathrm{MPa}$ while the $\mathrm{H}_{2} / \mathrm{CO}$ ratio was held at 2 .

Leonov deduced a power law kinetic model that takes into consideration the forward and backward carbon monoxide hydrogenation reaction: 


$$
r_{\text {methanol }}=k\left(\frac{p_{C O}^{0.5} p_{H_{2}}}{p_{C H, O H}^{0.66}}-\frac{p_{C H, O H}^{0.34}}{p_{C O}^{0.5} p_{H_{2}} K_{\text {Cq1 }}}\right)
$$

Where $\mathrm{k}$ and $\mathrm{K}_{\text {eql }} \mathrm{l}$ are the reaction rate constant and the thermodynamic equilibrium constant of the forward carbon monoxide hydrogenation reaction, respectively.

Weimer et al. (1987) conducted liquid phase methanol production operations in a one liter slurry reactor at $5.2 \mathrm{MPa}$ and $523 \mathrm{~K}$. Space velocities were varied between 5000 and $15000 \mathrm{l} / \mathrm{hr} \mathrm{kg}$ cat and the $\mathrm{H}_{2} / \mathrm{CO} / \mathrm{CO}_{2} / \mathrm{N}_{2}$ ratio was set at either $35 / 51 / 13 / 1$ (CO rich gas) or 55/19/5/21 (balanced gas), respectively. The catalyst particle size was less than 10 microns.

Carbon monoxide rich gas feed was used to simulate synthesis gas derived from coal. When carbon monoxide rich gas was fed, increasing the space velocity caused the carbon monoxide conversions to decrease and the methanol productivity to increase. The same trend was observed for the balanced gas case. It was shown that the mass transfer resistances were negligible at a stirter speed of $1200 \mathrm{rpm}$ for $10 \mathrm{wt}$. \% slurry. Weimer indicates that methanol production rate is approximately proportional to $P_{C O}^{1 / 3}$ and $P_{H z}^{2 / 3}$ by postulating the following rate expression:

$$
r_{\text {methanol }}=W_{\text {cal }} k\left(f_{C O} f_{H_{2}}^{2}\right)^{m}\left(1 \cdot \frac{f_{C H, O H}}{K_{C q 1} f_{C O} f_{H_{2}}^{2}}\right)
$$

Where $\mathrm{k}$ is the reaction constant, $\mathrm{K}_{\mathrm{eq}} \mathrm{l}$ is the equilibrium constant for the carbon monoxide hydrogenation reaction, and the $f_{i}$ 's are the fugacities of each component. The value of $m$ depends on the catalyst and for this case it was $1 / 3$ since the data collected indicate an overall first order behavior. The water partial pressure term was neglected because water production rate was small. 
The other study in which methanol synthesis was investigated in the liquid phase was conducted by von Wedel et al. (1988). A slurry reactor was used with a $\mathrm{CuO} / \mathrm{ZnO} / \mathrm{Al}_{2} \mathrm{O}_{3}$ catalyst. The temperature was in the range of 490 to $520 \mathrm{~K}$ and the pressure was in the range of 2 to $6 \mathrm{MPa}$. The partial pressure of carbon dioxide was increased from 0 to $1 \mathrm{MPa}$ while the $\left(\mathrm{CO}+\mathrm{H}_{2}\right)$ partial pressure was varied between 1 and $5 \mathrm{MPa}$ in order to find the optimal synthesis gas composition at which maximum methanol production rate is achieved. That composition was found at a carbon dioxide partial pressure of 0.2 . Although the effect of carbon dioxide on methanol production was not incorporated in the suggested rate equation, von Wedel et al. indicated that the role of carbon dioxide is to keep the catalyst in the active state, and proposed the following power law rate equation:

$$
r_{\text {mentanol }}=\left(A_{1} e^{E_{I} / R T} p_{C O}^{0.4} p_{H_{2}}^{0.18}\right)-\left(A_{2} e^{E_{1} / R T} p_{C H \text { OOH }}^{0.13}\right)
$$

$E_{f}$ and $E_{b}$ are the activation energies for the forward and reverse carbon monoxide hydrogenation reaction, respectively. The parameters $A_{1}$ and $A_{2}$ were derived from kinetic data and reported as $1.97^{*} 10^{7}$ and $2.51^{*} 10^{10}$ respectively, where the partial pressures are given in MPa.

\subsection{The $\mathrm{CuO} / \mathrm{ZnO} / \mathrm{Al}_{2} \mathrm{O}_{3}$ Catalyst}

The $\mathrm{CuO} / \mathrm{ZnO} / \mathrm{Al}_{2} \mathrm{O}_{3}$ catalyst used in this study was supplied by United Catalyst. The manufacturer reports that the catalyst is $42 \mathrm{wt} . \% \mathrm{CuO}, 47 \mathrm{wt} . \% \mathrm{ZnO}$, and $10 \mathrm{wt}$. \% $\mathrm{Al}_{2} \mathrm{O}_{3}$ along with traces of graphite, sulfur, sodium, chlorine, and other heavy metals. The manufacturer indicates that the catalyst surface area is $55 \mathrm{~m}^{2} / \mathrm{g}$ with a pore volume of 0.2 to $0.3 \mathrm{cc} / \mathrm{g}$ for pores with radius greater than 29.2 angstroms.

Natta (1955) and Chinchen et al. (1990) indicate that the activity of the catalyst under investigation is a function of the copper metal area and not the wt. \% of copper and 
it is independent of the support indicating that the reaction occurs on the copper. They also indicated that alumina or chromia along with $\mathrm{ZnO}$ hinder agglomeration of $\mathrm{Cu}$ particles, and interestingly, $\mathrm{ZnO}$ reacts with alumina or chromia to block the conversion of methanol to dimethyl ether which is a thermodynamically favored reaction under industrial operating conditions. Also, $\mathrm{ZnO}$ plays the role of a sink for poisons by reacting with chlorine and sulfur components. 


\section{CHAPTER III}

\section{EXPERIMENTAL}

\subsection{Apparatus}

A methanol production unit was designed and built. It consists of three zones; the gas feed mixing, the slurry reactor, and products separation and analysis. The system diagram is shown in figure 1. All kinetic experiments were conducted in a stirred $100 \mathrm{cc}$ Autoclave laboratory reactor model EZE-seal. The body of the reactor is made of stainless steel with an inner diameter of $46 \mathrm{~mm}$ and $13 \mathrm{~mm}$ thick, with a maximum working pressure of $3300 \mathrm{psi}$ at $850 \mathrm{oF}$. The vessel has six ports, one gas inlet, and one thermowell. One of the ports is used to install a $U$ shaped thermowell to measure the temperature of the gas phase in order to eliminate wall effects on the measured gas phase temperature. The reactor effluent port is connected to a 5.0 micrometer filter to prevent the catalyst entrainment. The feed gas and the recycled oil are introduced to the reactor at two different ports. A baffle bar and a bladed impeller are connected to the stainless steel reactor cover. The baffle bar is used in order to inhibit vortex formation. The impeller is used to keep the catalyst suspended in the slurry and enhance the mixing of the reactants in the slurry phase. The impeller is driven by a Magnadrive II stirrer model $0.75-1$ that is capable of delivering $0.45 \mathrm{hp}$ at $3000 \mathrm{rpm}$. Cooling water is run through the Magnadrive assembly to keep the temperature of the assembly in the permissible range. A rupture disc with a rating of 3000 psi was supplied by the manufacturer for safety reasons. A schematic drawing of the slurry reactor is shown in figure 2.

Feed gases, $\mathrm{H}_{2}$, premixed $\mathrm{CO} / \mathrm{CO}_{2}$, and nitrogen, are supplied in cylinders. Before being introduced to the system, hydrogen is passed through a molecular sieve guard bed to remove moisture, and the $\mathrm{CO} / \mathrm{CO}_{2}$ mixture is passed through two stainless steel guard vessels in order to remove catalyst poisons like iron and nickel carbonyls. The first vessel contains molecular sieve and the second contains activated carbon. The 


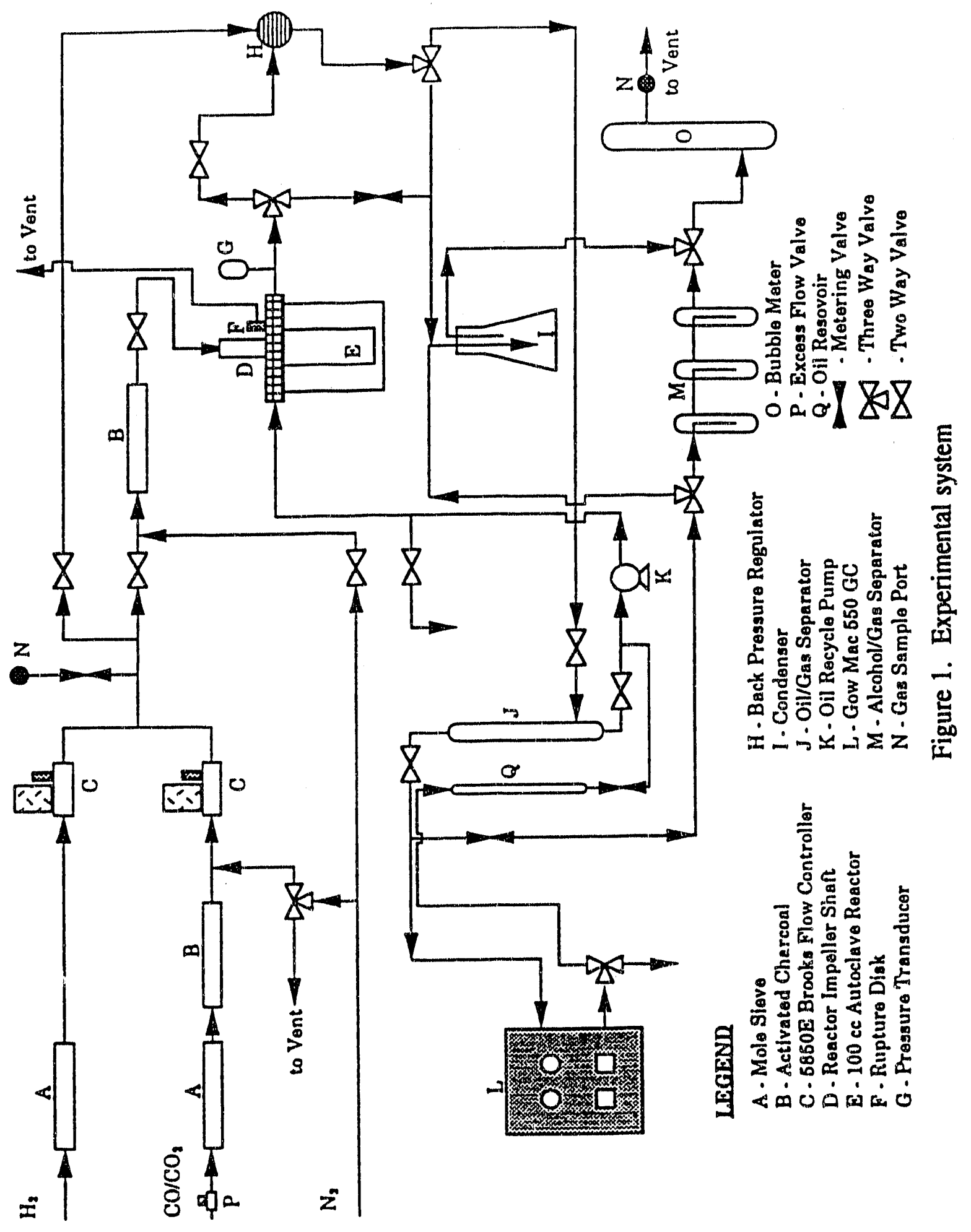




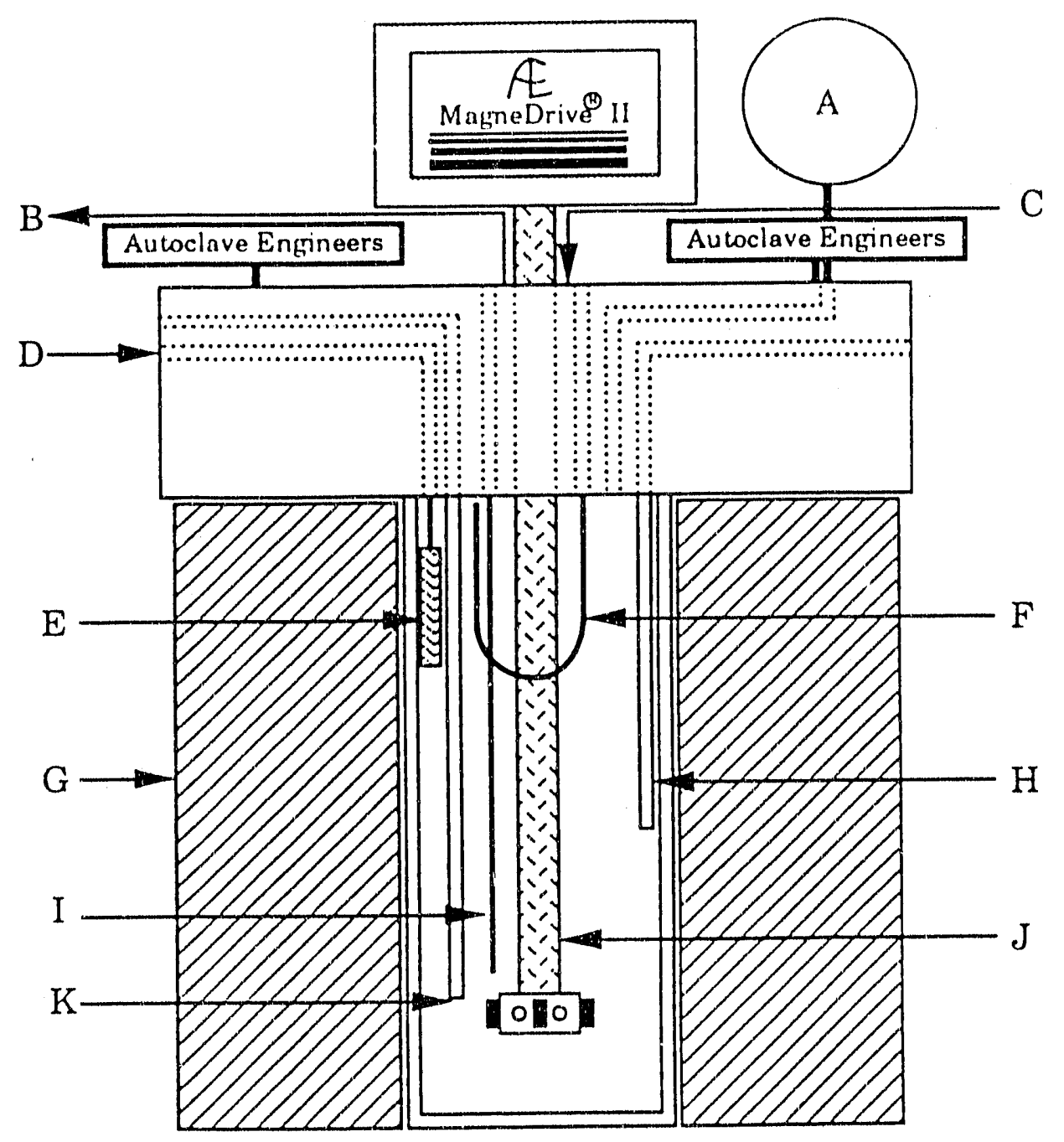

\section{LEGEND}
A - Pressure Gauge
G - Heating Element
B - Impeller Cooling Water Oulet
$\mathrm{H}$ - Oil Recycle Inlet
C - Impeller Cooling Water Inlet
I - Liquid Phase Thermocouple
D - Reactor Effluent Outlet
$J$ - Impeller Shaft
E - Metal Porous Filter for Outlet K - Reactant Inlet
F - Gas Phase Thermocouple

Figure 2. Schematic diagram of the slurry reactor 
activated carbon vessel is located behind the molecular sieve vessel in order to remove $\mathrm{Ni}(\mathrm{CO})_{4}$, because cornmercial methanol catalysts can not accommodate carbonyl poisons of more than 10 parts per billion (Golden et al. 1991). An activated carbon filter is installed just before the reactor inlet in order to further remove impurities

Two mass flow controllers are provided to adjust the flow of feed gases. Both of the flow meters are Brooks model 5850E equipped with Brooks 5869 flow indicators. The hydrogen mass flow controller has a range of 0 to 1000 standard milliliters per minute (smlpm) and that of $\mathrm{CO} / \mathrm{CO}_{2}$ have a range of 0 to $2000 \mathrm{smlpm}$. The manufacturer indicates that the measurement percent error range of both flow controllers is -0.25 to +0.4 . When both streams leave their designated flow controllers they are mixed at a $\mathrm{T}$ fitting. The composition of that mixture $\left(\mathrm{H}_{2}, \mathrm{CO}\right.$, and $\left.\mathrm{CO}_{2}\right)$ is checked by introducing a high pressure inlet gas sampling port equipped with a metering valve to reduce flow. The flow controllers are calibrated using a vertical bubble flow meter over the entire operating range. The calibration curves for Hydrogen and $\mathrm{CO} / \mathrm{CO}_{2}$ flow controllers are shown in Figure 3 and 4 respectively.

Two pressure gauges are installed to monitor the pre-reactor and the reactor pressures respectively, and the reactor outlet pressure is monitored by a pressure transducer model 406-50051 made by Consolidated Controls and powered by a 12 volt power supply. The pressure transducer output is continuously plotted by a Houston Instruments strip chart recorder. The reactor outlet pressure is reduced to atmospheric pressure using a Tescom back pressure regulator.

As the reactor effluent leaves the back pressure regulator it passes into an oil/gas separator which is a glass cylinder with a diameter of $4 \mathrm{~cm}$ and a height of $4, \mathrm{~cm}$. The upper part of the oil/gas separator is filled with glass wool to improve separation. 


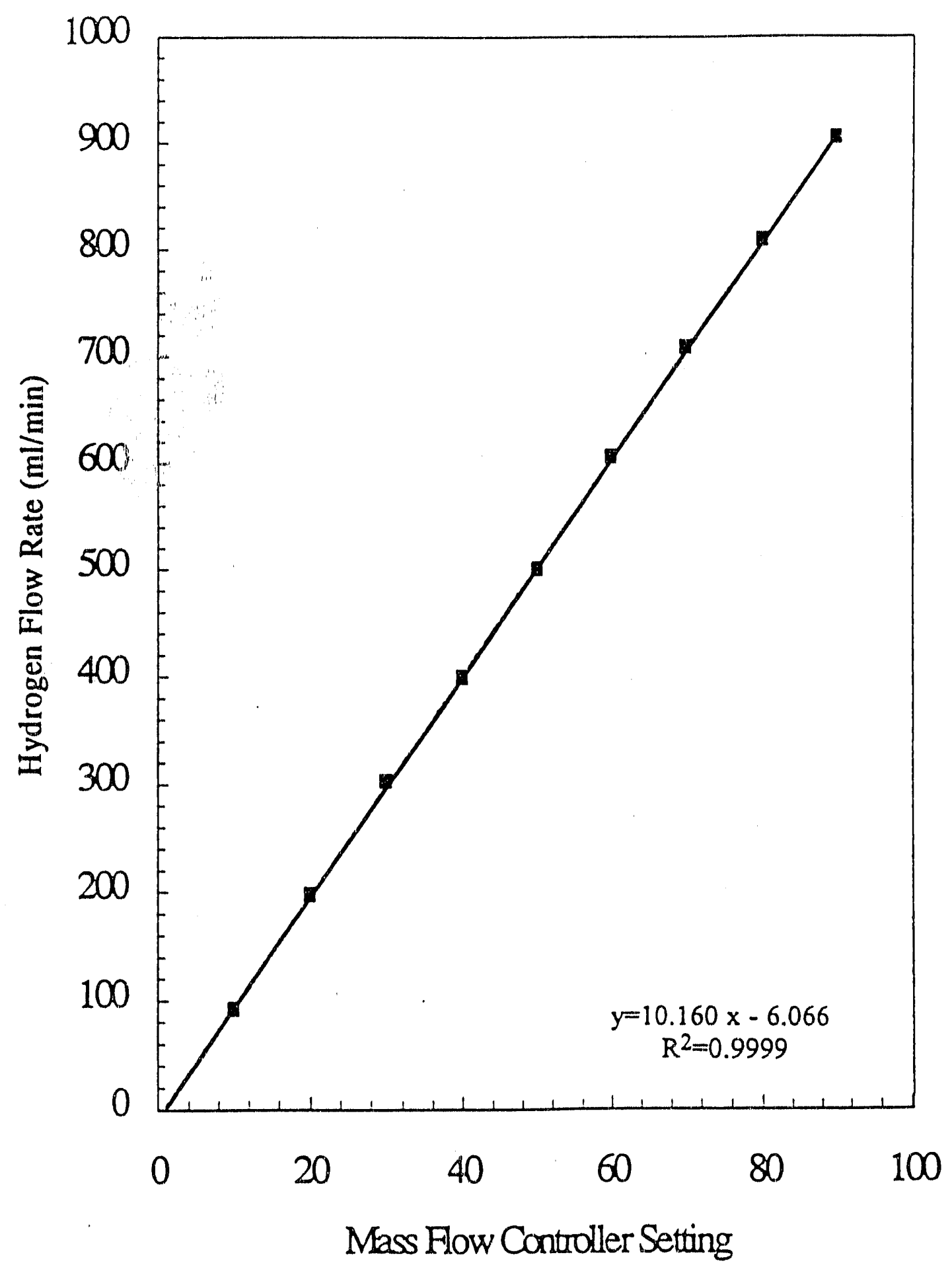

Figure 3. Hydrogen mass flow controller calibration line. 


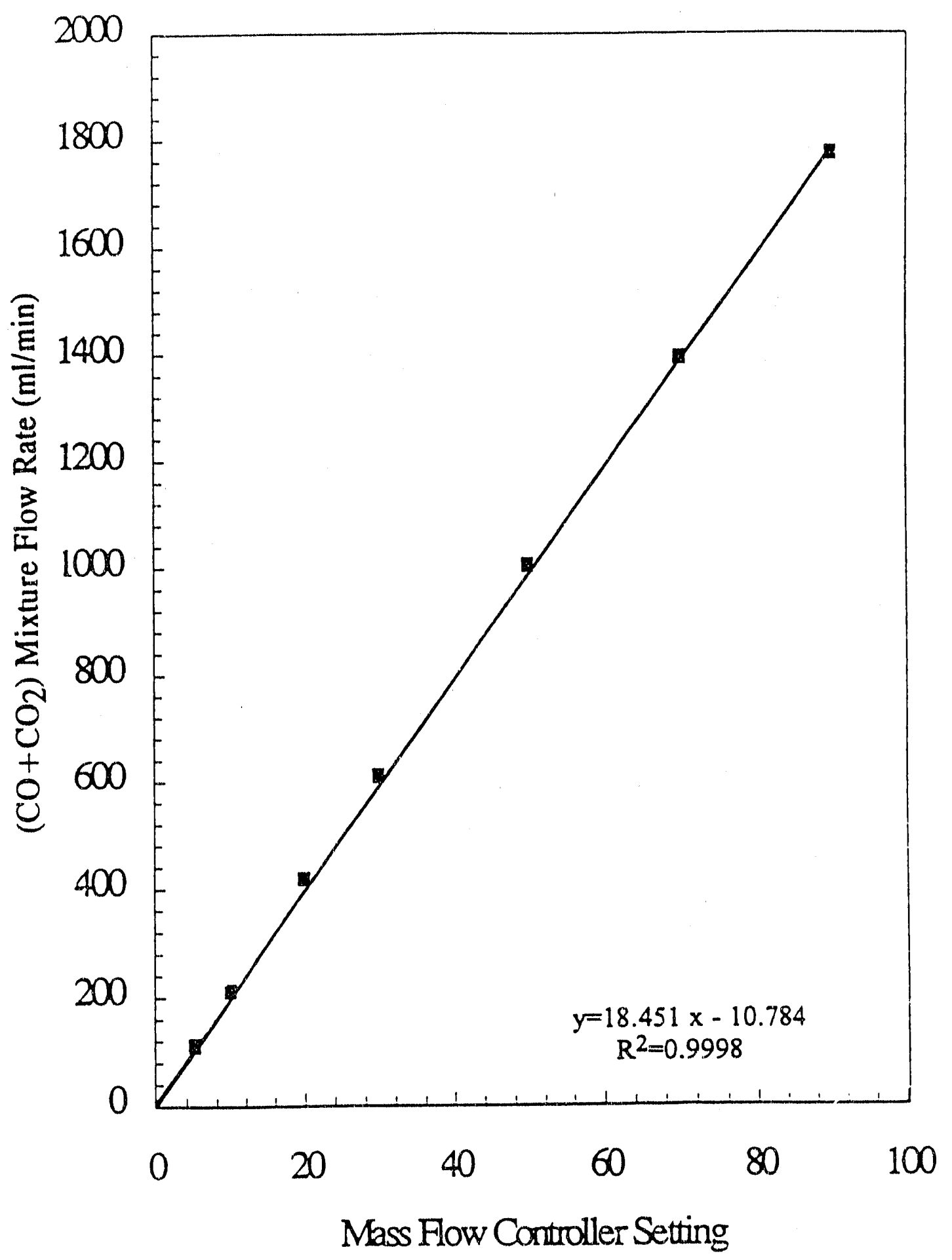

Figure 4. $\mathrm{CO} / \mathrm{CO}_{2}$ mass flow controller calibration line. 
The oil level in the sepsrator is maintained at a level of $3 \mathrm{~cm}$ from the bottom using an Eldex A-30-S pump that recycles the collected oil back to the reactor.

After passing through the gas/oil separator, the gas is either sent to an on line Gow Mac 550 gas chromatograph equipped with a Varian 4290 integrator for analysis, or to an alcohol/gas separator where condensable gases are collected using a dry ice and acetone bath. The tail gas flow rate is measured using a $1000 \mathrm{cc}$ bubble flow meter. A sampling port located after the bubble flow meter is used to collect samples of tail gas to be analyzed on a Carle gas chromatograph equipped with a Varian 4290 integrator. Both gas chromatographs use a thermal conductivity detector (TCD).

Three Staco Variable voltage auto-transformers are used to supply power to heating tapes in order to maintain the temperature of the lines after the reactor along with the gas/oil separator at $373 \mathrm{~K}$. The reactor is heated using a furnace supplied by the manufacturer which is controlled by a Thermolyne Furnatrol I furnace controller. Type $\mathrm{K}$ thermocouples are used to measure temperatures at six different locations throughout the system along with that of the gas/oil separator.

The catalyst used in this study is a $\mathrm{CuO} / \mathrm{ZnO} / \mathrm{Al}_{2} \mathrm{O}_{3}$ alcohol catalyst \# L-951 supplied by United Catalyst. Surface area measurement on this catalyst was performed using the BET technique in our laboratory. The surface area of the fresh catalyst was found to be $49.1 \mathrm{~m}^{2} / \mathrm{g}$ compared to $55 \mathrm{~m}^{2} / \mathrm{g}$ as reported by the manufacturer. The oil used in this investigation is Freezene Heavy supplied by Witco. The oil is mainly saturated aliphatic and naphthenic hydrocarbons with a molecular weigh of 349 and a specific gravity of 0.71 at $523 \mathrm{~K}$ ( Ledakowics and Nowicki, 1987). 


\subsection{Procedure}

\subsubsection{Catalyst Loading}

Five grams of catalyst with a particle size of 500-600 microns are loaded into the reactor. The catalyst bulk density is $1.38 \mathrm{~g} / \mathrm{cc}, 40 \mathrm{ml}$ of oil is transferred to the reactor giving a $12.4 \%$ slurry. The reactor is then sealed and its cover top is wrapped with a heating tape and an insulation material to control gas phase temperature.

\subsubsection{Catalyst Reduction}

Since the catalyst supplied by the manufacturer is partially oxidized, it must be brought to the active state. In-situ reduction of the catalyst is carried out according to guidelines described by Sawant et al. (1987). The reduction procedure consist of flowing a mixture of nitrogen and hydrogen at a ratio of $95 / 5$ and a space velocity of 3000 $1 / \mathrm{hr} \mathrm{kg}_{\text {cat }}$ through the slurry at $1.7 \mathrm{MPa}$ and $298 \mathrm{~K}$ with the impeller speed set at 1200 rpm. Nitrogen flow rate is controlled through $\mathrm{CO} / \mathrm{CO}_{2}$ mass flow controller since the two gases have the same sensor conversion factor and specific gravity. The lines after the reactor are kept at $373 \mathrm{~K}$. First, the feed gas is run at the desired rate through the bypass and not through the reactor in order to analyze the gas composition by taking a sample from the inlet sampling port and injecting it into the Carle gas chromatograph . When the analysis result agree with the flow controllers readings, the flow is directed to the reactor to start the reduction procedure. The reactor is heated from $298 \mathrm{~K}$ to $398 \mathrm{~K}$ at a rate of $1 \mathrm{~K} / \mathrm{min}$ and kept at $398 \mathrm{~K}$ for one hour. The reactor is heated again to $448 \mathrm{~K}$ at the same rate and held there for another hour. Then, the reactor temperature is raised to $478 \mathrm{~K}$ at a rate of $1 \mathrm{~K} / \mathrm{min}$. At this point, synthesis gas is introduced to the reactor at $3000 \mathrm{l} / \mathrm{hr} \mathrm{kg}_{\text {cat }}$ with $\mathrm{H}_{2} /\left(\mathrm{CO}+\mathrm{CO}_{2}\right)$ ratio of $2 / 1$ and kept at these conditions for six hours. 


\subsubsection{Reaction Procedure}

At the end of the six hours, the reactor pressure and temperature are raised slowiy and cautiously to $5.2 \mathrm{MPa}$ and $523 \mathrm{~K}$ respectively. The temperature is increased at the same rate of $1 \mathrm{~K} / \mathrm{min}$. As soon as these conditions are reached, the hydrogen flow is stopped letting only nitrogen flow through the system for 15 minutes. Then, the slurry reactor is isolated by closing the inlet and outlet valves and opening the bypass line valve. Hydrogen at the desired flow rate is introduced to the systern through the bypass. No flow rate fluctuations were cbserved. Moreover, the pressure drop across the mass flow controller was around the permissible value of 40 psig. The manufacturer recommends 45 minutes warm up period before introducing flow through the mass flow controllers. This recommendation was followed. When the desired $\mathrm{H}_{2}$ flow rate is established, $\mathrm{CO} / \mathrm{CO}_{2}$ mixture at the desired flow rate is also introduced to the system through the bypass using the other mass flow controller, which exhibits the same characteristics as those of the $\mathrm{H}_{2}$ flow controller. The total flow rate is checked by a vertical $1000 \mathrm{cc}$ bubble flow meter. A sample is taken from the inlet gas sampling port and analyzed on the Carle gas chromatograph to ensure that the inlet composition meets that of the desired composition. The reaction is started by opening the reactor's inlet and outlet valves and closing the bypass valve.

Fine adjustments are made to the reactor's pressure and liquid and gas phase temperatures. On line analysis is conducted every 45 minutes to check for steady state conditions. When no changes in pressure, temperatures, flow rate, and composition are observed, steady state in the reactor is reached.

Cleaned and dryed condensers are weighed, and placed in a container and connected to the system. The container is then filled with dry ice and the flow is directed towards the condensers in order to collect all condensable products in the tail gas leaving the reactor for a time period of two hours. During the material balance period, gas samples are taken twice from the outlet gas sampling port to analyze for $\mathrm{H}_{2}, \mathrm{CO}, \mathrm{CO}_{2}$, 
and any other gas product on the Carle gas chromatograph. At the end of the two hours period, flow through the condensers is stopped. The condensers are dried from the outside to remove moisture and weighed to determine the condensate production rate. Condensate samples are injected in the Gow Mac gas chromatograph to analyze for methanol, water, and dimethyl ether. Methanol production rate is determined marking the end of the mass balance procedure.

At this point it is possible to switch to other conditions by following the same reaction procedure described above. Otherwise, the reaction is terminated by slowly reducing the reactor's temperature and pressure and stopping the synthesis gas flow and introducing Nitrogen instead at 200 smlpm.

\subsubsection{Kinetic Data Gathering}

The reaction is started at a temperature of $523 \mathrm{~K}$, pressure of $5.2 \mathrm{MPa}$, $\mathrm{H}_{2} /\left(\mathrm{CO}+\mathrm{CO}_{2}\right)$ ratio of 2 , and space velocity of $5000 \mathrm{Mhr} \mathrm{kg}_{\text {cat }}$. These are considered as the overall base line conditions for all other runs. The reaction is initiated at these conditions and left undisturbed until steady state conversions are reached after 175 hours of continuos operation, during which the material balance procedure are conducted daily. When steady state conversions are reached at the temperature, pressure, and $\mathrm{H}_{2} /\left(\mathrm{CO}+\mathrm{CO}_{2}\right)$ ratio specified above, the space velocities are manipulated in the order of $7500,5000,3000,5000,10000$, and $5000 \mathrm{lhr} \mathrm{kg}_{\text {cat }}$ respectively from which kinetic data are collected. The run with space velocity of $5000 \mathrm{Vhr} \mathrm{kg}_{\text {cat }}$ is alternatively performed to establish the overall base line conditions in order to continuously monitor the catalyst activity.

Then the $\mathrm{H}_{2} /\left(\mathrm{CO}+\mathrm{CO}_{2}\right)$ ratio is set to 1 at a space velocity of $5000 \mathrm{lhr} \mathrm{kg}_{\text {cat. }}$ When steady conversions are reached, kinetic data are collected by setting the space velocity to $8000,5000,3000,5000,13000$, and $5000 \mathrm{l} / \mathrm{hr} \mathrm{kg}_{\mathrm{cat}}$, respectively, and performing the material balance procedure described above at each space velocity. The 
run at $5000 \mathrm{l} / \mathrm{hr} \mathrm{kg}_{\text {cat }}$ is conducted repeatedly in order to check the catalyst activity within the experimental series at the $\mathrm{H}_{2} /\left(\mathrm{CO}+\mathrm{CO}_{2}\right)$ of 1 .

After concluding the experimental series at the $\mathrm{H}_{2} /\left(\mathrm{CO}+\mathrm{CO}_{2}\right)$ of 1 , the overall base line conditions run at $5000 \mathrm{l} / \mathrm{hr} \mathrm{kg}_{\text {cat }}$ and $\mathrm{H}_{2} /\left(\mathrm{CO}+\mathrm{CO}_{2}\right)$ ratio of 2 is performed again to detect any loss of catalyst activity. Then the $\mathrm{H}_{2} /\left(\mathrm{CO}+\mathrm{CO}_{2}\right)$ ratio is switched to 0.5 at $5000 \mathrm{Mhr} \mathrm{kg}_{\text {cat }}$ and held their until steady state conversions are achieved. Then the space velocity is changed in the sequence of $8000,5000,3000,5000,13000$, and $5000 \mathrm{l} / \mathrm{hr} \mathrm{kg}$ cat and the kinetic data are collected. The overall base line condition is re-run after the end of this experimental series also.

The final experimental series is at a temperature of $508 \mathrm{~K}$ and a $\mathrm{H}_{2} /\left(\mathrm{CO}+\mathrm{CO}_{2}\right)$ ratio of 2. The space velocity is set at $5000,7500,5000,3000,5000 \mathrm{l} / \mathrm{hr} \mathrm{kg}_{\text {cat }}$ and the same procedure is followed as described above for collecting kinetic data and monitoring the catalyst activity. Before terminating the reaction, the overall base line conditions run is performed for the last time.

\subsubsection{Analytical Procedure}

Two gas chromatographs are dedicated for this investigation, a Gow Mac 550 and a Carle series S. Each gas chromatograph is connected to a Varian 4290 integrator. Both gas chromatographs use a thermal conductivity detector (TCD).

The Gow Mac G. C. is used to analyze for the reaction products, methanol, water, and dimethyl ether. It is equipped with a $1 \mathrm{~m}$ long $\mathrm{Q}$ type Porapak column which is effective for the separation of reaction products. It is also equipped with a 6 port sampling valve made by Varian. The gas chromatograph settings are as follow: the

column temperature is $392 \mathrm{~K}$, the detector temperature is $473 \mathrm{~K}$, the injection port thermostat is set to 35 , the detector power setting is $200 \mathrm{~mA}$, and the carrier gas flow rate is set at $20 \mathrm{cc} / \mathrm{min}$. 
Since the analysis on the Gow Mac G. C. is performed using a sampling valve, the response factor for methanol, $R F_{\text {methanol }}$ is given by:

$$
R F_{\text {methenol }}=y_{\text {mehanol }} / A C_{\text {methenol }}
$$

where $\mathrm{y}_{\text {methanol }}$ and $\mathrm{AC}_{\text {methanol }}$ are the mole fraction and the area count of methanol respectively. To find the methanol response factor, pure methane is bubbled at a rate of $10 \mathrm{cc} / \mathrm{min}$ through a three stage bubbler containing methanol. The bubbler is connected to the sampling valve of the G. C. The methanol saturated methane is injected into the Gow Mac through the sample loop. The mole fraction of methane is calculated by the following equation:

$$
y_{\text {maknare }}=A C_{\text {methonel }} A C_{\text {wowal }}
$$

the balance is $y_{\text {methanol }}$ which is used in equation (11) to calculate the response factor of methanol.

The same procedure is followed to determine the response factor of water. In the case of dimethyl ether, pure samples are injected into the Gow Mac through the sample loop. Nevertheless, the calculation procedure remains the same.

The Carle gas chromatograph is used to determine the concentration of hydrogen, carbon monoxide, and carbon dioxide. The Carle G. C. has the following settings: the temperature adjustment for the hydrogen transfer tube is set to 73 , the output is set to 1 , the bridge is set to thermostor, and the column temperature is $323 \mathrm{~K}$. A calibration mixture containing $51.5 \%$ hydrogen and $48.5 \%$ carbon monoxide is used to calculate the hydrogen and the carbon monoxide response factors using equation (11). the carbon dioxide response factor is determined by using another calibration gas mixture containing $10 \%$ carbon dioxide and $90 \%$ carbon monoxide. The response factors on the Carl G. C. 
are updated periodically. Typical response factors for the gases involved in this investigation on both gas chromatographs are given in table 1.

Table 1. Response factors for the Carle and Gow Mac gas chromatographs

\begin{tabular}{|c|c|c|}
\hline Component & Response Factor & G. C. Type \\
\hline Methanol & $5.71 \pm 0.015\left(10^{-6}\right)$ & Gow Mac \\
\hline Water & $4.40 \pm 0.070\left(10^{-6}\right)$ & Gow Mac \\
\hline Dimethyl ether & $3.93 \pm 0.011\left(10^{-6}\right)$ & Gow Mac \\
\hline $\mathrm{H}_{2}$ & $19.10 \pm 0.082\left(10^{-5}\right)$ & Carle \\
\hline $\mathrm{CO}_{2}$ & $2.51 \pm 0.009\left(10^{-5}\right)$ & Carle \\
\hline $\mathrm{CO}$ & $3.31 \pm 0.018\left(10^{-5}\right)$ & Carle \\
\hline
\end{tabular}




\section{CHAPTER IV}

\section{RESULTS AND DISCUSSION}

\subsection{Time on Stream Study (Figures 5-17)}

The time on stream study showed that constant catalyst activity can be achieved for a long period of time. Continuous operation of 660 hours attests to this fact. Figure 5 indicates that the catalyst activity, represented by methanol production rate, decreases sharply during the first 150 hours, after which it reaches a constant value of about 4.70 $\mathrm{mol} / \mathrm{hr} \mathrm{kg}_{\mathrm{cat}}$ for the next 510 hours. On the other hand, water production rate increases steadily from $0.16 \mathrm{~mol} / \mathrm{hr} \mathrm{kg}$ cat at 8 hours of time on stream to $0.67 \mathrm{~mol} / \mathrm{hr} \mathrm{kg}$ cat at 660 hours of time on stream as indicated in figure 6. The methanol mole fraction in the condensate steadily decreases during the time on stream study from 0.99 at 8 hours to 0.87 at 660 hours, while that of water increases in from 0.011 at 7 hours to 0.12 at 660 hours as shown in figure 7 , indicating that by 660 hours of continuous operation, the water mole fraction in the condensate increased 11 fold from its initial value while the water production rate increased 4 fold from its initial value. On the other hand, methanol production rate remained unchanged during the steady state portion of the time on stream study. From this observation, it can be concluded that the extent of the carbon dioxide hydrogenation is increasing with time on stream.

This conclusion is also confirmed by figures 10,11 , and 12 . In figure 10 , it can be observed that higher hydrogen \% conversions than that of carbon monoxide are achieved, for a $\mathrm{H}_{2} /\left(\mathrm{CO}+\mathrm{CO}_{2}\right)$ ratio of 2 the hydrogen and carbon monoxide \% conversions should be equal, indicating that more hydrogen is reacting than carbon monoxide. Figure 11 indicates that as time on stream increases carbon dioxide $\%$ conversion increases, implying that the extent of carbon dioxide hydrogenation reaction increases as the time on stream increases. Moreover, the \% conversion of carbon 
monoxide to carbon dioxide is increasing negatively with time on stream as illustrated in figure 12 indicating that the extent of the reverse water gas shift reaction is increasing with time on stream, and by comparing figures 11 and 12 it can be concluded that the extent of the carbon dioxide hydrogenation reaction is higher than that of the reverse water gas shift reaction at $\mathrm{H}_{2} /\left(\mathrm{CO}+\mathrm{CO}_{2}\right)$ ratio of 2 and a space velocity of 5000 $\mathrm{l} / \mathrm{hr} \mathrm{kg}_{\text {cat }}$. Therefore a net increase in water production rate was observed with time on stream.

The \% conversion of hydrogen decreases rapidly during the first 150 hours of time on stream after which it reaches a steady state value of 6.8 as shown in figure 8 . On the other hand, hydrogen to methanol \% conversion has a steady state value of 6.4 as shown in figure 16. The steady state hydrogen \% conversion and the hydrogen to methanol \% conversion values are statistically equal, indicating that although the water gas shift reaction is taking place as proven above, its extent is small.

The \% conversion of carbon monoxide decreases rapidly during the first 150 hours of time on stream after which it reaches a steady state value of 4.5 as shown in figure 9. On the other hand, carbon monoxide to methanol \% conversion has a steady state value of 7.2 as shown in figure 14. The steady state carbon monoxide \% conversion is lower than carbon monoxide to methanol \% conversion indicating that some of the carbon monoxide is involved in the reverse water gas shift reaction. Attesting to this conclusion are figures 15 and 17 in which it can be observed that the total carbon to methanol \% conversion with a steady state value of 6.4 is lower than carbon monoxide conversion to methanol.

Finally, figure 13 shows that the steady state value of the total carbon \% conversion is 5 which is lower than that of total carbon to methanol \% conversion indicating that methanol, the feed carbon oxides, and hydrogen, undergo side reactions. The detection of dimethyl ether in the condensate along with trace amounts of acetic acid confirm this inference. 


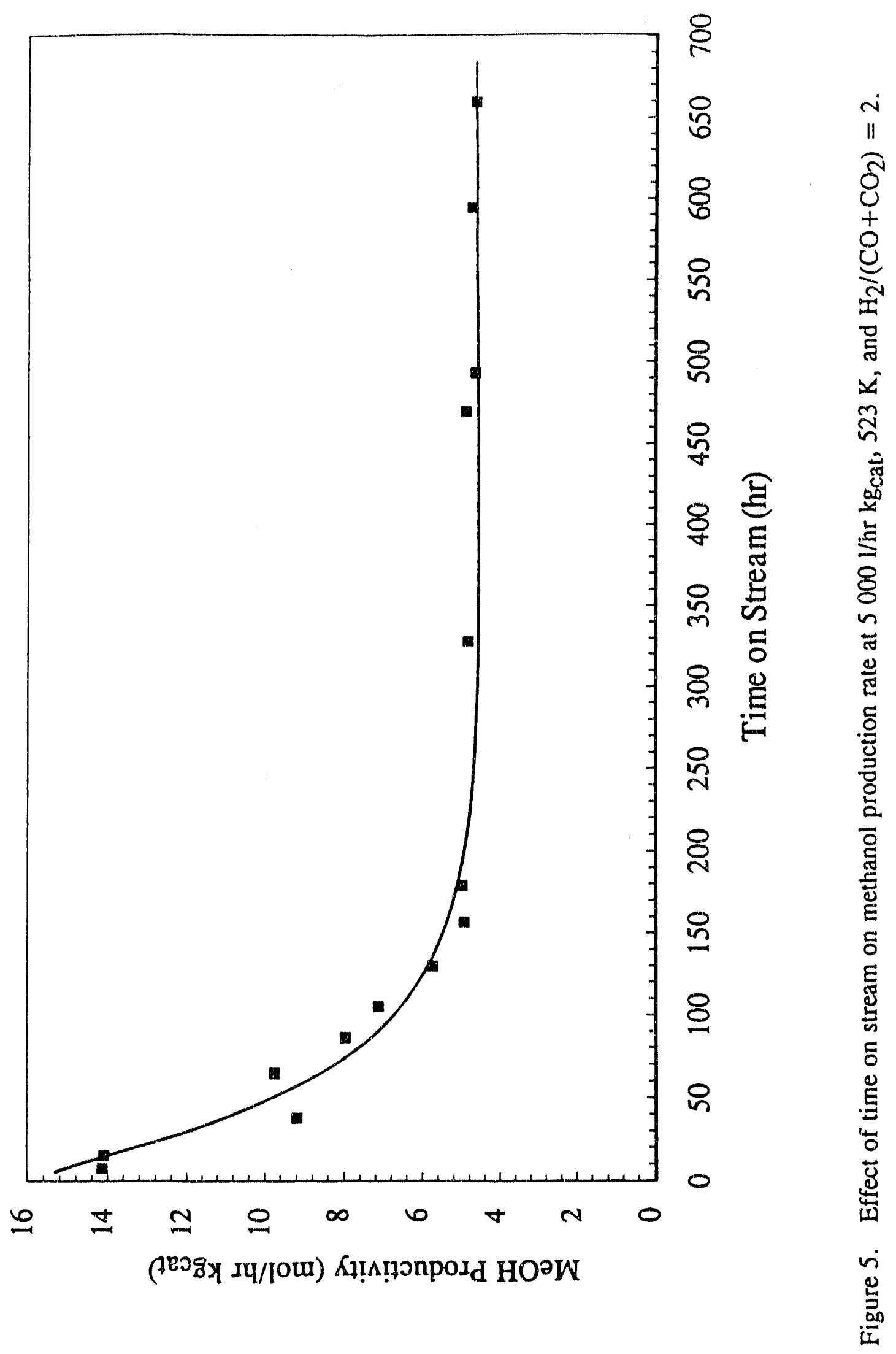




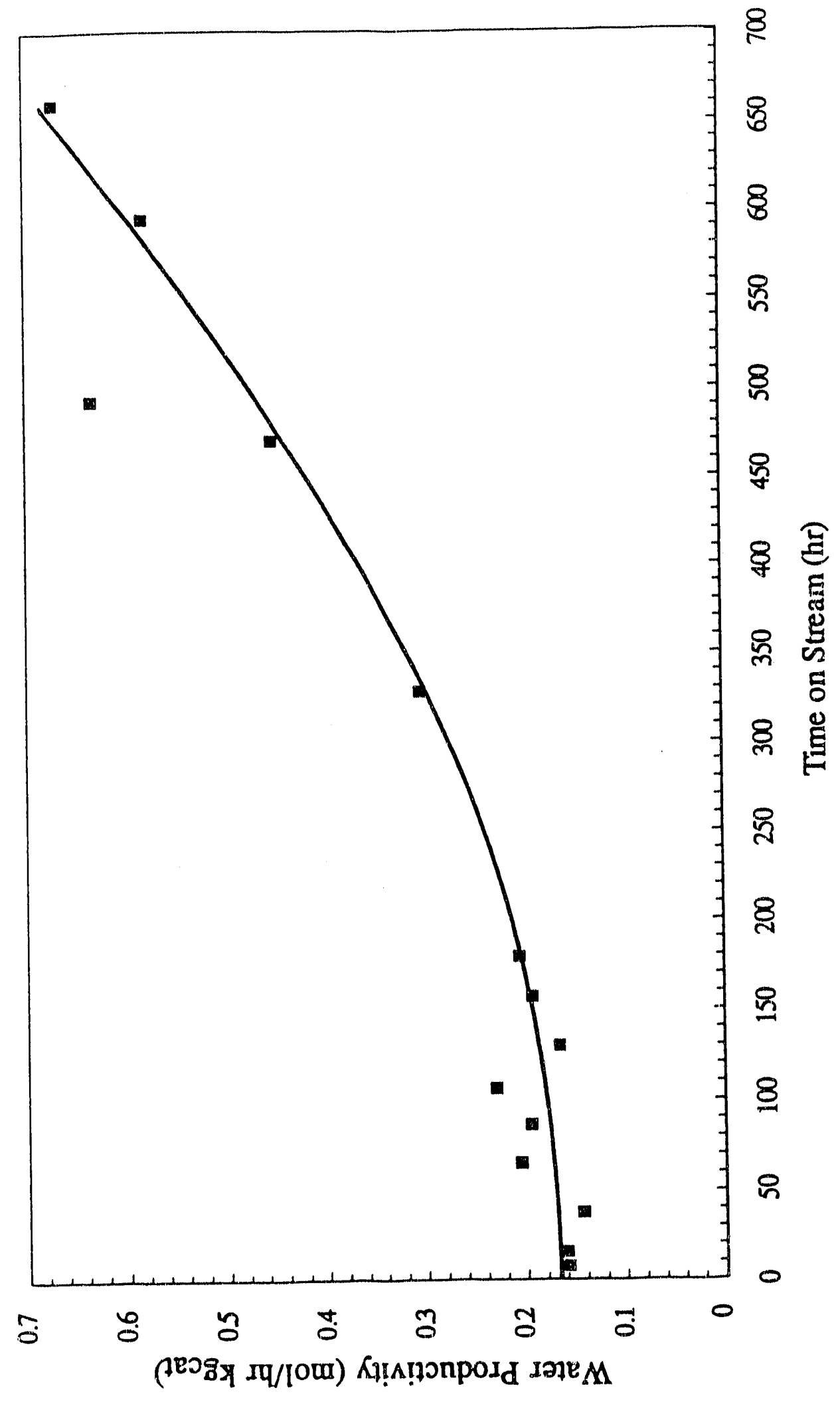

ปิ

它 


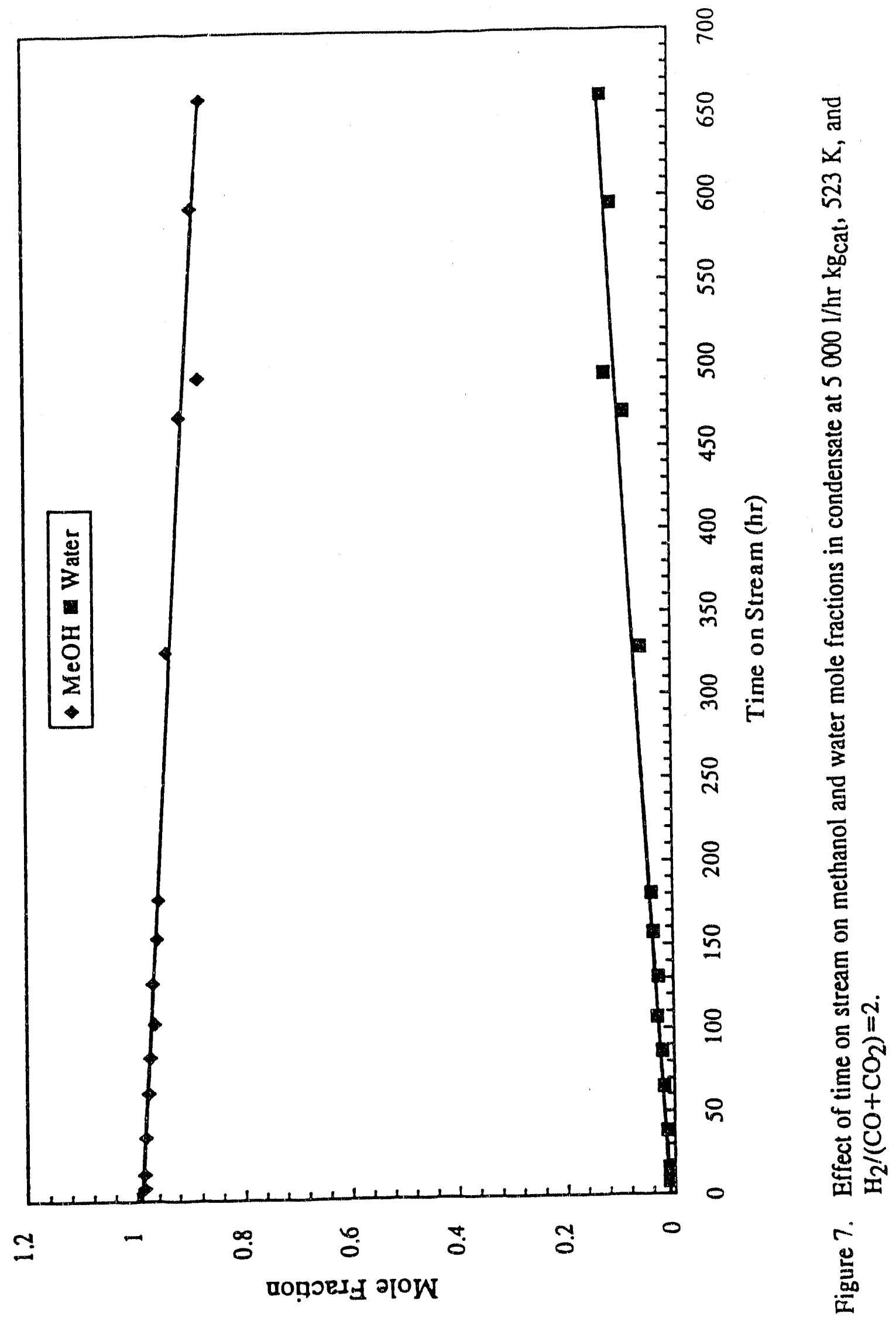




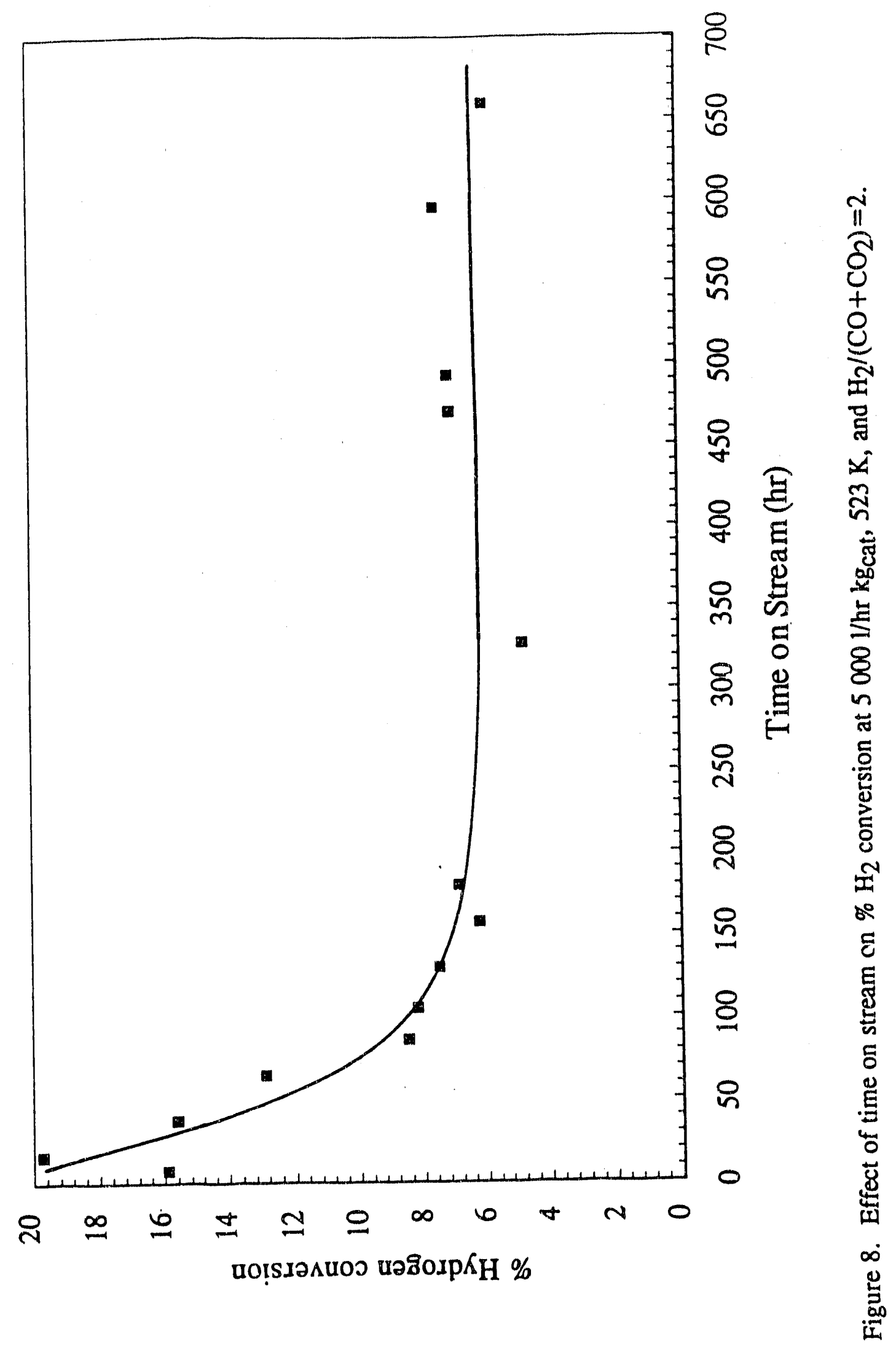




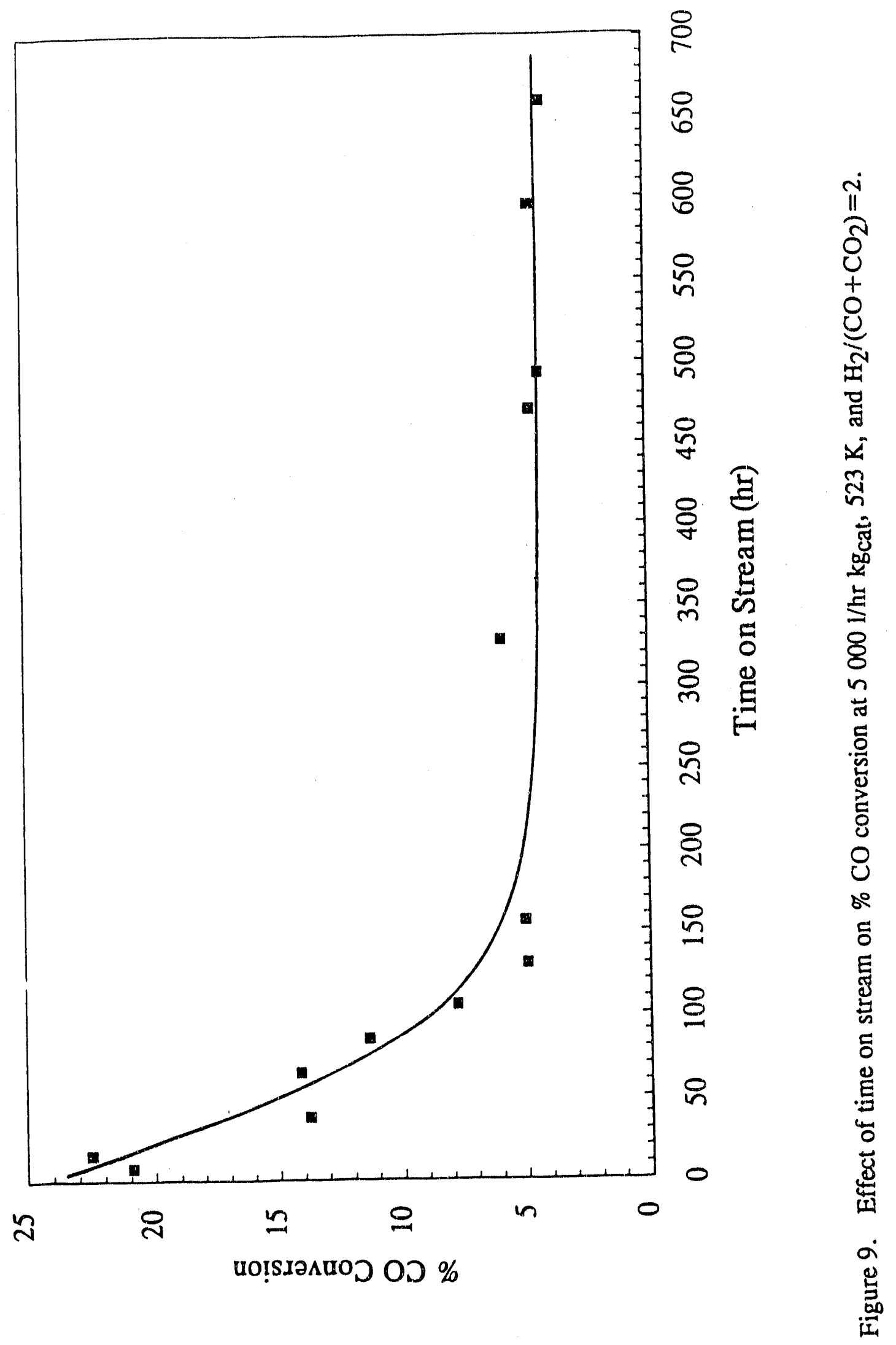




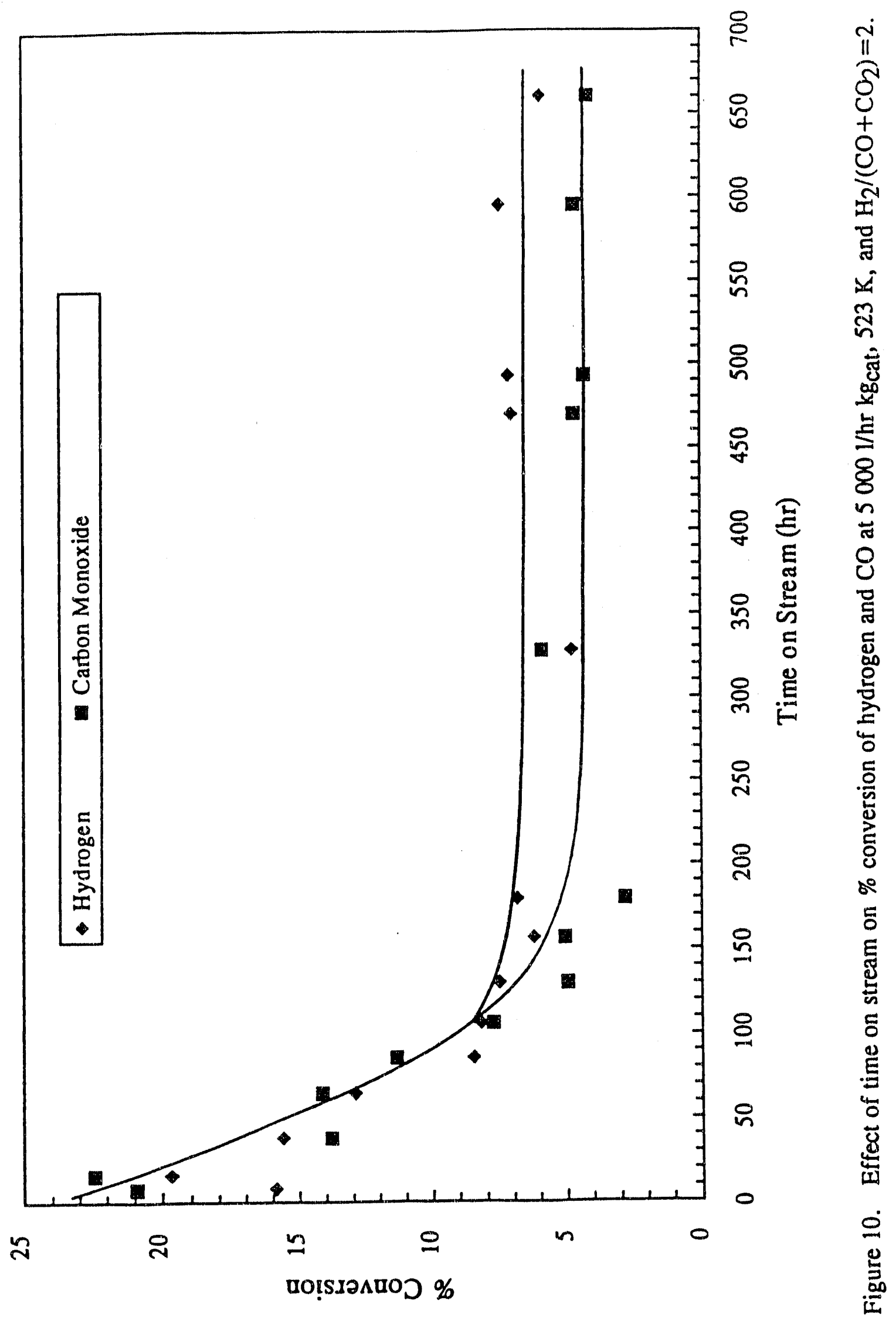




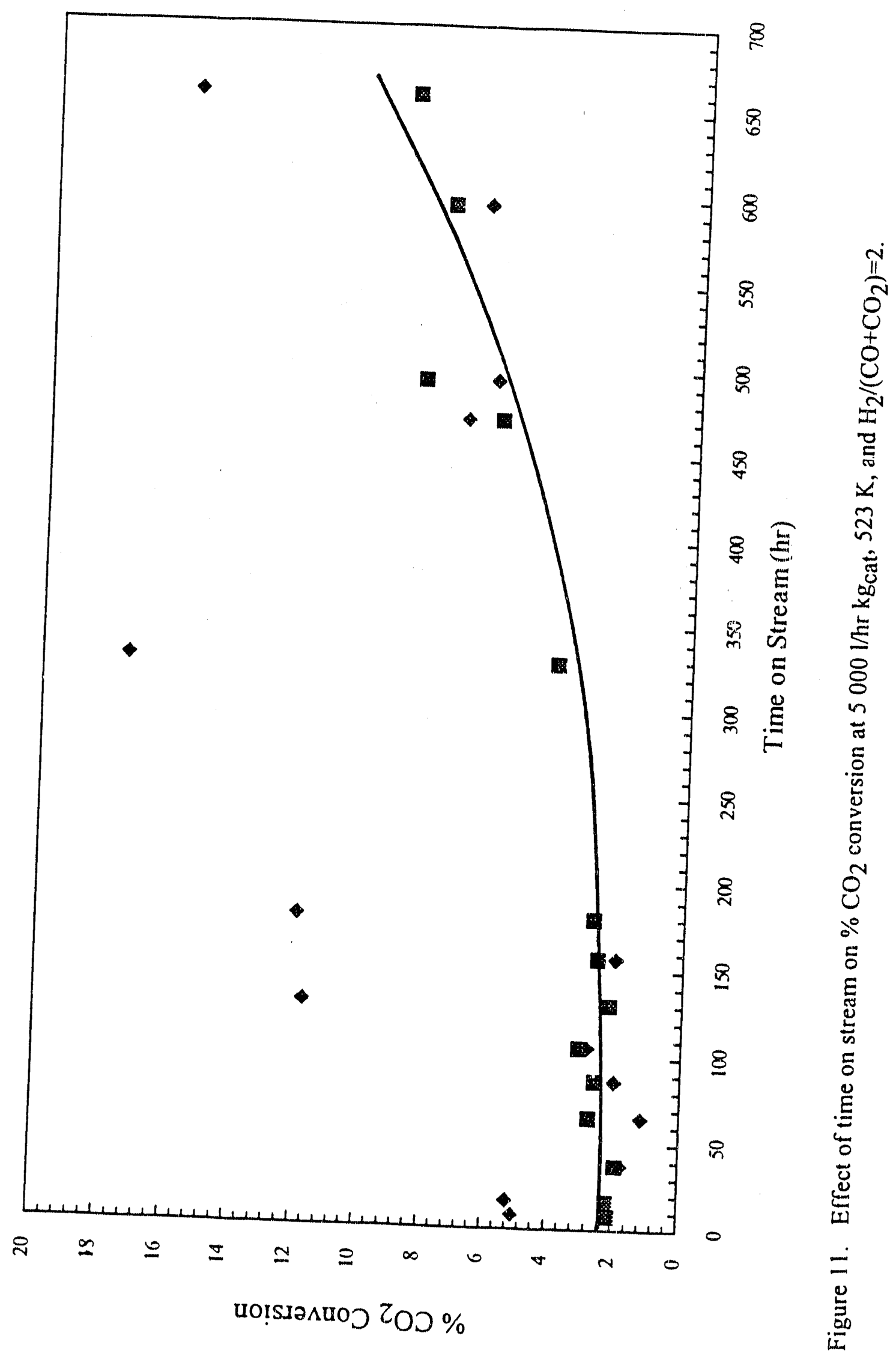




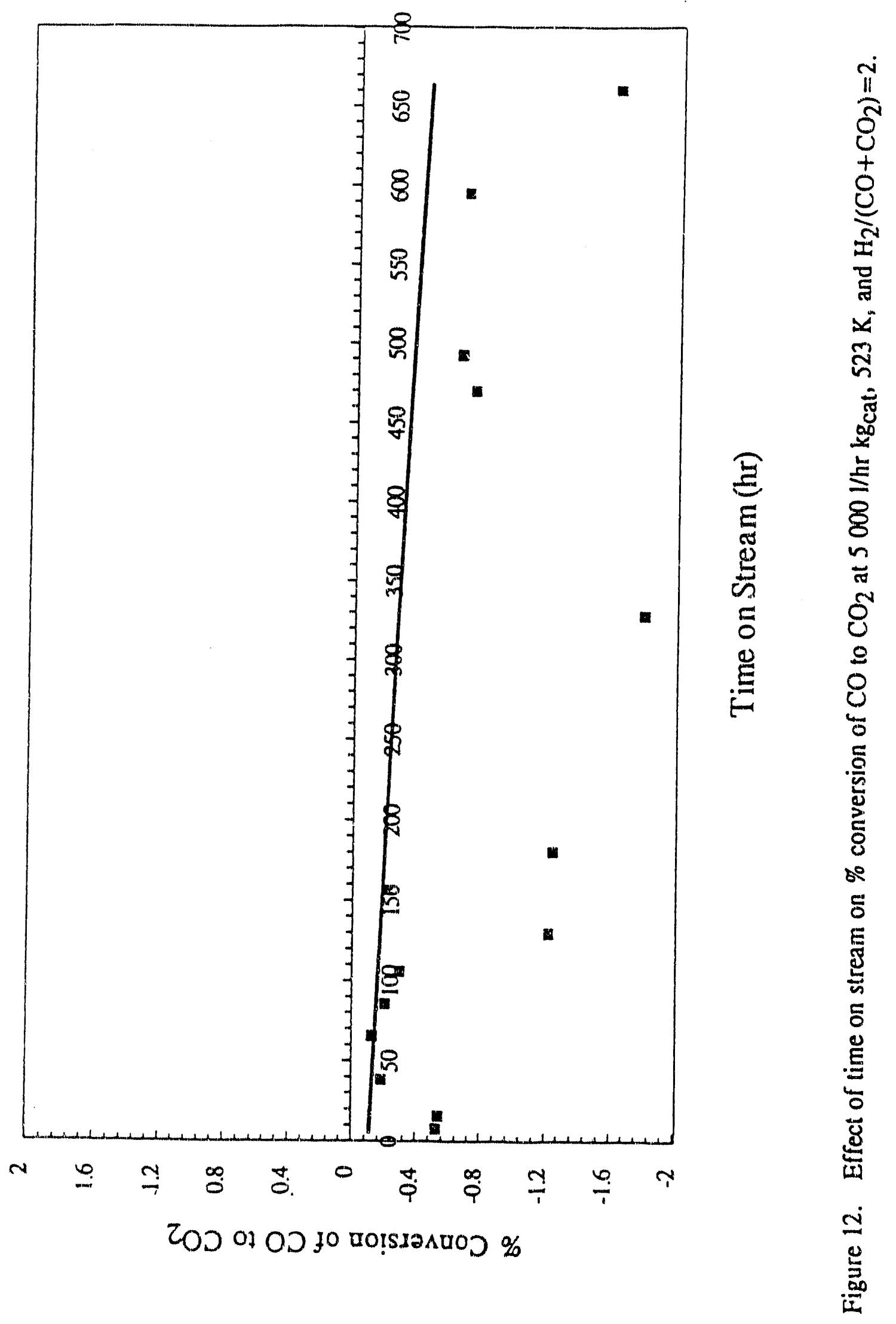




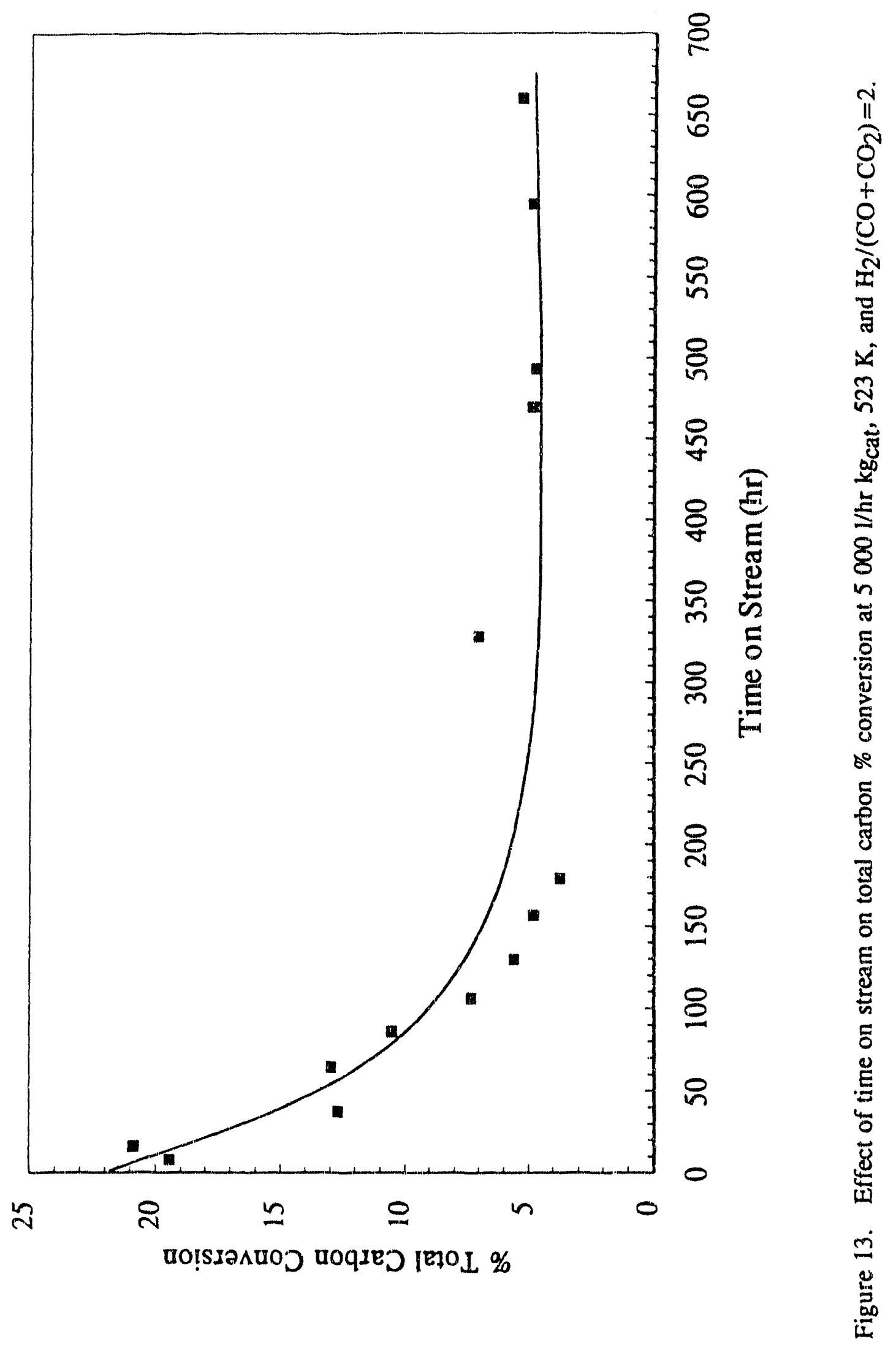




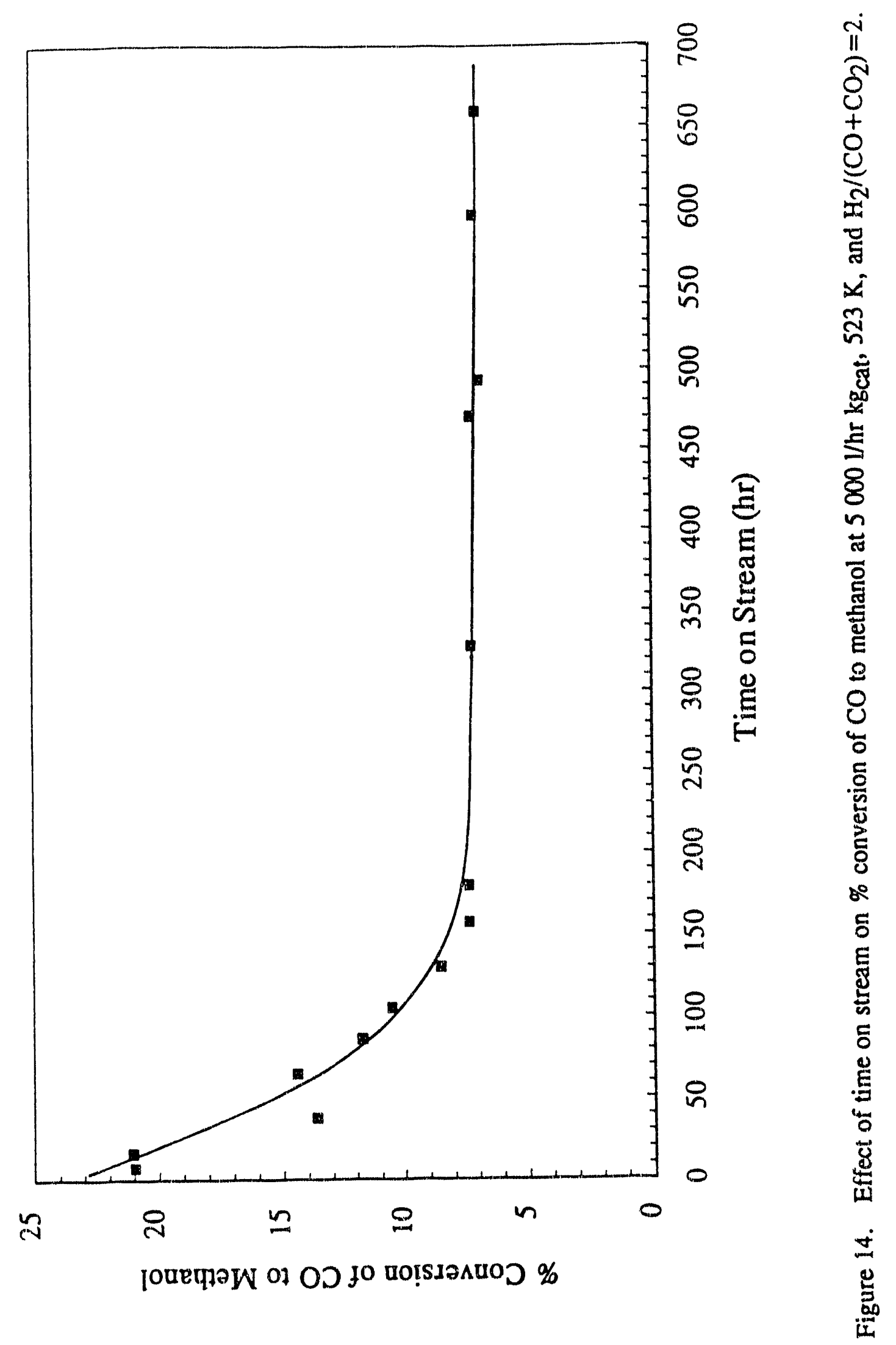




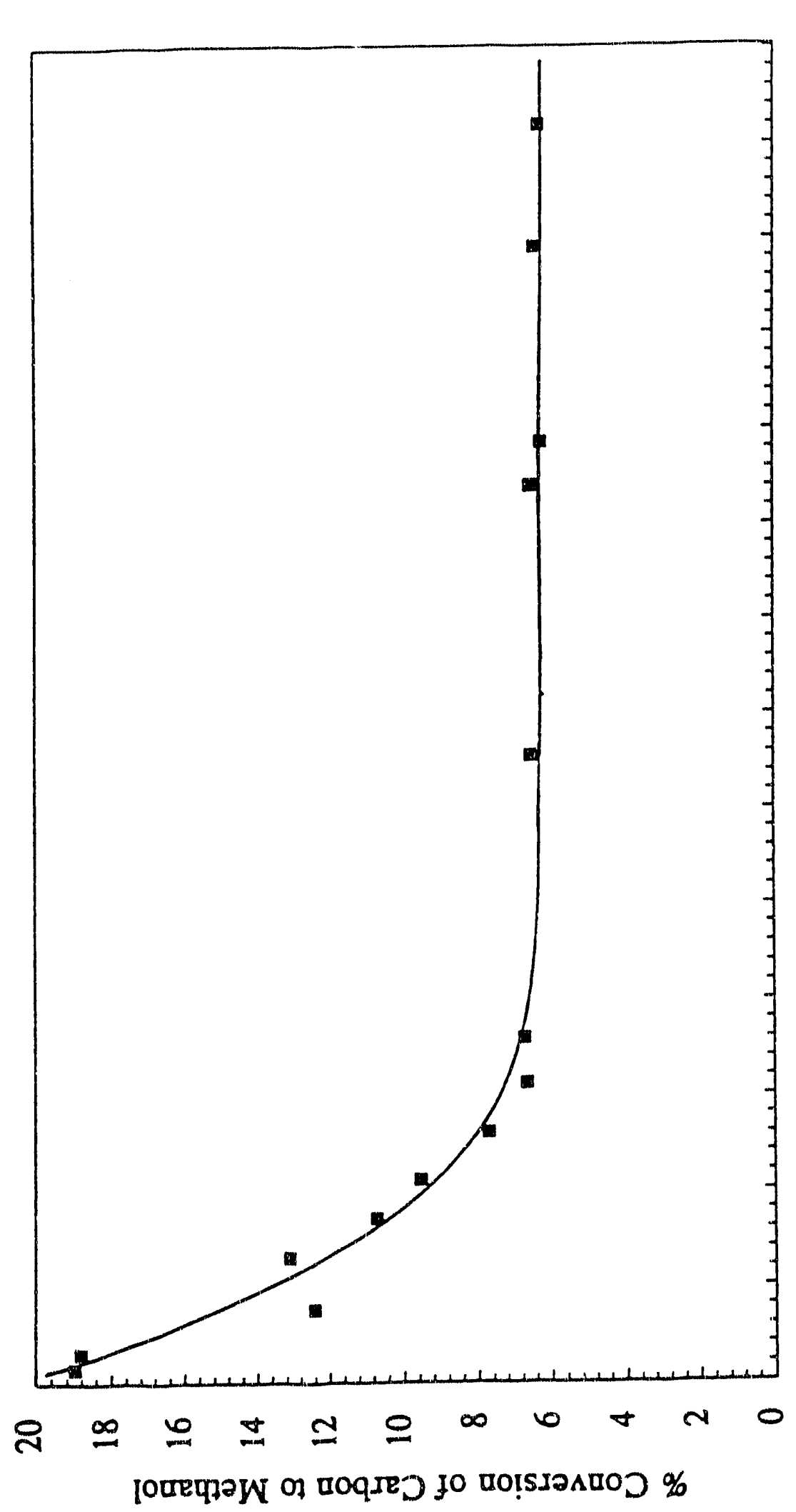

8

ชู

8요

II

ถ

番

요

ร

ᄋ

ถึ ฝั

$E$

กั

욜 ․ㅗㄹ

8

유

ป્్ّ

ถ

点

E

5

$\frac{5}{5}$

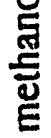

ธิ

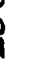

8

อ

동

늘

69

등

톡

药

ถ

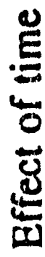

$\frac{n}{0}$ 


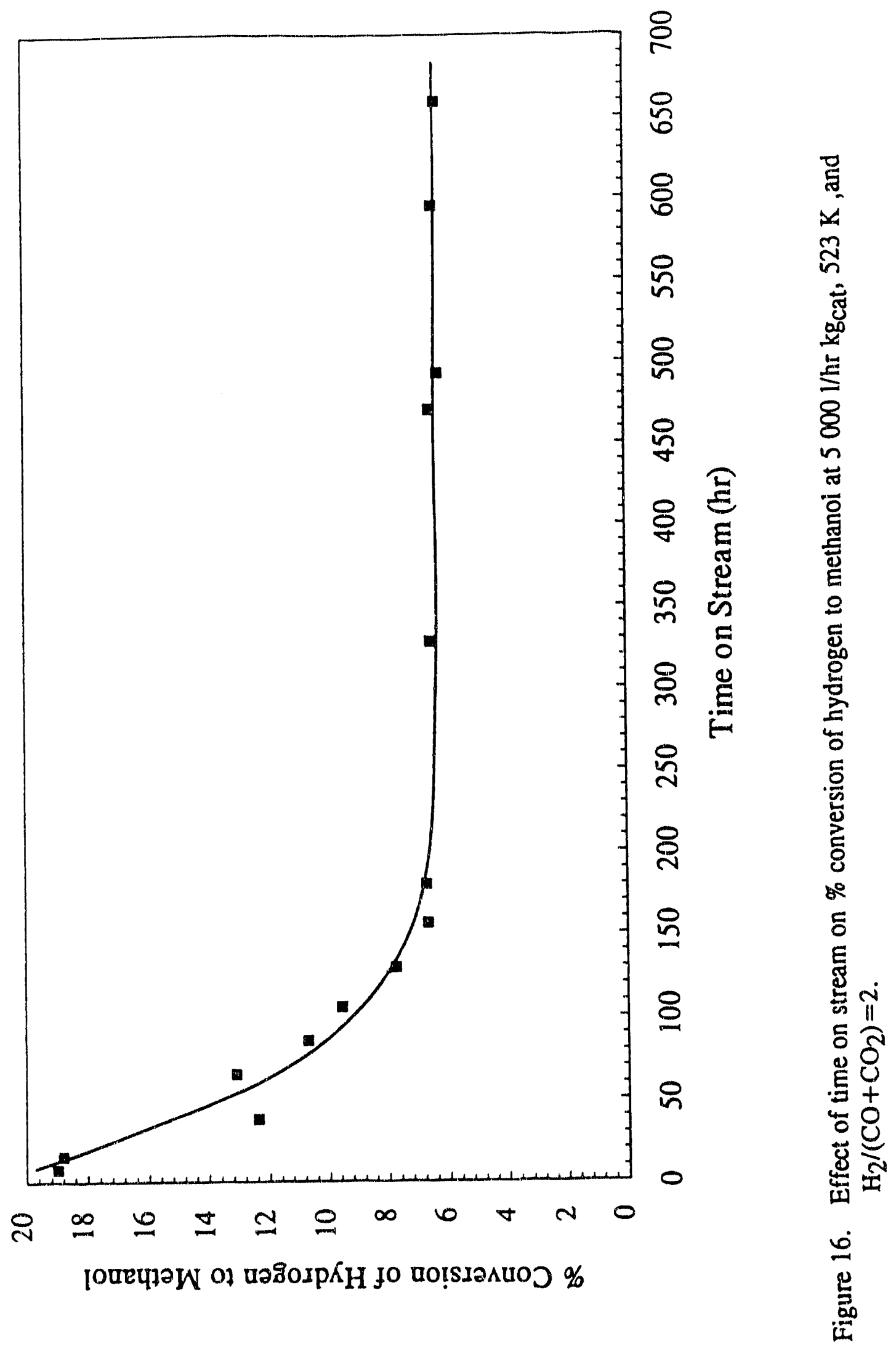




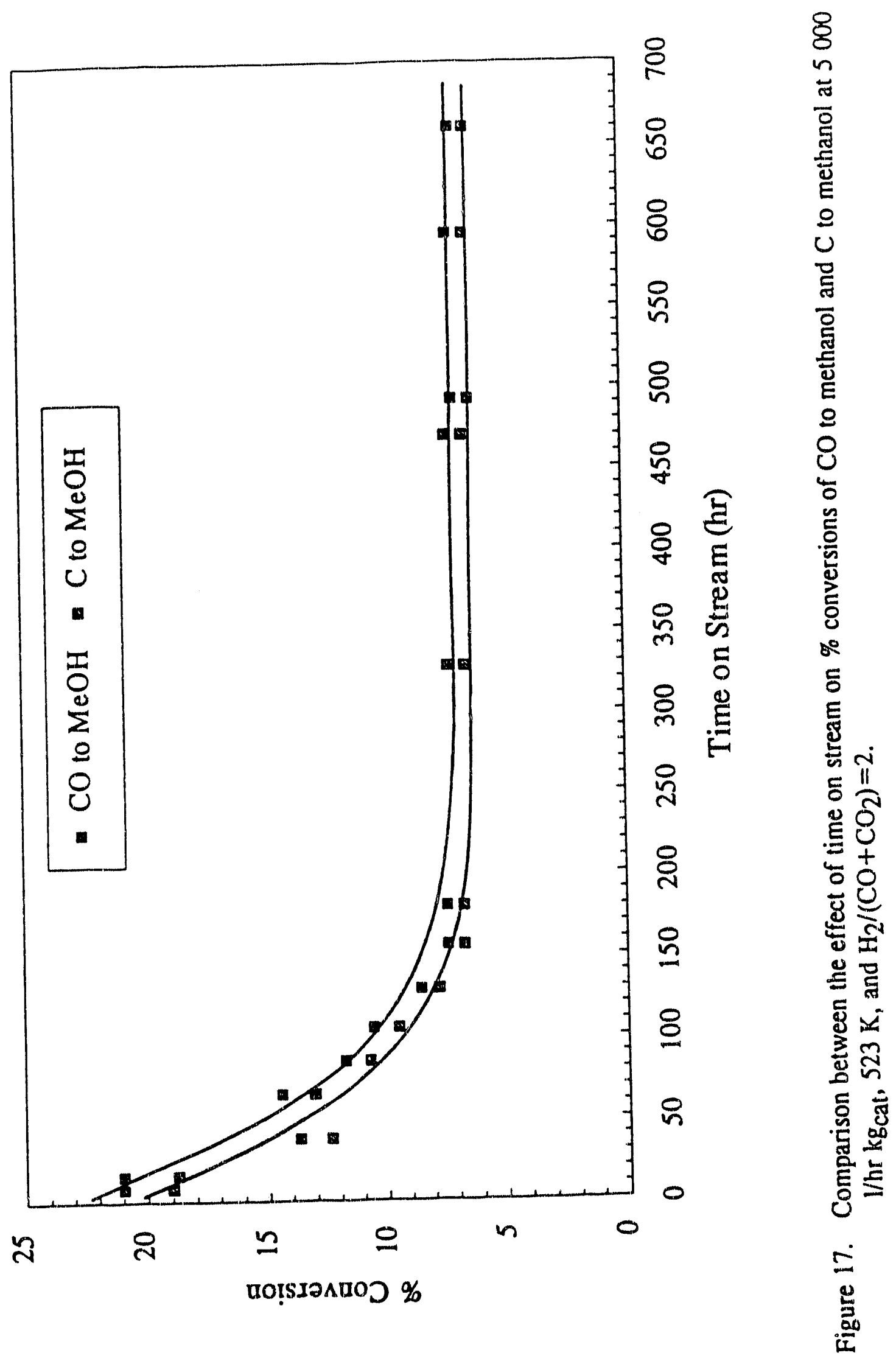


4.2 Effect of Space Velocity and $\mathrm{H}_{2} /\left(\mathrm{CO}+\mathrm{CO}_{2}\right)$ Ratio (Figures 18-32)

Kinetic data were collected by adjusting the $\mathrm{H}_{2} /\left(\mathrm{CO}+\mathrm{CO}_{2}\right)$ ratio at 2,1 , and 0.5 respectively, while the $\mathrm{CO} / \mathrm{CO}_{2}$ ratio was maintained at 9 . At each $\mathrm{H} 2 /\left(\mathrm{CO}+\mathrm{CO}_{2}\right)$ ratio the space velocity is set at four different values in the range of $3000-13000 \mathrm{l} / \mathrm{hr} \mathrm{kg}$ cat .

The results indicate that the highest methanol production rate can be achieved at $\mathrm{H}_{2} /\left(\mathrm{CO}+\mathrm{CO}_{2}\right)$ ratio of 1 followed by $\mathrm{H}_{2} /\left(\mathrm{CO}+\mathrm{CO}_{2}\right)$ ratio of 0.5 and 2 respectively as shown in figure 19. At all ratios, methanol production rate increases as the space velocity increases.

Moreover, water production rate increases as the space velocity increases at all $\mathrm{H}_{2} /\left(\mathrm{CO}+\mathrm{CO}_{2}\right)$ ratios following the same CSTR performance equation. As figure 19 shows, the highest water production rate is achieved at $\mathrm{H}_{2} /\left(\mathrm{CO}+\mathrm{CO}_{2}\right)$ ratio of 2 followed by $\mathrm{H}_{2} /\left(\mathrm{CO}+\mathrm{CO}_{2}\right)$ ratio of 0.5 and 1 respectively. One the other hand, dimethyl ether production rate increases as the space velocity increases for $\mathrm{H}_{2} /\left(\mathrm{CO}+\mathrm{CO}_{2}\right)$ ratio of 2 and 1, while at $\mathrm{H}_{2} /\left(\mathrm{CO}+\mathrm{CO}_{2}\right)$ ratio of 0.5 dimethyl ether production rate increases until reaching a maximum at $5000 \mathrm{l} / \mathrm{hr} \mathrm{kg}_{\text {cat }}$, then it starts decreasing. This observation is illustrated in figure 20.

Figures 21 and 22 show the opposite effect of space velocity on methanol and water mole fractions in the condensate. As the space velocity increases the mole fraction of methanol in the condensate decreases while that of water increases, indicating that methanol selectivity is inversely proportional to space velocity. At all space velocity values, $\mathrm{H}_{2} /\left(\mathrm{CO}+\mathrm{CO}_{2}\right)$ ratio of 1 has the highest methanol mole fraction followed by $\mathrm{H}_{2} /\left(\mathrm{CO}+\mathrm{CO}_{2}\right)$ ratio of 0.5 and 2 respectively.

The hydrogen and carbon monoxide \% conversions decrease with increasing the space velocity for all $\mathrm{H}_{2} /\left(\mathrm{CO}+\mathrm{CO}_{2}\right)$ ratios tested. This is shown in figures 23 and 25 respectively.

On the other hand, carbon dioxide \% conversion increases with increasing space velocity as illustrated in figure 24 . At a $\mathrm{H}_{2} /\left(\mathrm{CO}+\mathrm{CO}_{2}\right)$ ratio of 0.5 , carbon dioxide \% 
conversion has a negative value indicating that carbon dioxide is being, produced. The carbon dioxide hydrogenation reaction is not taking place while the reverse water gas shift reaction is taking place, or the extent of carbon dioxide hydrogenation reaction is lower than that of the reverse water gas reaction causing a net production of carbon dioxide.

At $\mathrm{H}_{2} /\left(\mathrm{CO}+\mathrm{CO}_{2}\right)$ ratio of 2 , carbon dioxide $\%$ conversion has a negative value at space velocities lower than $4000 \mathrm{l} / \mathrm{hr} \mathrm{kg}_{\text {cat }}$ indicating that there is a net production of carbon dioxide, but as the space velocity increases carbon dioxide $\%$ conversion attains a positive value indicating that the carbon dioxide is consumed and the extent of the carbon dioxide hydrogenation reaction is higher than that of the reverse water gas shift reaction which produces carbon dioxide.

At $\mathrm{H}_{2} /\left(\mathrm{CO}+\mathrm{CO}_{2}\right)$ ratic of 1 , carbon monoxide $\%$ conversion is always positive and increases with increasing space velocity indicating that carbon dioxide is another source for methanol by reacting with hydrogen. It can also be concluded that as the space velocity increases, more methanol is being produced by the carbon dioxide hydrogenation reaction and the extent of the reverse water gas shift reaction decreases.

Figure 26, which shows the effect of space velocity on $\mathrm{CO}$ to $\mathrm{CO}_{2} \%$ conversion attests to the conclusions made in the last paragraph since it is consistent with figure 25 . At all $\mathrm{H}_{2} /\left(\mathrm{CO}+\mathrm{CO}_{2}\right)$ ratios, the $\mathrm{CO}$ to $\mathrm{CO}_{2} \%$ conversion decreases as the space velocity increases suggesting that the extent of the reverse water gas shift reaction is decreasing with increasing the space velocity. 


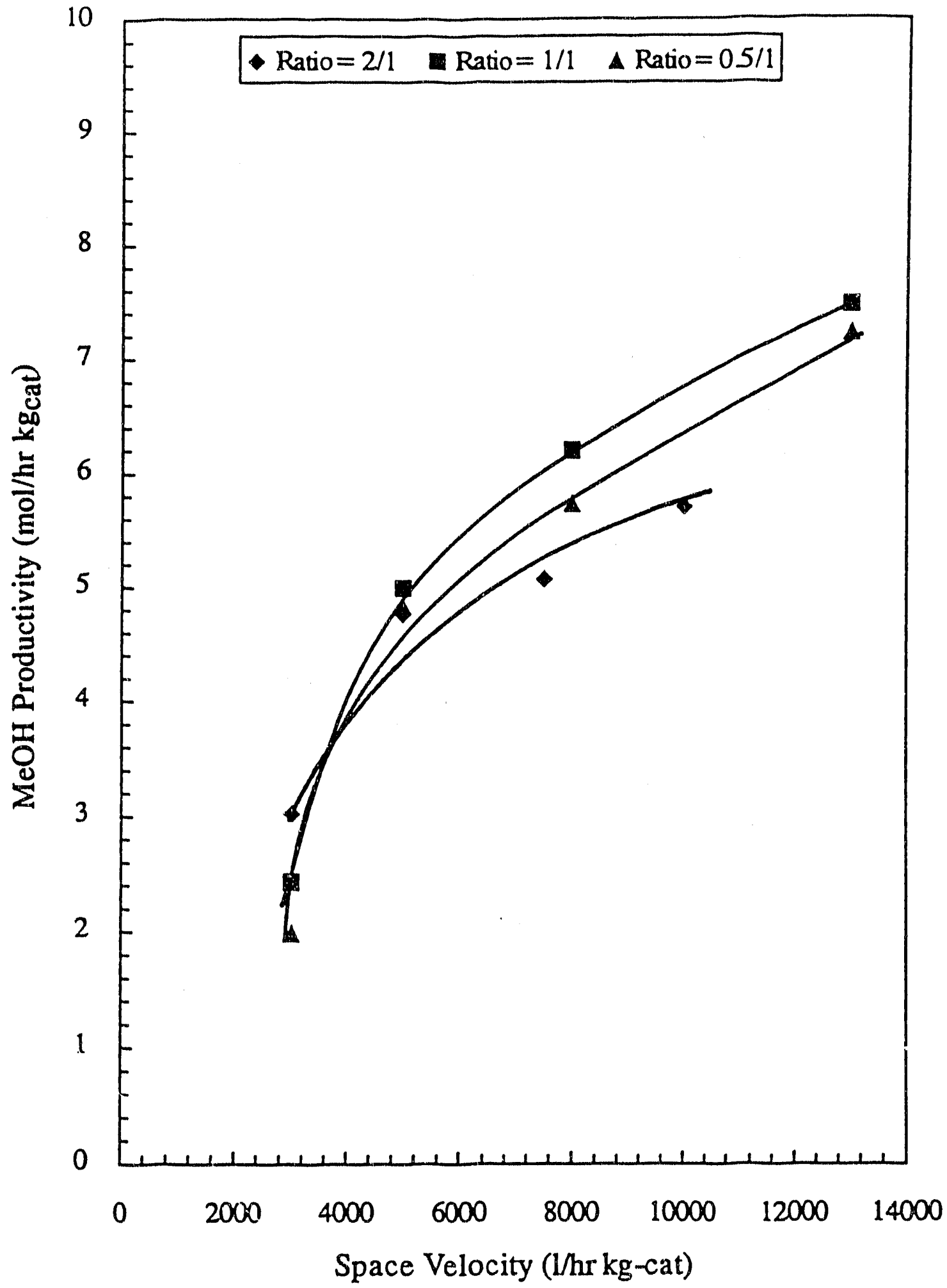

Figure 18. Effect of space velocity on methanol production rate at $523 \mathrm{~K}$ and different $\mathrm{H}_{2} /\left(\mathrm{CO}+\mathrm{CO}_{2}\right)$ ratios. 


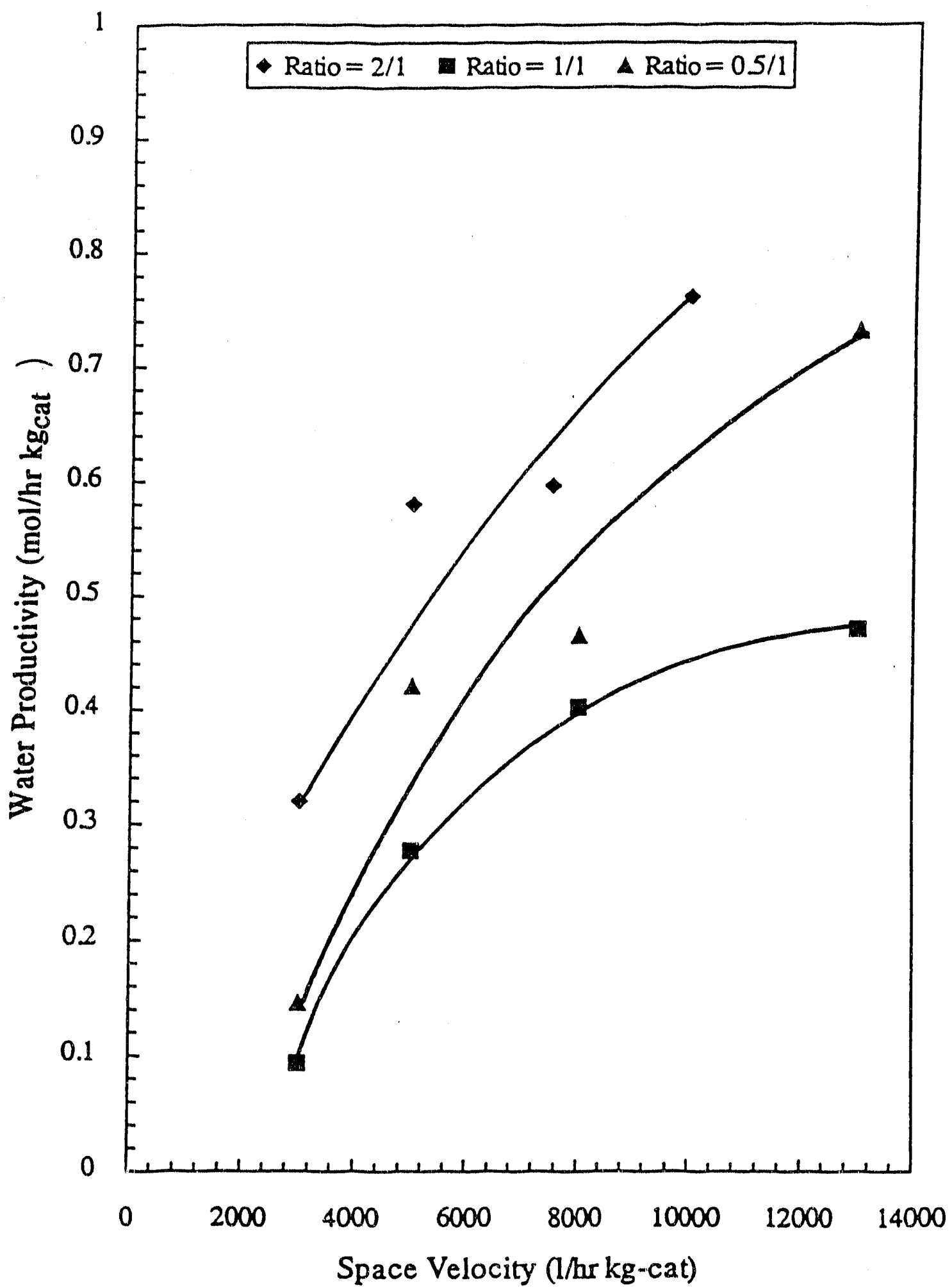

Figure 19. Effect of space velocity on water production rate at $523 \mathrm{~K}$ and different $\mathrm{H}_{2} /\left(\mathrm{CO}+\mathrm{CO}_{2}\right)$ ratios. 


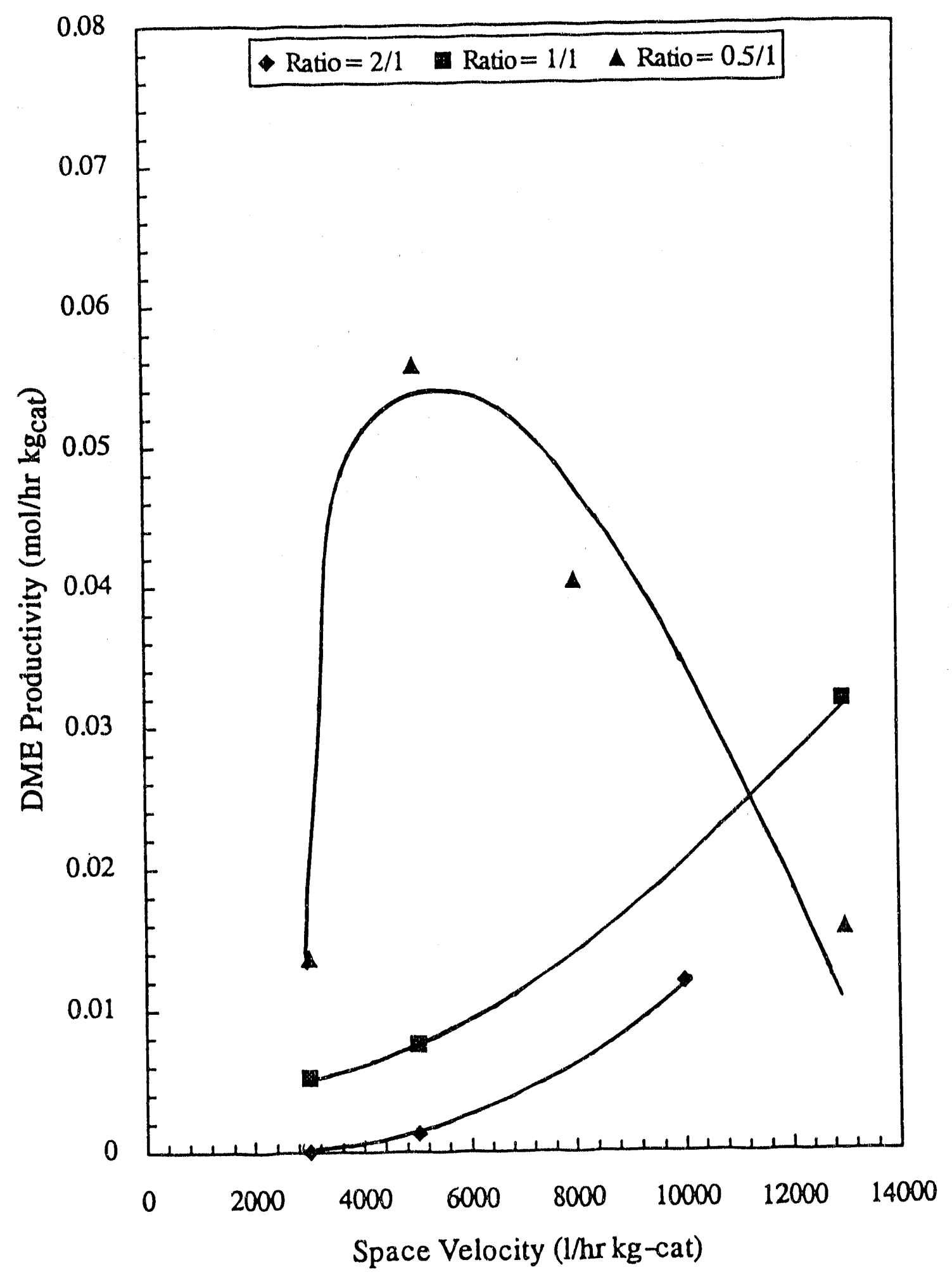

Figure 20. Effect of space velocity on DME production rate at $523 \mathrm{~K}$ and different $\mathrm{H}_{2} /\left(\mathrm{CO}+\mathrm{CO}_{2}\right)$ ratios. 


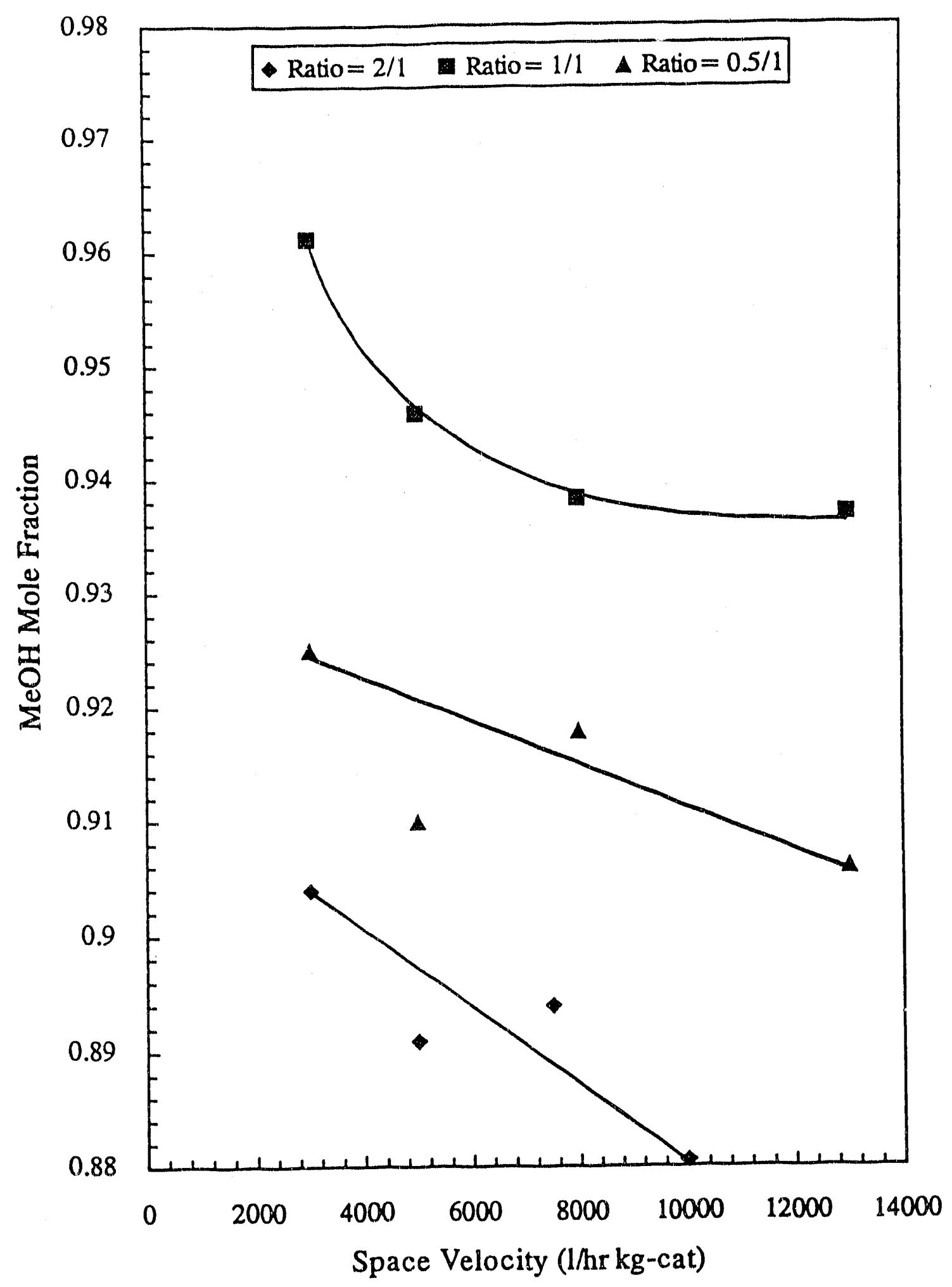

Figure 21. Effect of space velocity on methanol mole fraction in condensate at $523 \mathrm{~K}$ and different $\mathrm{H}_{2} /\left(\mathrm{CO}+\mathrm{CO}_{2}\right)$ ratios. 


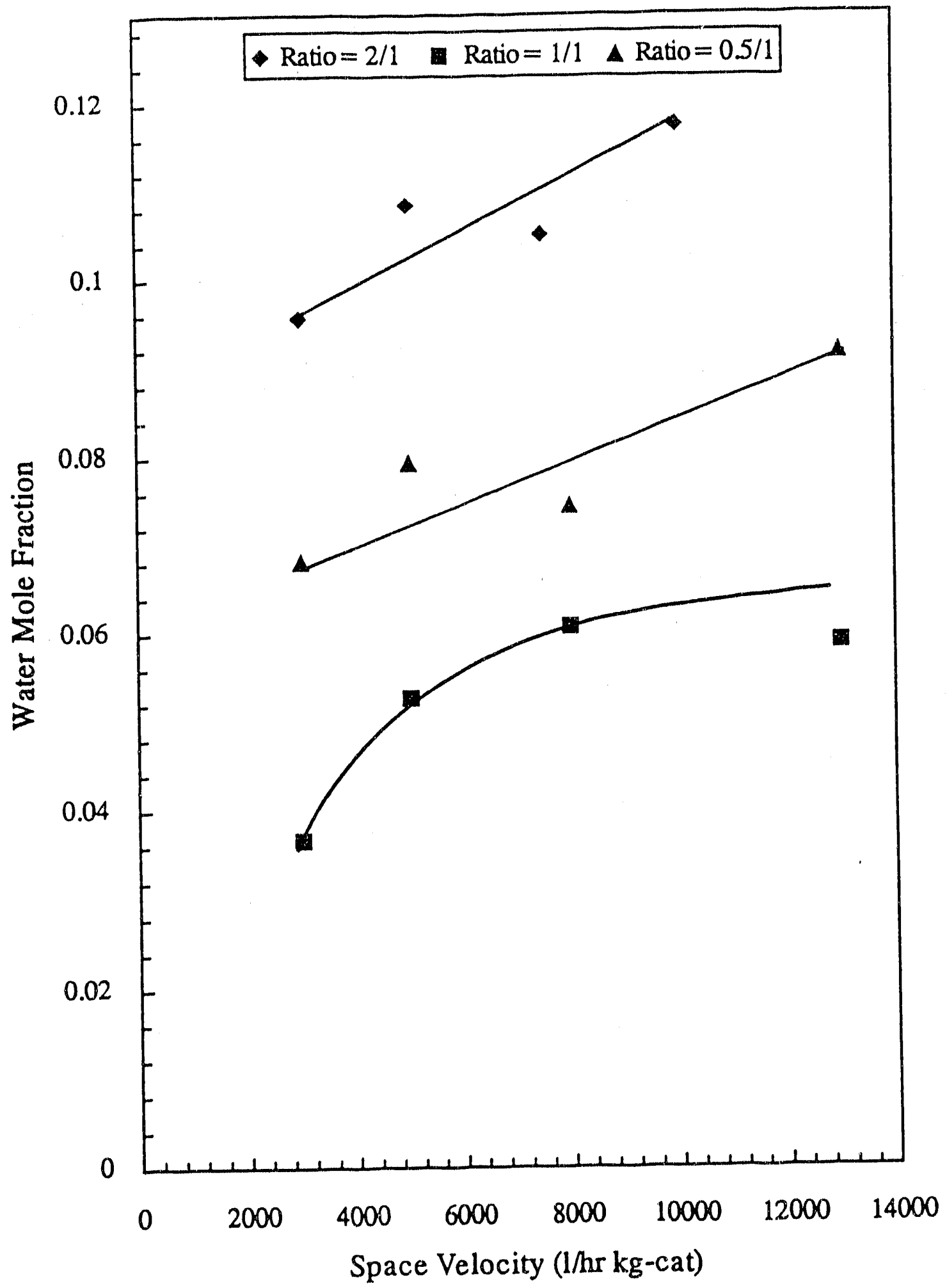

Figure 22. Effect of space velocity on water mole fraction in condensate at $523 \mathrm{~K}$ and different $\mathrm{H}_{2} /\left(\mathrm{CO}+\mathrm{CO}_{2}\right)$ ratios. 


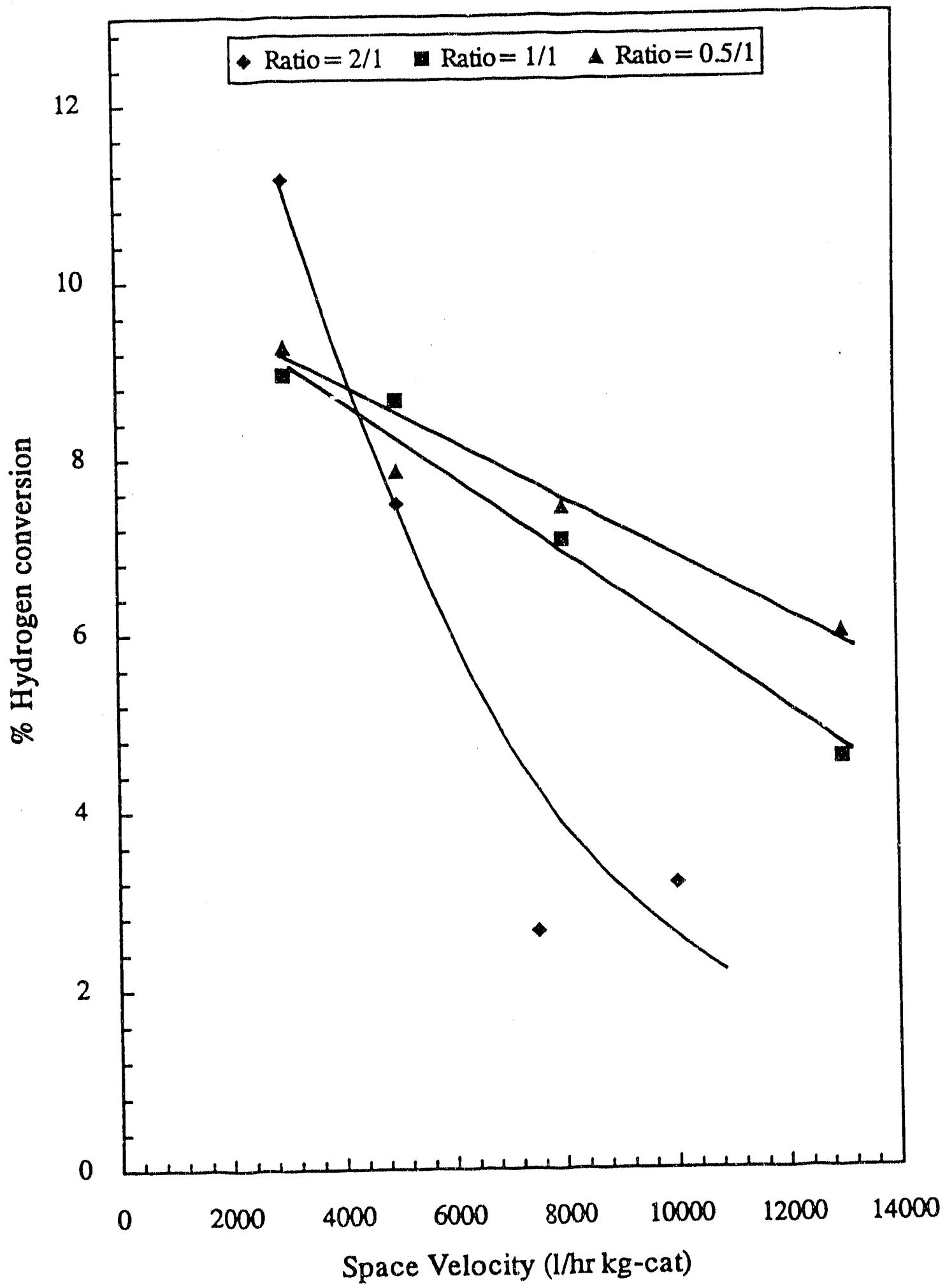

Figure 23. Effect of space velocity on hydrogen \% conversion at $523 \mathrm{~K}$ and different $\mathrm{H}_{2} /\left(\mathrm{CO}+\mathrm{CO}_{2}\right)$ ratios. 


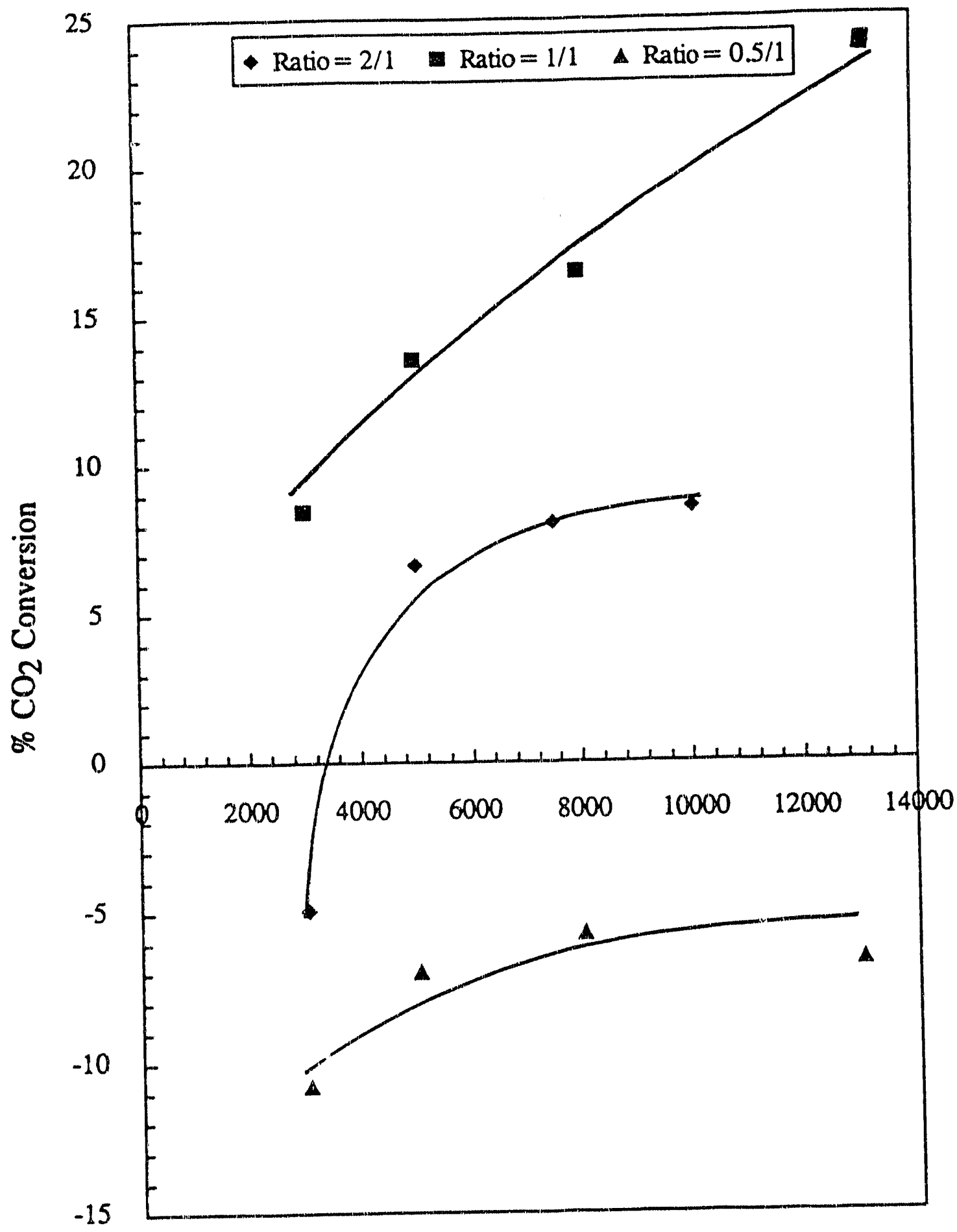

Space Velocity (l/hr kg-cat)

Figure 24. Effect of space velocity on $\mathrm{CO}_{2} \%$ conversion at $523 \mathrm{~K}$ and different $\mathrm{H}_{2} /\left(\mathrm{CO}+\mathrm{CO}_{2}\right)$ ratios. 


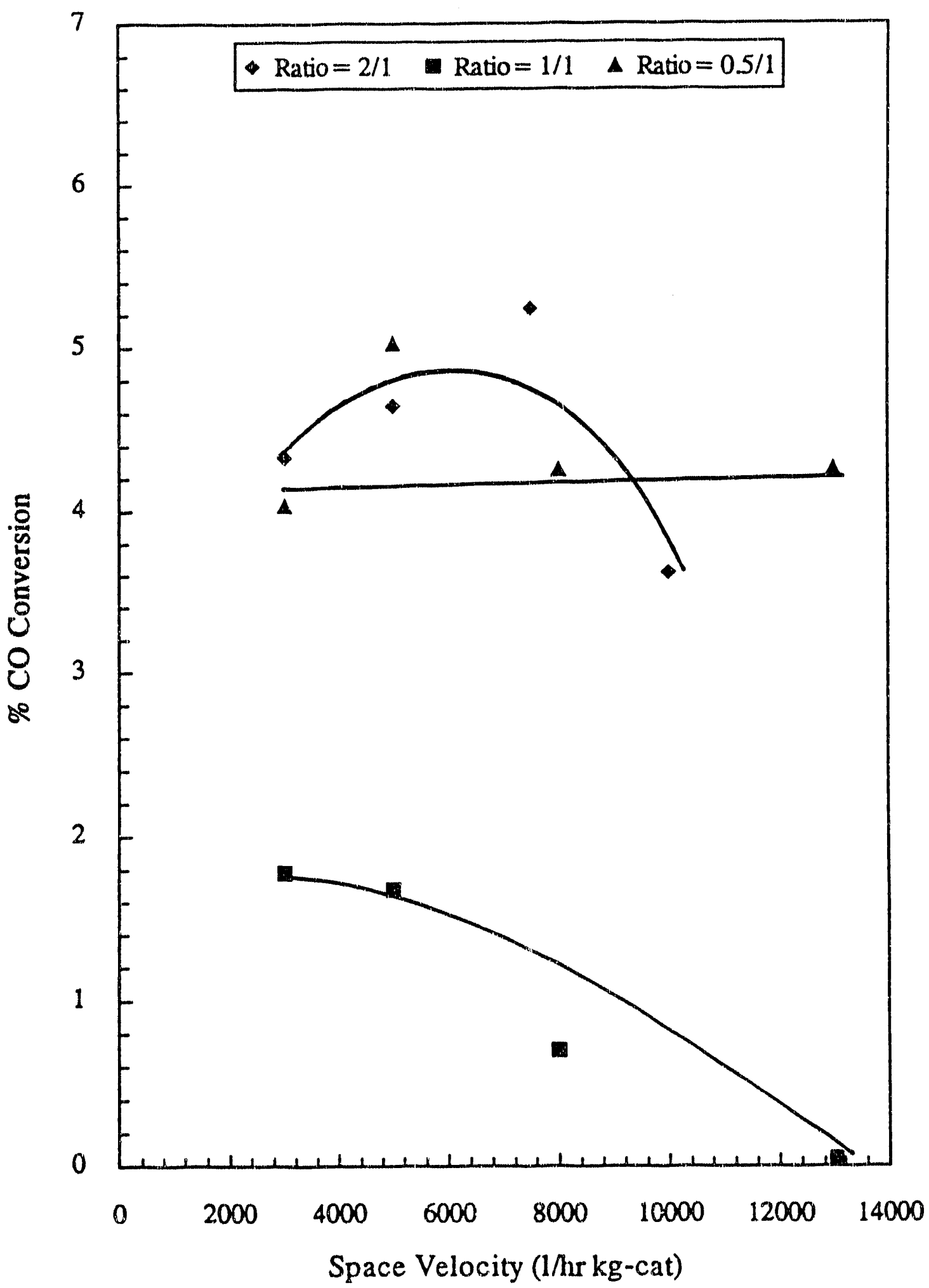

Figure 25. Effect of space velocity on CO \% conversion at $523 \mathrm{~K}$ and different $\mathrm{H}_{2} /\left(\mathrm{CO}+\mathrm{CO}_{2}\right)$ ratios. 


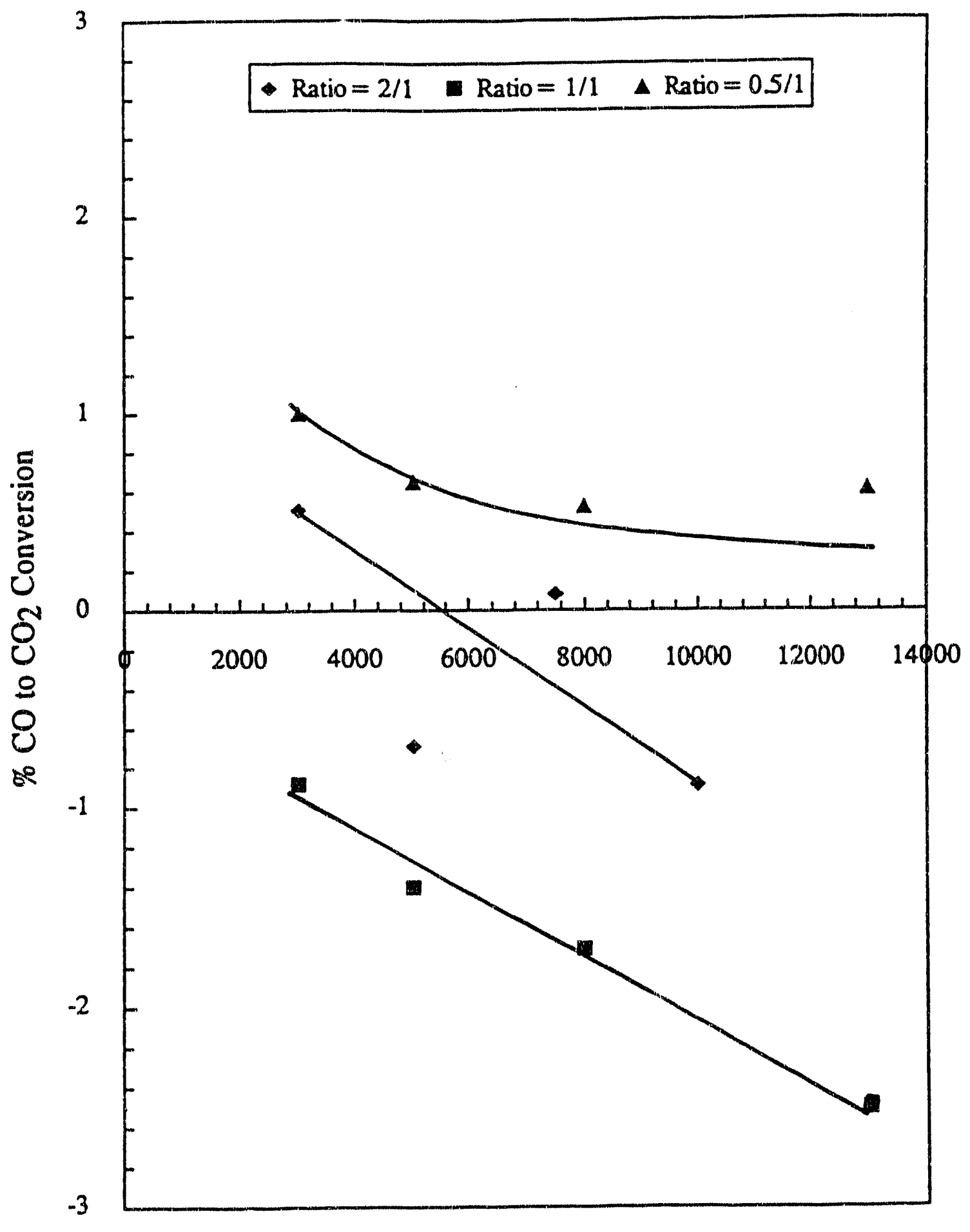

Space Velocity (1/hr kg-cat)

Figure 26. Effect of space velocity on $\mathrm{CO}$ conversion to $\mathrm{CO}_{2}$ at $523 \mathrm{~K}$ and different $\mathrm{H}_{2} /\left(\mathrm{CO}+\mathrm{CO}_{2}\right)$ ratios. 


\subsection{Effect of Temperature}

The reaction was also conducted at $508 \mathrm{~K}$ and $\mathrm{H}_{2} /\left(\mathrm{CO}+\mathrm{CO}_{2}\right)$ ratio of 2 . Lower methanol productivities were observed as indicated in figure 27. In addition, lower \% conversions were achieved at $508 \mathrm{~K}$ than these achieved at $523 \mathrm{~K}$. In all cases, \% conversions decrease with increasing space velocity.

Total carbon to methanol \% conversion and hydrogen to methanol \% conversion at $508 \mathrm{~K}$ decrease in a path parallel to these at $523 \mathrm{~K}$. This is shown in figures 31 and 32 respectively. Unlike the $523 \mathrm{~K}$ case, hydrogen $\%$ conversion experienced a very small decrease with increasing space velocity as shown in figure 28 . In the case of carbon monoxide \% conversion and total carbon \% conversion different decreasing paths are observed for each temperature as shown in figures 29 and 30 respectively. The reason behind this is the fact that a different reaction sequence takes place at each temperature. This conclusion can be confirmed by the fact that at a higher temperature the reaction with a higher activation energy is favored, and at lower temperatures the reaction with lower activation energy is favored (Levenspiel, 1972).

The activation energy for the carbon monoxide hydrogenation reaction is 16.53 $\mathrm{kcal} / \mathrm{mol}$ while that of carbon dioxide hydrogenation reftction is $11.28 \mathrm{kcal} / \mathrm{mol}$ (Klier et al.,1982). Therefore at the higher temperature of $523 \mathrm{~K}$ the carbon monoxide hydrogenation reaction is favored while at the lower temperature of $508 \mathrm{~K}$ the carbon dioxide hydrogenation reaction is favored which explains the different paths followed by hydrogen, carbon monoxide, and total carbon \% conversions at each temperature when increasing the space velocity, Schack et al.(1989) suggest that carbon monoxide hydrogenation is the main route to methanol at higher temperatures while carbon dioxide hydrogenation is the main route at lower tempratures. 


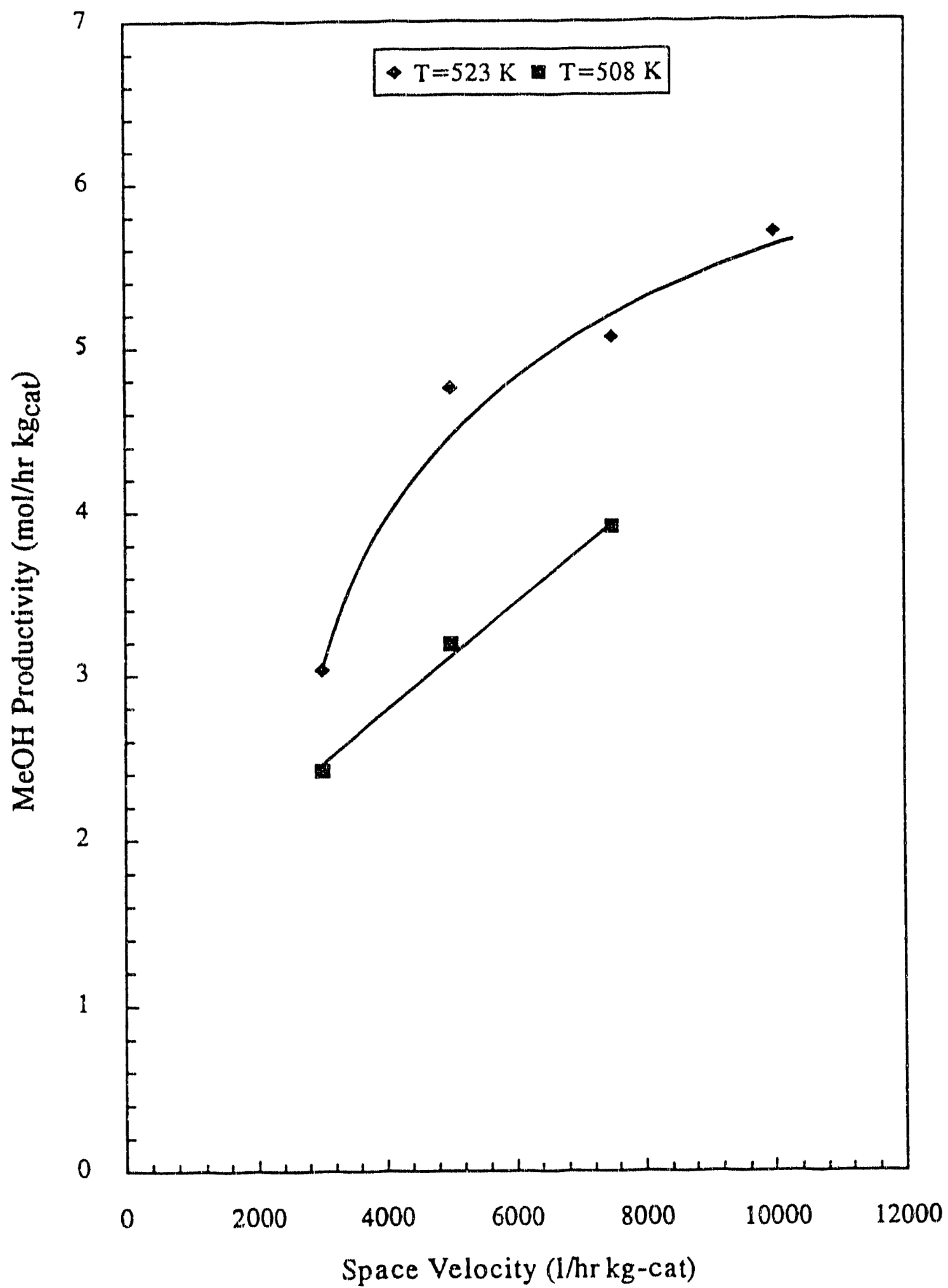

Figure 27. Effect of space velocity on methanol production rate at $\mathrm{H}_{2} /\left(\mathrm{CO}+\mathrm{CO}_{2}\right)=2$ and different temperatures. 


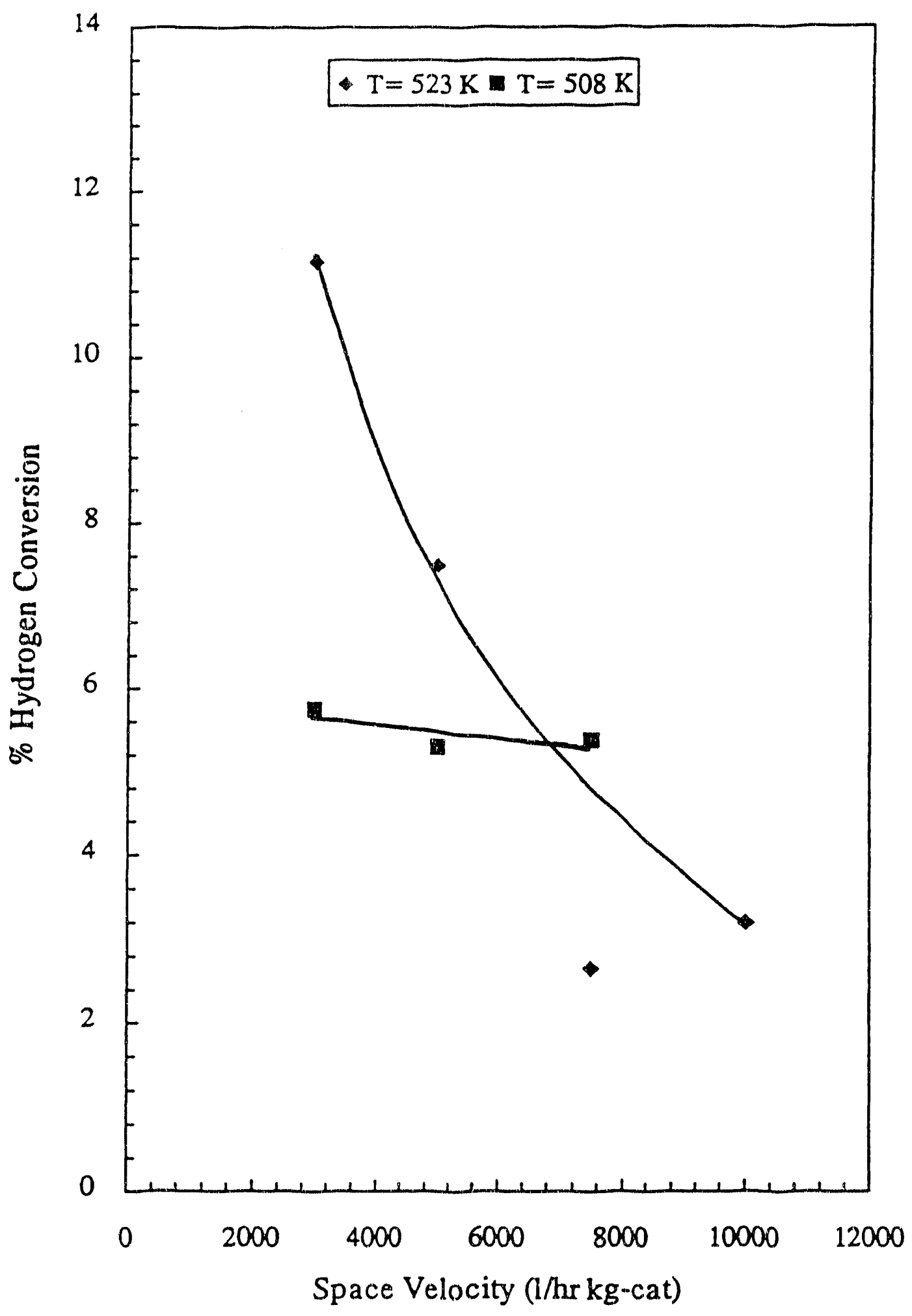

Figure 28. Effect of space velocity on $\%$ hydrogen conversion at $\mathrm{H}_{2} /\left(\mathrm{CO}+\mathrm{CO}_{2}\right)=2$ and different temperatures. 


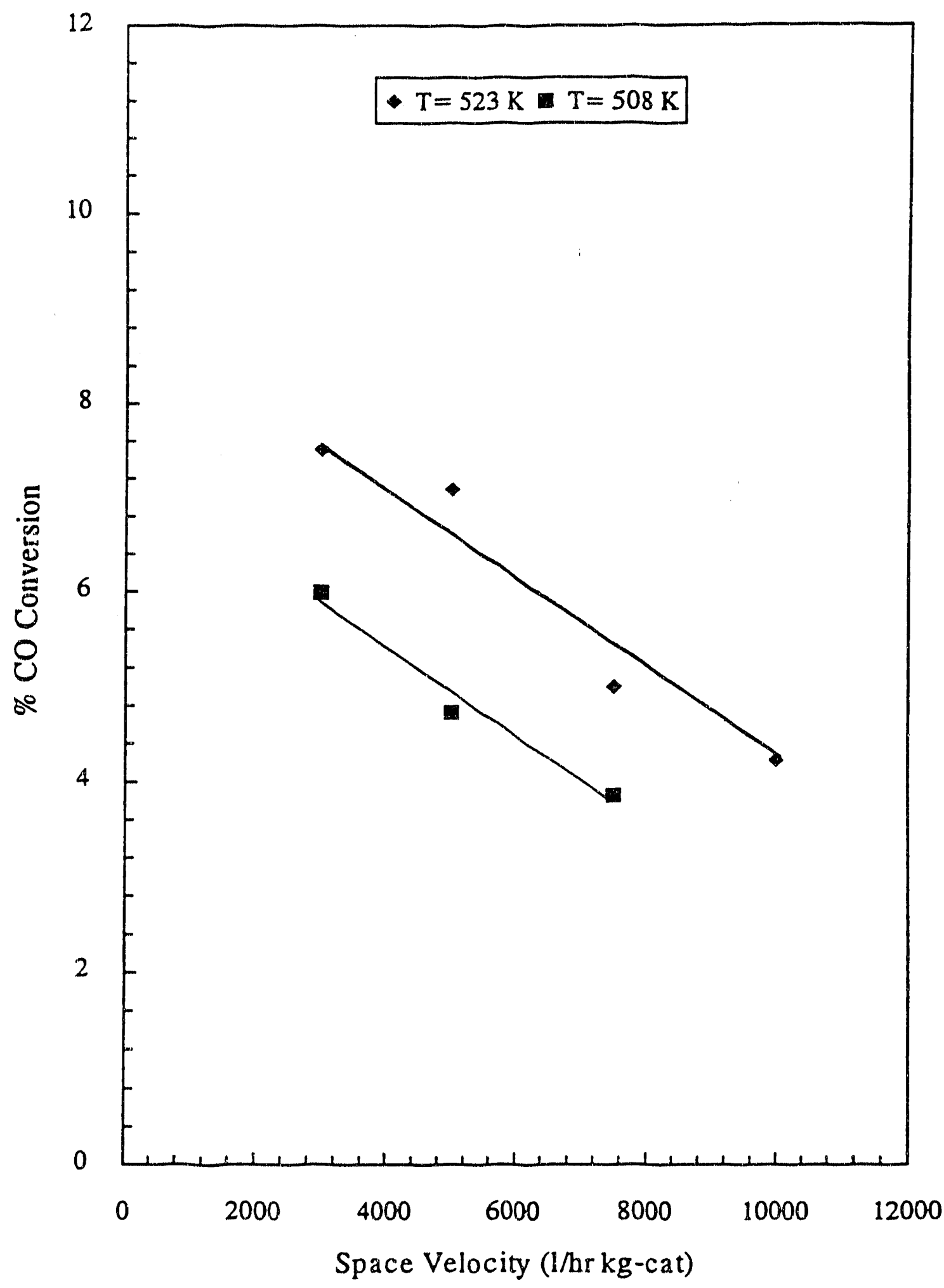

Figure 29. Effect of space velocity on $\mathrm{CO} \%$ conversion to methanol at $\mathrm{H}_{2} /\left(\mathrm{CO}+\mathrm{CO}_{2}\right)=2$ and different temperatures. 


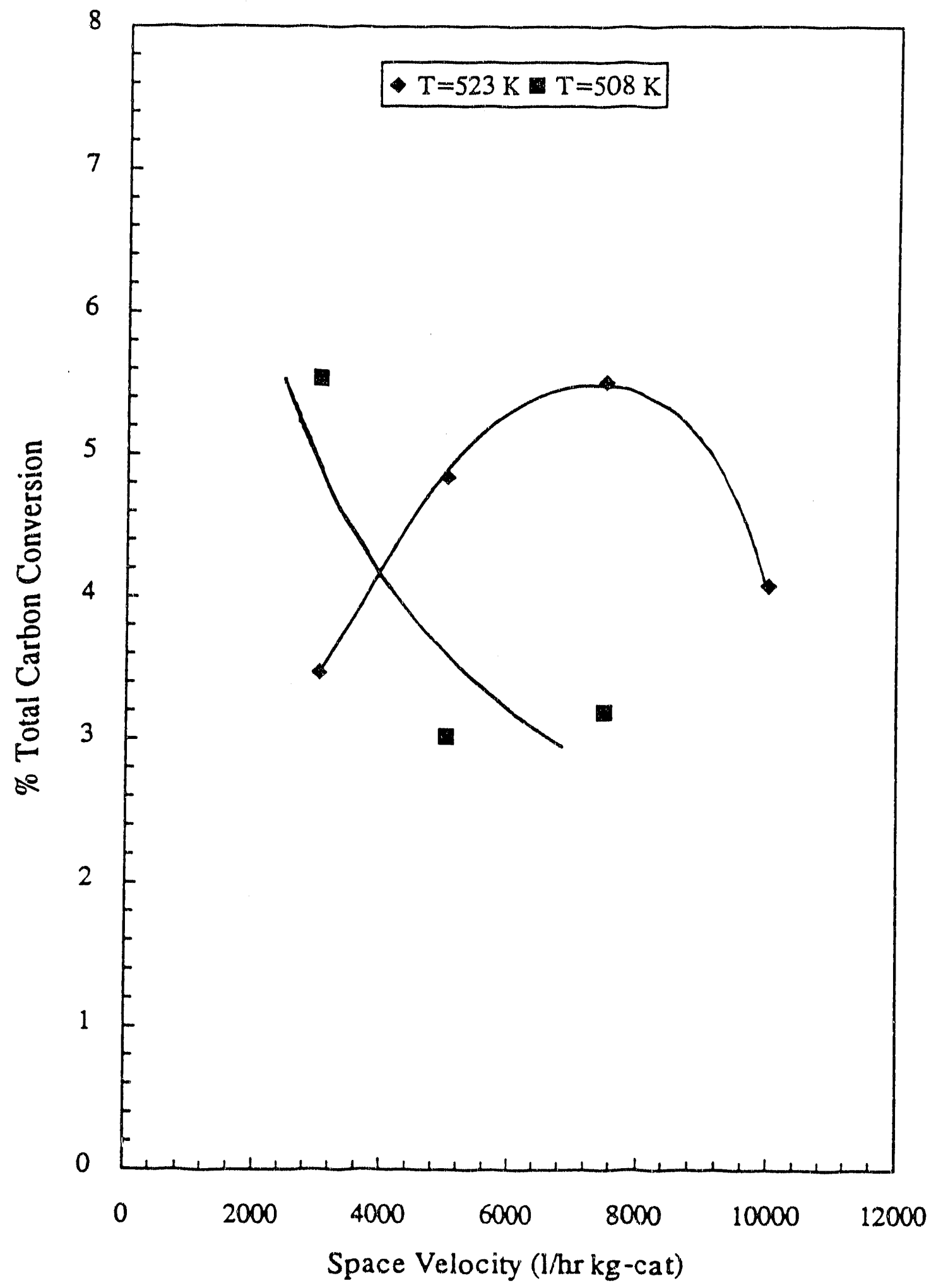

Figure 30. Effect of space velocity on total carbon $\%$ conversion at $\mathrm{H}_{2} /\left(\mathrm{CO}+\mathrm{CO}_{2}\right)$ and different temperatures. 


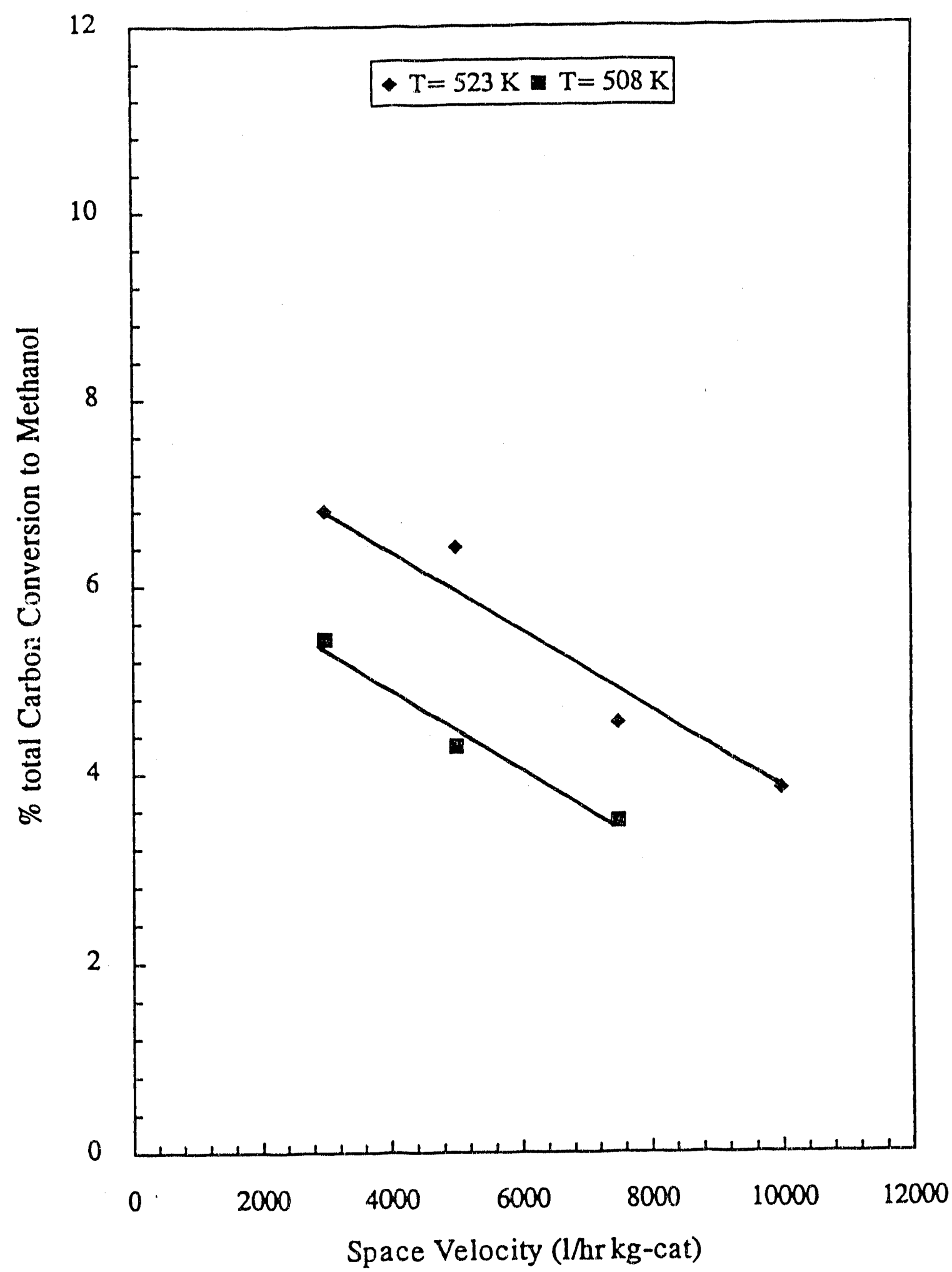

Figure 31. Effect of space velocity on total carbon $\%$ conversion to methanol at $\mathrm{H}_{2} /\left(\mathrm{CO}+\mathrm{CO}_{2}\right)=2$ and different temperatures. 


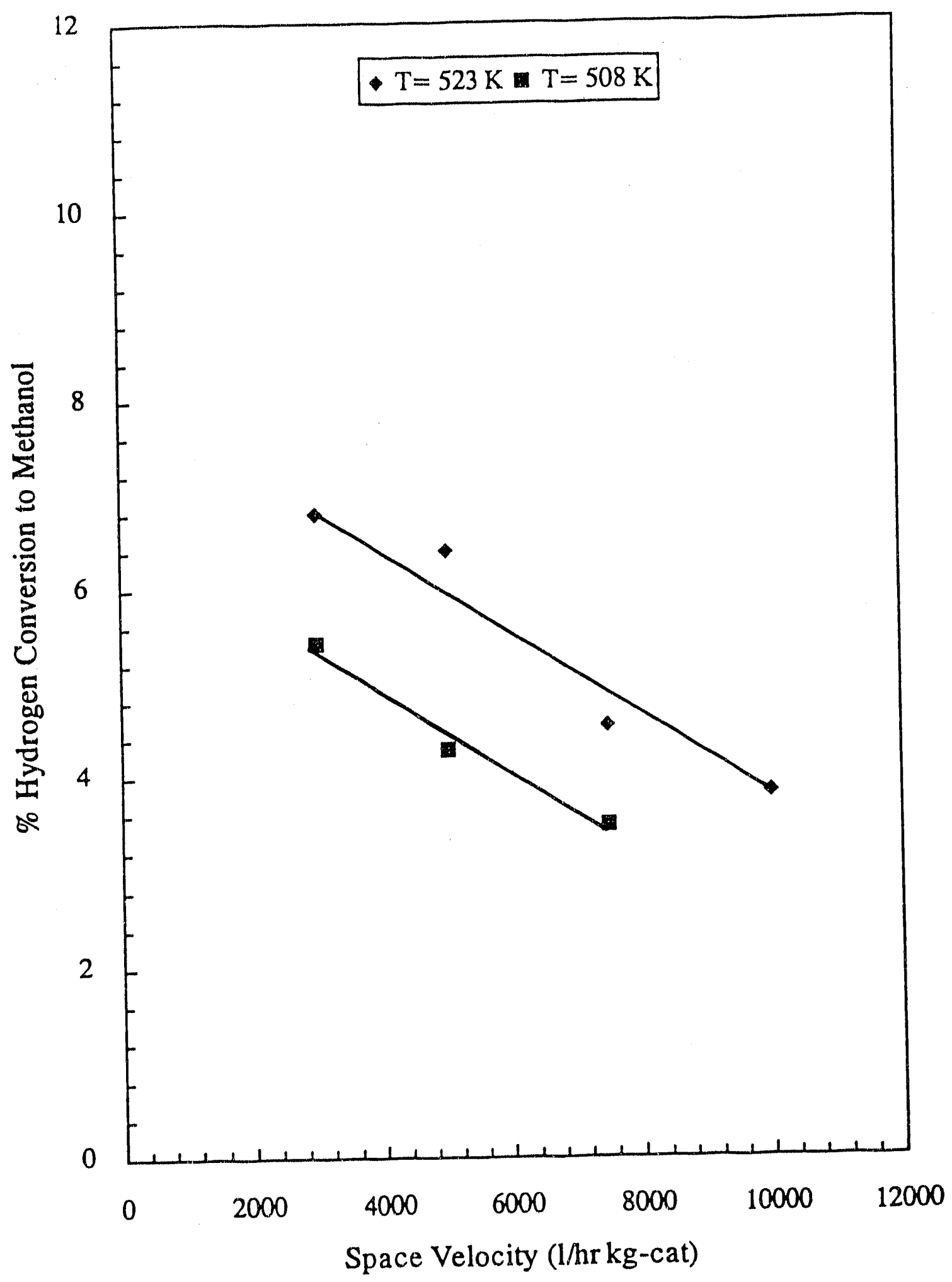

Figure 32. Effect of space velocity on hydrogen \% conversion to methanol at $\mathrm{H}_{2} /\left(\mathrm{CO}+\mathrm{CO}_{2}\right)=2$ and different temperatures. 


\subsection{Comparison with Other Studies}

The results obtained by this study on the effect of space velocity on methanol production rate are compared with these obtained by other studies conducted in slurry reactors using a $\mathrm{CuO} / \mathrm{ZnO} / \mathrm{Al}_{2} \mathrm{O}_{3}$ catalyst. The values of the methanol production rate achieved by this study were corrected to values at initial activity by multiplying the steady state values by an activity factor of 3 .

Figure 33 compares the change in methanol production rate with space velocity at $\mathrm{H}_{2} /\left(\mathrm{CO}+\mathrm{CO}_{2}\right)$ of 0.5 to data by Frank and Mednick (1982) and Weimer et al. (1987). All studies were conducted in a slurry reactor at $523 \mathrm{~K}$. Frank and Mednick (1982) study was carried out in a 2 liter autoclave with catalyst loading of 10-30\% at $7 \mathrm{MPa}$ and $\mathrm{H}_{2} /\left(\mathrm{CO}+\mathrm{CO}_{2}\right)$ of 0.6 while the a mount of $\mathrm{CO}_{2}$ was not specified. Weimer et al.(1987) conducted their study in a 0.3 liter autoclave with catalyst loading of $15 \%$ at $5.2 \mathrm{MPa}$ and $\mathrm{H}_{2} /\left(\mathrm{CO}+\mathrm{CO}_{2}\right)$ of 0.55 . The highest production rates were achieved by Frank and Mednick (1982) due to higher catalyst loadings and higher pressure.

Figure 34 compares the change in methanol production rate with space velocity at $523 \mathrm{~K}$ and $5.2 \mathrm{MPa}$, and $\mathrm{H}_{2} /\left(\mathrm{CO}+\mathrm{CO}_{2}\right)$ of 1 to data by (Pass, 1990) who used the same type of catalyst as that used in this study. Both studies were conducted in a slurry reactor at $523 \mathrm{~K}$. Pass' study was carried out in a 0.3 liter autoclave with catalyst loading of 23 $\%$. Similar production rates were achieved by both studies.

Figure 35 compares the change in methanol production rate with space velocity at $\mathrm{H}_{2} /\left(\mathrm{CO}+\mathrm{CO}_{2}\right)$ of 2 to data by Frank and Mednick (1982) and Weimer et al. (1987). All studies were conducted in a slurry reactor at $523 \mathrm{~K}$. Franks and Mednicks study was carried out in a 2 liter autoclave with catalyst loading of 10-30\% at $7 \mathrm{MPa}$ and $\mathrm{H}_{2} /\left(\mathrm{CO}+\mathrm{CO}_{2}\right)$ of 2 while the a mount of $\mathrm{CO}_{2}$ not specified. Weimer et al. conducted their study in a 1 liter autoclave with catalyst loading of 10-25\% at $5.2 \mathrm{MPa}$ and $\mathrm{H}_{2} /\left(\mathrm{CO}+\mathrm{CO}_{2}\right)$ of 2.3 . The highest production rates were achieved by Frank and Mednick (1982) due to higher catalyst loadings and higher pressure. 


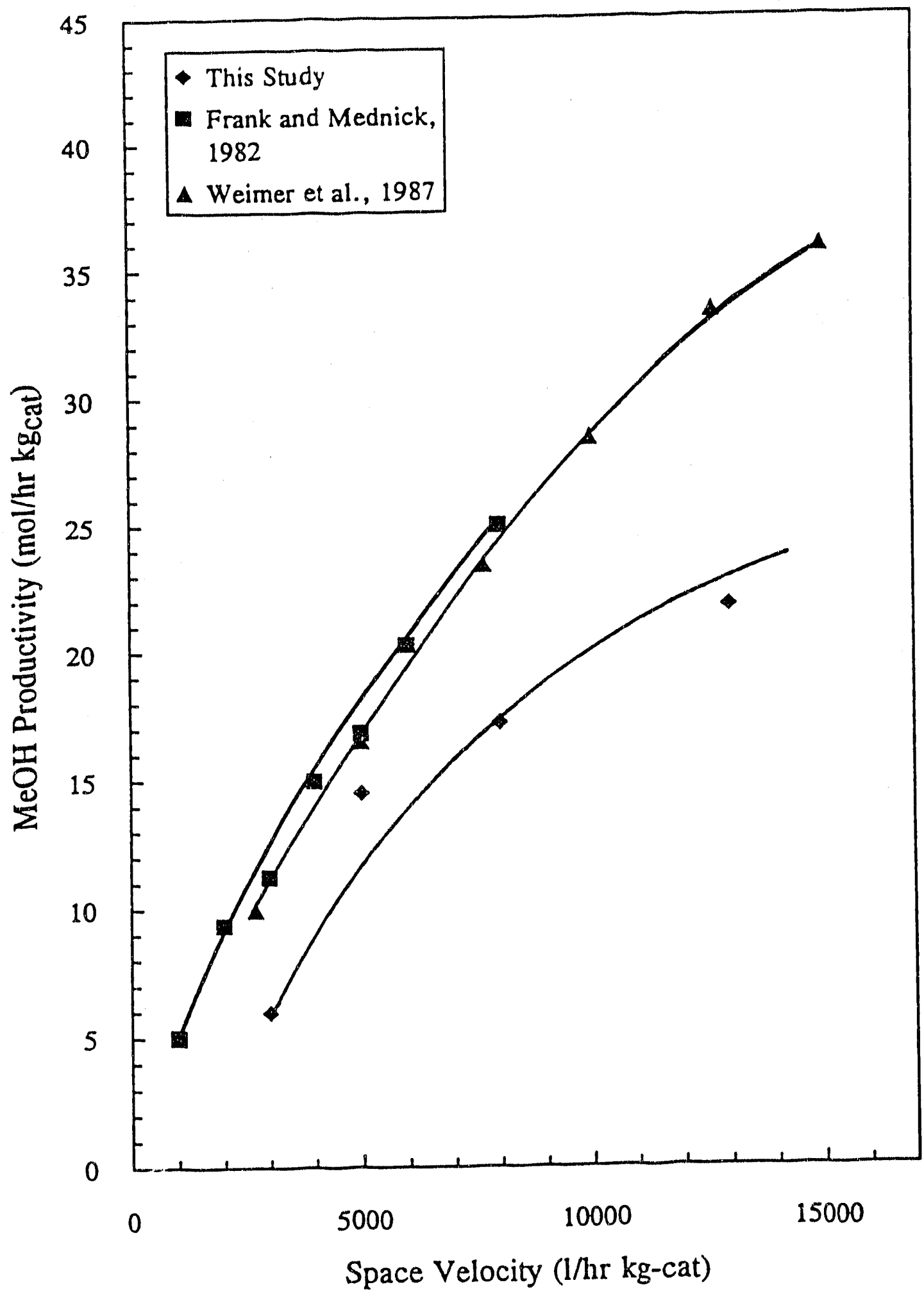

Figure 33. Comparison between methanol productivity as a function of space velocity for a slurry reactor at $523 \mathrm{~K}$ and $\mathrm{H}_{2} /\left(\mathrm{CO}+\mathrm{CO}_{2}\right)$ ratio of 0.5 to 0.6 . 


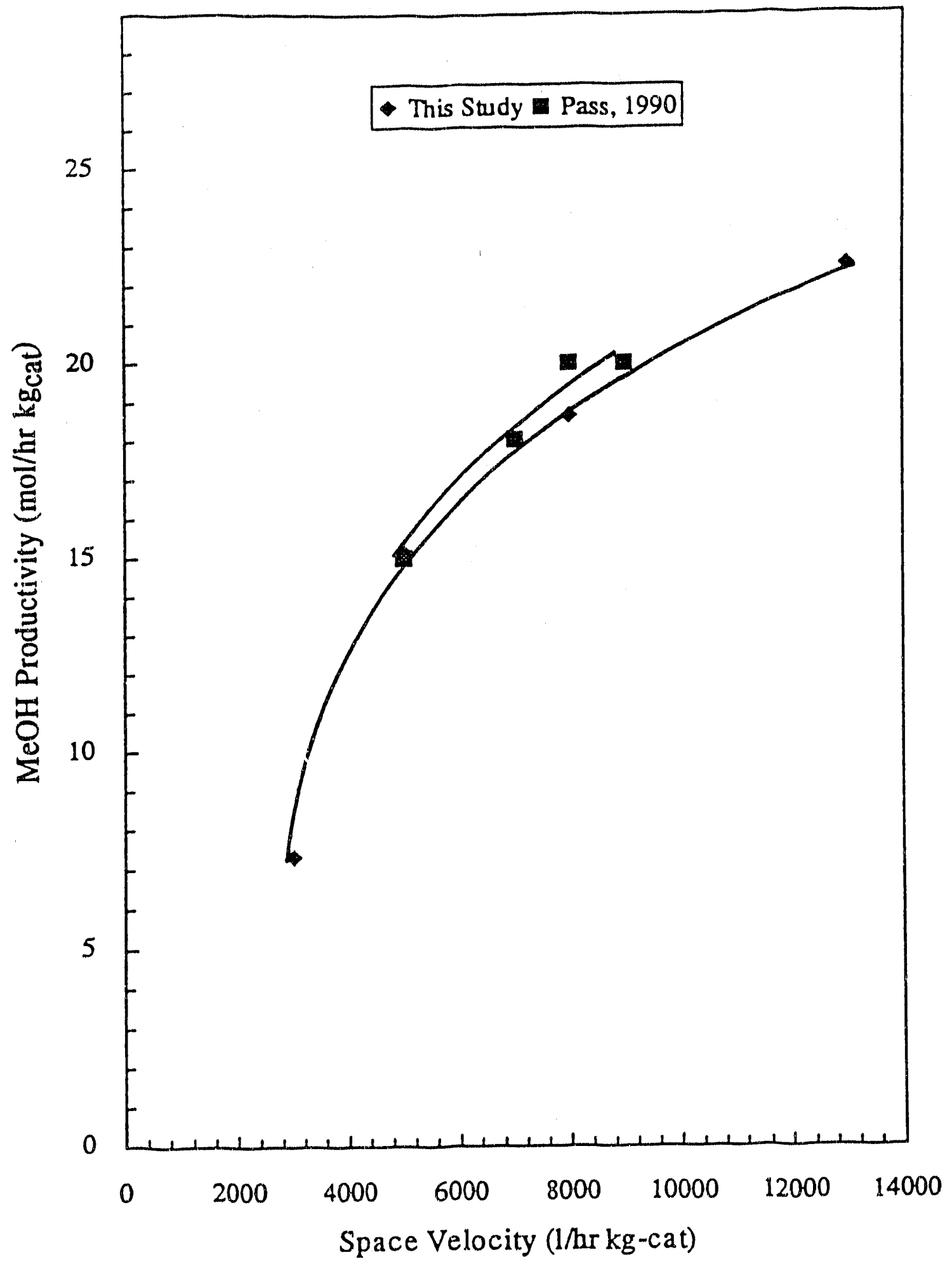

Figure 34. Comparison between methanol productivity as a function of space velocity for a slurry reactor at $523 \mathrm{~K}$ and $\mathrm{H}_{2} /\left(\mathrm{CO}+\mathrm{CO}_{2}\right)$ ratio of 1 . 


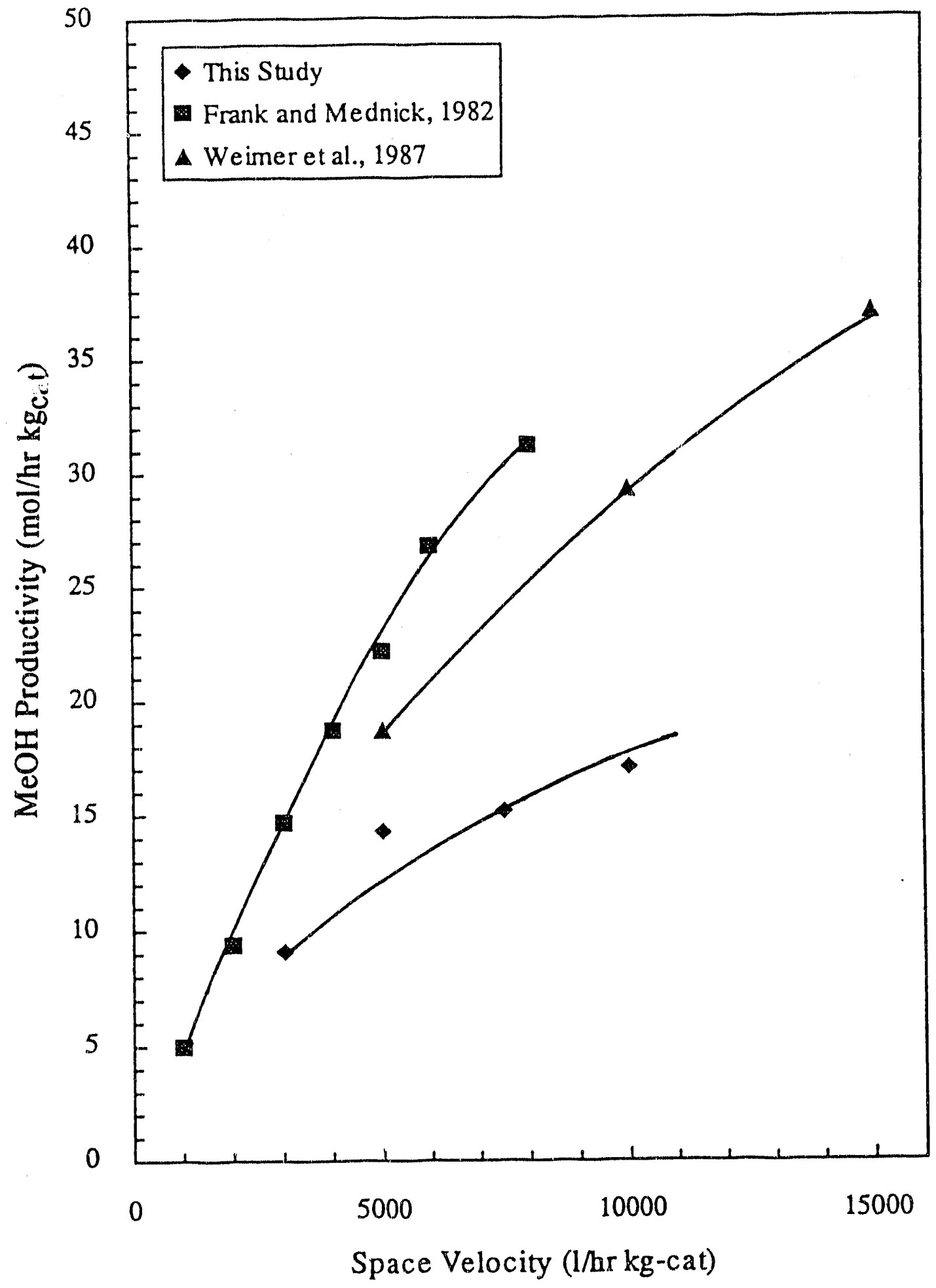

Figure 35. Comparison between methanol productivity as a function of space velocity for a slurry reactor at $523 \mathrm{~K}$ and $\mathrm{H}_{2} /\left(\mathrm{CO}+\mathrm{CO}_{2}\right)$ ratio of 2 to 2.3. 
The relatively low methanol production rate achieved in this study in comparison with those achieved by the other three studies could be related to differences in catalyst 1. iuction procedures, different catalyst types, or different catalyst loadings.

\subsection{Role of Carbon Dioxide}

Methanol production rate as a function of mole percent carbon dioxide in the feed is plotted in figure 36. It indicates that methanol production rate increases with increasing mole percent in the feed up to the optimum value of carbon dioxide mole percent in the feed of 4.7 at which methanol production rate reaches a maximum value, after which methanol production rate starts to decrease with increasing carbon dioxide mole percent in the feed.

This observation is confirmed by other studies. Lee et al. (1989) who conducted methanol synthesis studies in a 1 liter autoclave reactor at $7.2 \mathrm{MPa}, 6200 \mathrm{l} / \mathrm{hr} \mathrm{kg}_{\text {cat }}$, and different temperatures, found that methanol production rate attains a maximum value at 7.5 mole percent carbon dioxide in the feed. Lee also indicates that the location of the maximum is a function of temperature. Moreover, Schack et al. (1989) indicate that methanol production rate reaches a maximum value at 2 mole percent carbon dioxide in the fecd. The study Schack conducted was in a Berty reactor at $513 \mathrm{~K}, 4.38 \mathrm{MPa}$, and 8 $700 \mathrm{~V} / \mathrm{hr} \mathrm{kg}_{\text {cat }}$. Results obtained from both studies, along with these obtained by this study are shown in figure 37 .

The ratio of hydrogen moles reacted to carbon moles reacted is plotted in figure 38 as a function of time on stream at $523 \mathrm{~K}, 5000 \mathrm{lhr} \mathrm{kg}_{\text {cat }}$, and $\mathrm{H}_{2} /\left(\mathrm{CO}+\mathrm{CO}_{2}\right)$ ratio of 2. It can be seen from the figure that this ratio $i:$ near 4 which is the stoichiometric ratio of hydrogen to carbon in the carbon monoxide hydrogenation reaction, indicating that this particular reaction is the main route to methanol at the specified conditions. Confirming this conclusion is figure 39 in which the ratio of carbon moles reacted to oxygen moles reacted is plotted as a function of time on stream at $523 \mathrm{~K}$, 
$5000 \mathrm{l} / \mathrm{hr} \mathrm{kg}$ cat, and $\mathrm{H}_{2} /\left(\mathrm{CO}+\mathrm{CO}_{2}\right)$ ratic of 2 . It can be seen from figure 39 that this ratio is near 1 which is the stoichiometric ratio of oxygen to carbon of carbon monoxide in the carbon monoxide hydrogenation reaction, attesting that this reaction is the main route to methanol at the specified conditions.

One the other hand table 2 shows the effect of $\mathrm{H}_{2} /\left(\mathrm{CO}+\mathrm{CO}_{2}\right)$ ratio on the ratio of carbon moles reacted to oxygen moles reacted at $523 \mathrm{~K}$. The space velocity had no significant effect on the ratio of carbon moles reacted to oxygen moles reacted for space velocities higher than $4000 \mathrm{l} / \mathrm{hr} \mathrm{kg}$ cat. This is shown in figure 40 .

Table 2. Effect of $\mathrm{H}_{2} /\left(\mathrm{CO}+\mathrm{CO}_{2}\right)$ ratio on the ratio of carbon moles reacted to oxygen moles reacted

\begin{tabular}{|c|c|c|c|}
\hline $\mathrm{H}_{2} /\left(\mathrm{CO}+\mathrm{CO}_{2}\right)$ ratio & $0.5 / 1$ & $1 / 1$ & $2 / 1$ \\
\hline $\mathrm{CO}_{2}$ mole \% in feed & 3.1 & 4.7 & 5.6 \\
\hline$(\mathrm{C} / \mathrm{O})_{\text {reasied ratio }}$ & 1.2 & 0.66 & 0.94 \\
\hline
\end{tabular}

Table 2 indicates that the carbon monoxide hydrogenation reaction is the main route to methanol at $\mathrm{H}_{2} /\left(\mathrm{CO}+\mathrm{CO}_{2}\right)$ ratios of 0.5 and 2 since the ratio of carbon moles reacted to oxygen moles reactcd is approximately $1 . \mathrm{H}_{2} /\left(\mathrm{CO}+\mathrm{CO}_{2}\right)$ ratios of 0.5 and 2 correspond to carbon dioxide mole percent in the feed of 3.1 and 5.6 respectively.

However at $\mathrm{H}_{2} /\left(\mathrm{CO}+\mathrm{CO}_{2}\right)$ ratio of 1 which correspond to carbon dioxide mole percent in the feed of 4.7 , the main route to methanol is the carbon dioxide hydrogenation reaction or at least both $\mathrm{CO}$ and $\mathrm{CO}_{2}$ lead to methanol production since the ratio of carbon moles reacted to oxygen moles reacted has an average value of 0.66 that is close to the stoichiometric ratio 0.5 which is the stoichiometric ratio of oxygen to carbon of carbon dioxide in the carbon dioxide hydrogenation reaction. 


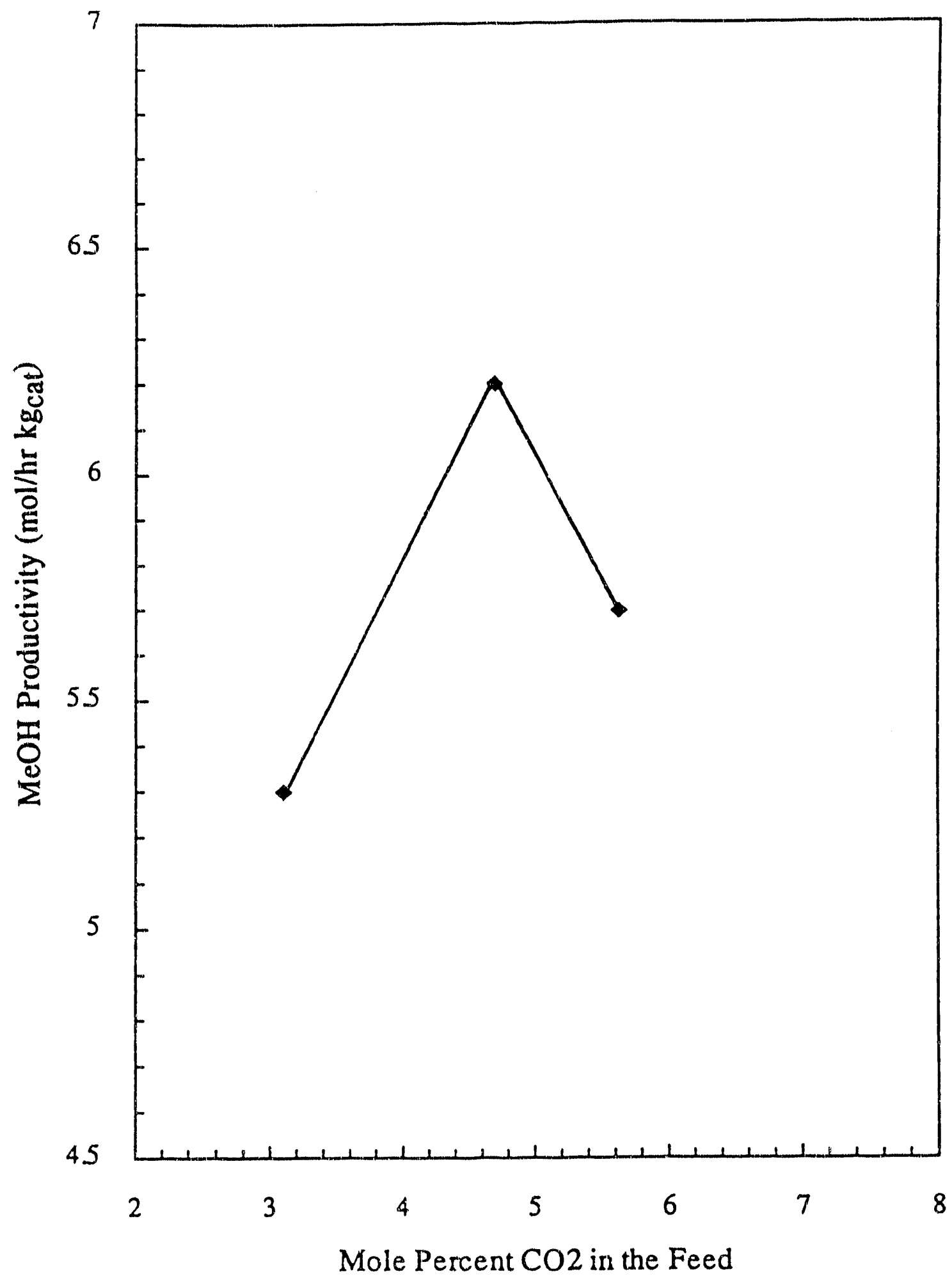

Figure 36. Effect of mole percent $\mathrm{CO}_{2}$ in the feed on methariol production rate at $5.2 \mathrm{Mpa}, 523 \mathrm{~K}$, and $8000 \mathrm{l} / \mathrm{hr} \mathrm{kg}_{\mathrm{cat}}$. 


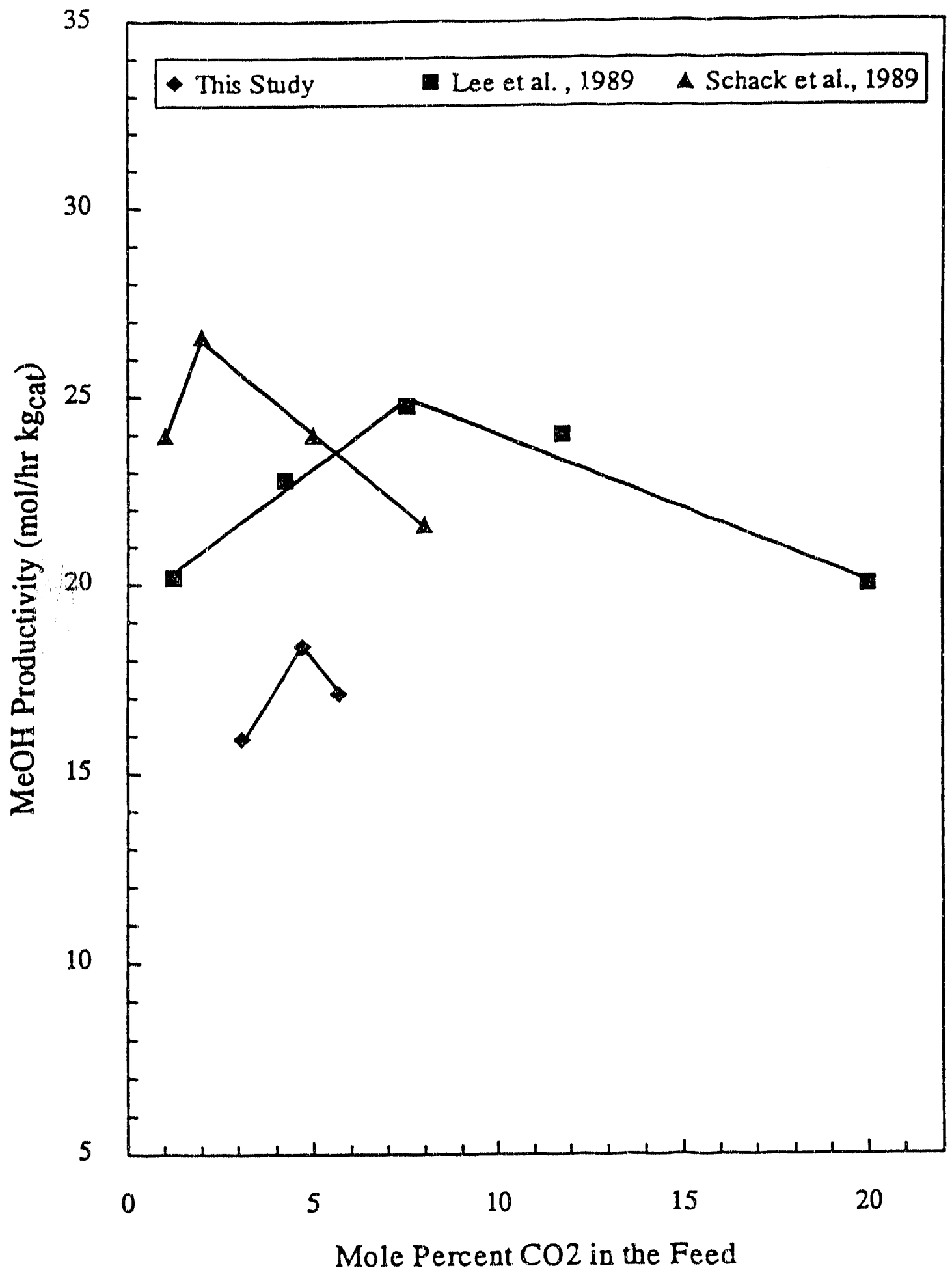

Figure 37. Comparison between the effect of mole percent $\mathrm{CO}_{2}$ in the feed on methanol production rate at 5.2 to $7 \mathrm{Mpa}, 523 \mathrm{~K}$, and space velocity range from 6200 to $8700 \mathrm{l} / \mathrm{hr} \mathrm{kgcat}$. 


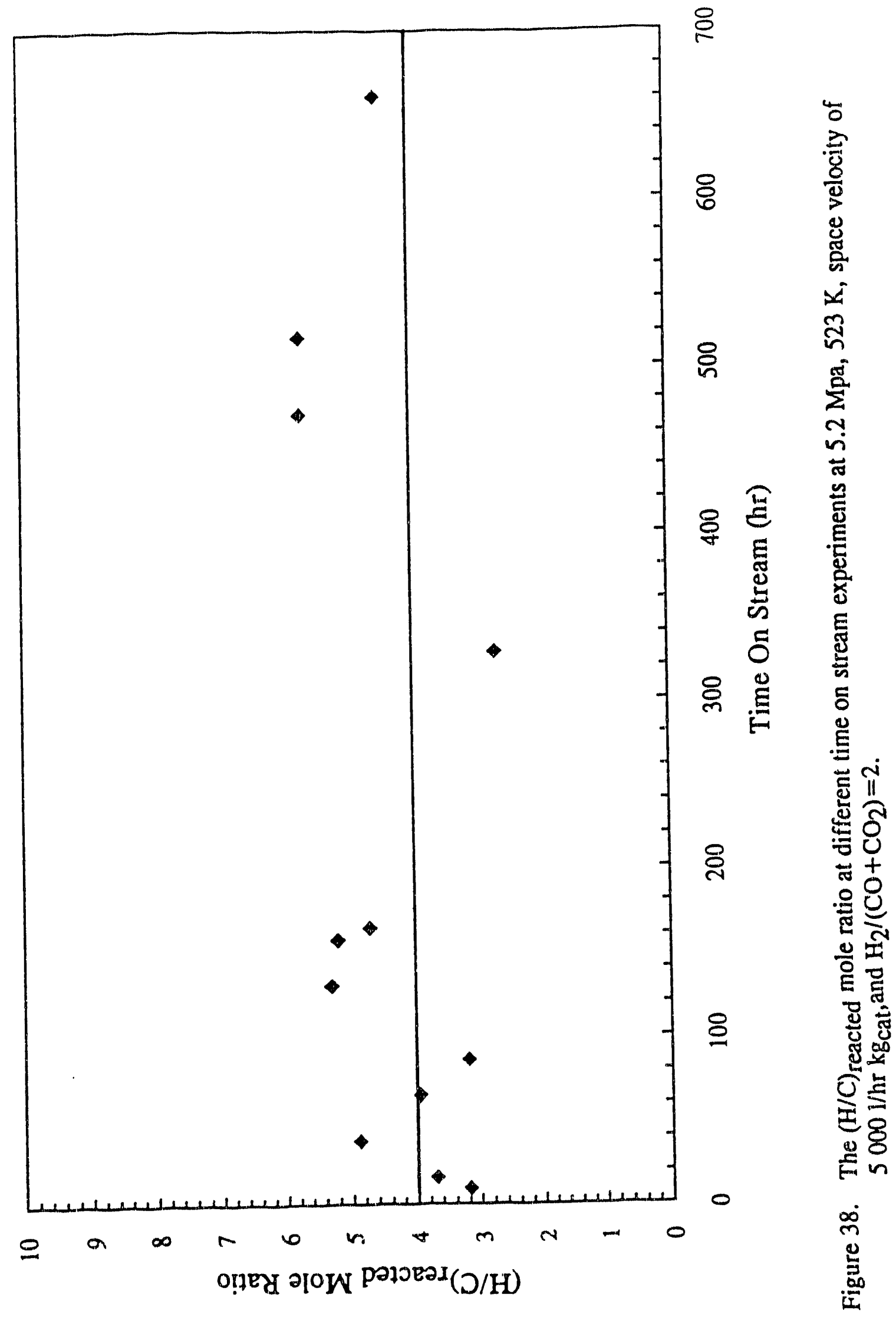




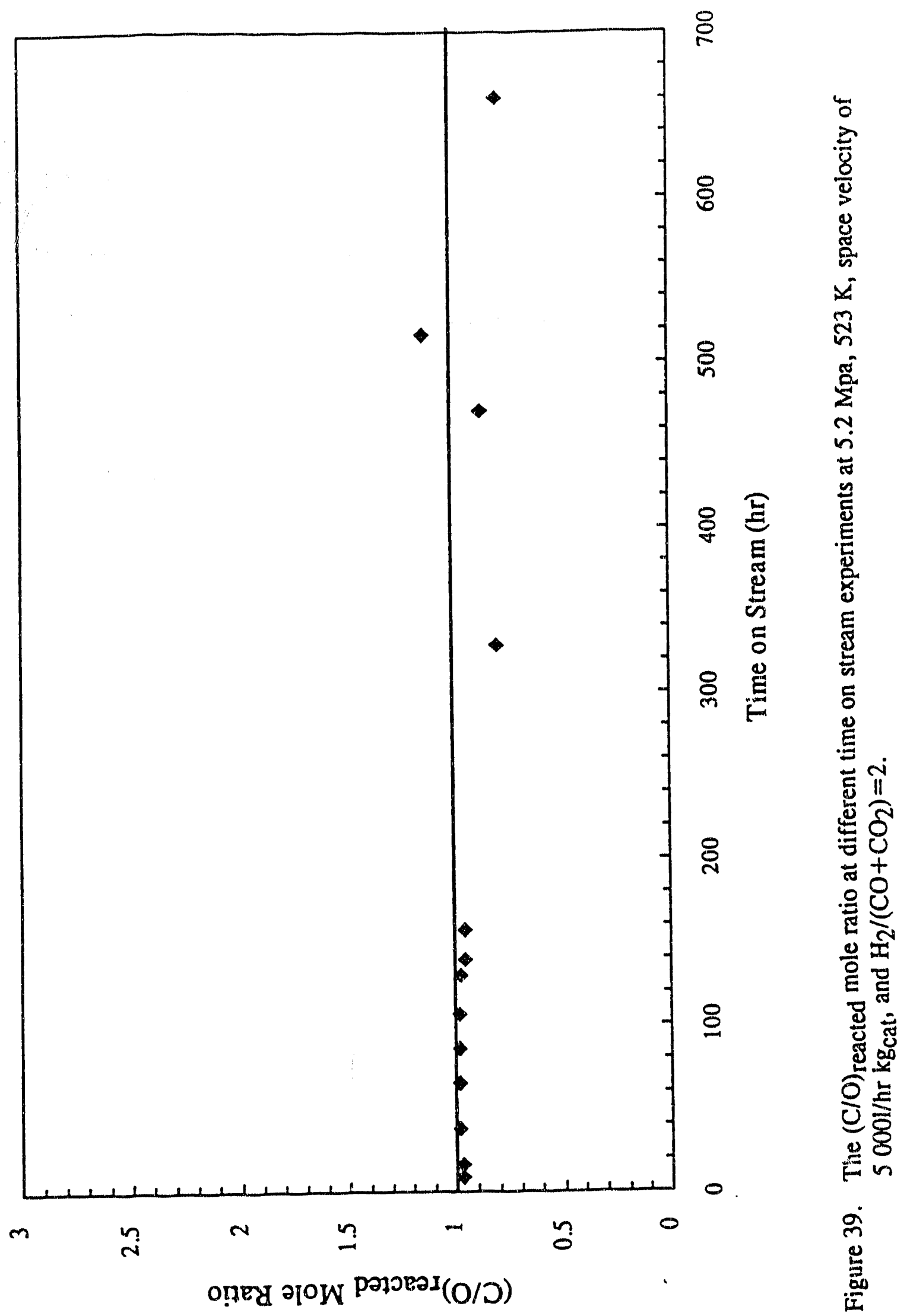




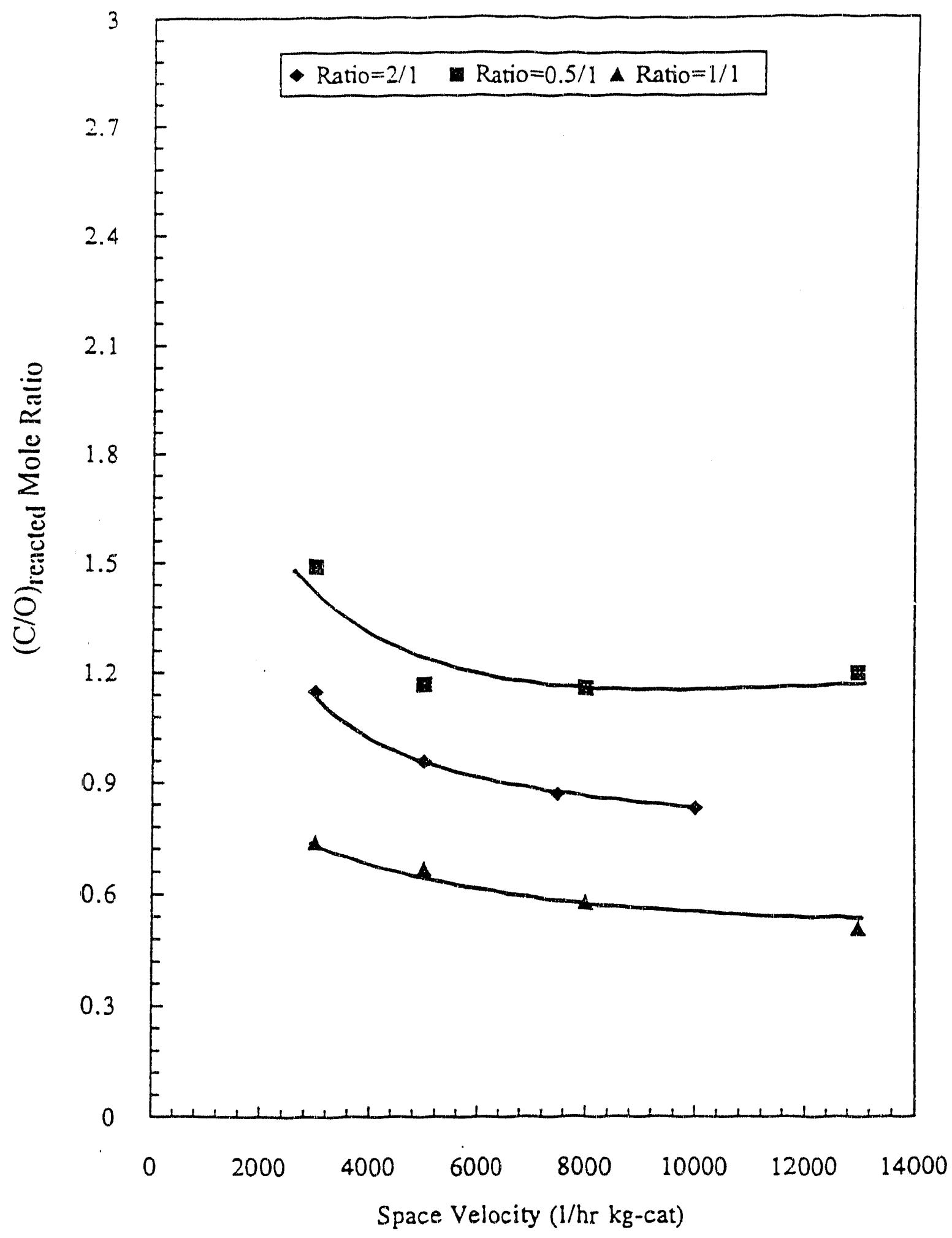

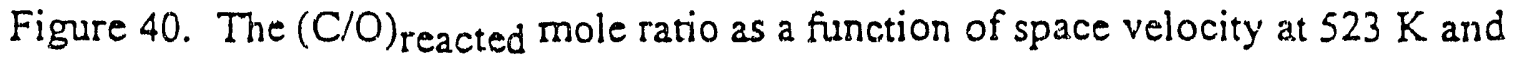
different $\mathrm{H}_{2} /\left(\mathrm{CO}+\mathrm{CO}_{2}\right)$ ratios. 


\subsection{Pore Diffusional Limitations}

Another experiment was conducted in which the catalyst particle size used was in the range of 250 to 300 microns instead of 500 to 600 microns. The same reduction procedure and reaction conditions were implemented. The $\mathrm{H}_{2} /\left(\mathrm{CO}+\mathrm{CO}_{2}\right)$ ratio was set at 2 for 360 hours of time on stream.

Figure 41 shows a comparison between the two experiments. It can be seen that higher methanol production rates are achieved during the experiment with particle size range of 250 to 300 microns for the first 150 hours of time on stream. due to the identical and continuous mixing and friction conditions in the slurry reactor between the catalyst particles in the two experiments, the catalyst particle size eventually reduces to an equal size. This is shown in figure 42 .

Therefore, it can be concluded that there is an experimental evidence of the existence of pore diffusional limitations. On the other hand, theoretical pore diffusional limitations calculations showed that these limitations do not exist. This observation is confirmed by Berty et al. (1983) who conducted a methanol synthesis study in a Berty reactor at a space velocity range of 2600 to $22100 \mathrm{l} / \mathrm{hr} \mathrm{kg}_{\text {cat }}$ and pressure of $5.2 \mathrm{MPa}$. The temperature was in the range of 477 to $505 \mathrm{~K}$ and the catalyst particle size was in the range of 1.5 to $5 \mathrm{~mm}$. Higher methanol production rates were achieved at smaller catalyst sizes verifying the existence of pore diffusional linitations.

Berty suggests that the contradiction between theoretical and experimental observations is due to fact that the Weisz- Prater criterion for diffusional limitation is based on $A \Leftrightarrow B$ reaction type while the methanol synthesis reaction is a reducing mole type, and due to the uncertainty in the tortuosity that is used in the calculation of effective diffusivity. 


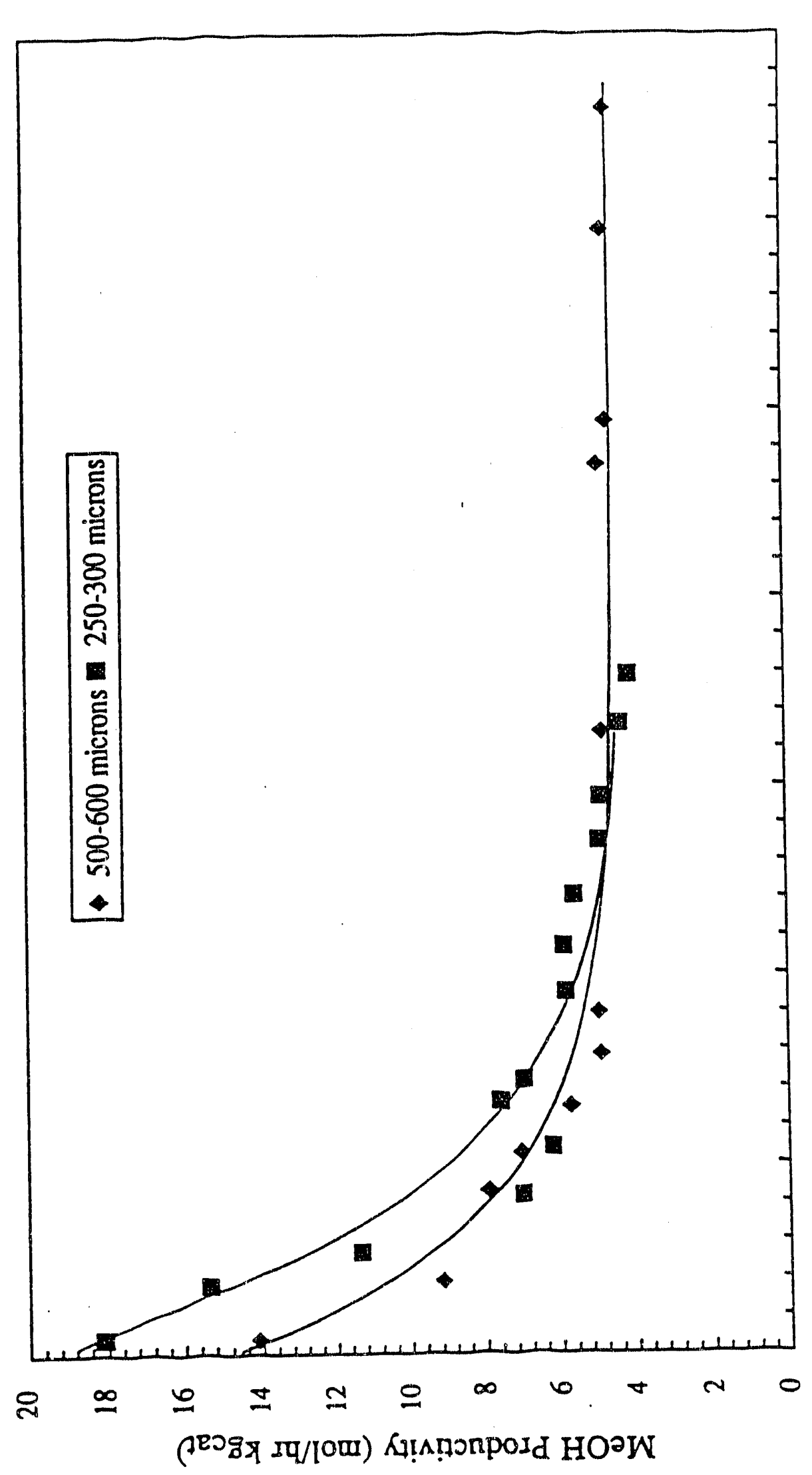

8

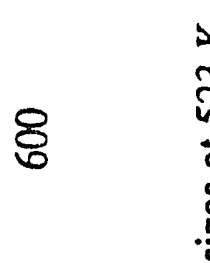

思

ถ

I

กิ

의 는

\&

岕

동

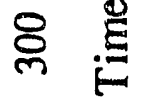

.0ํํำ

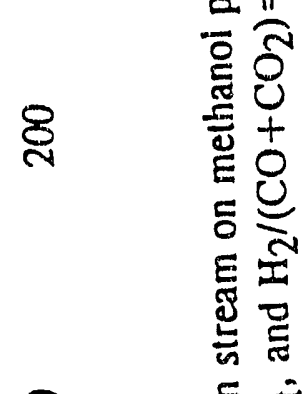

o

옹

등

㟧

娄

पु

ज文

$\bar{\nabla}$

는

江 


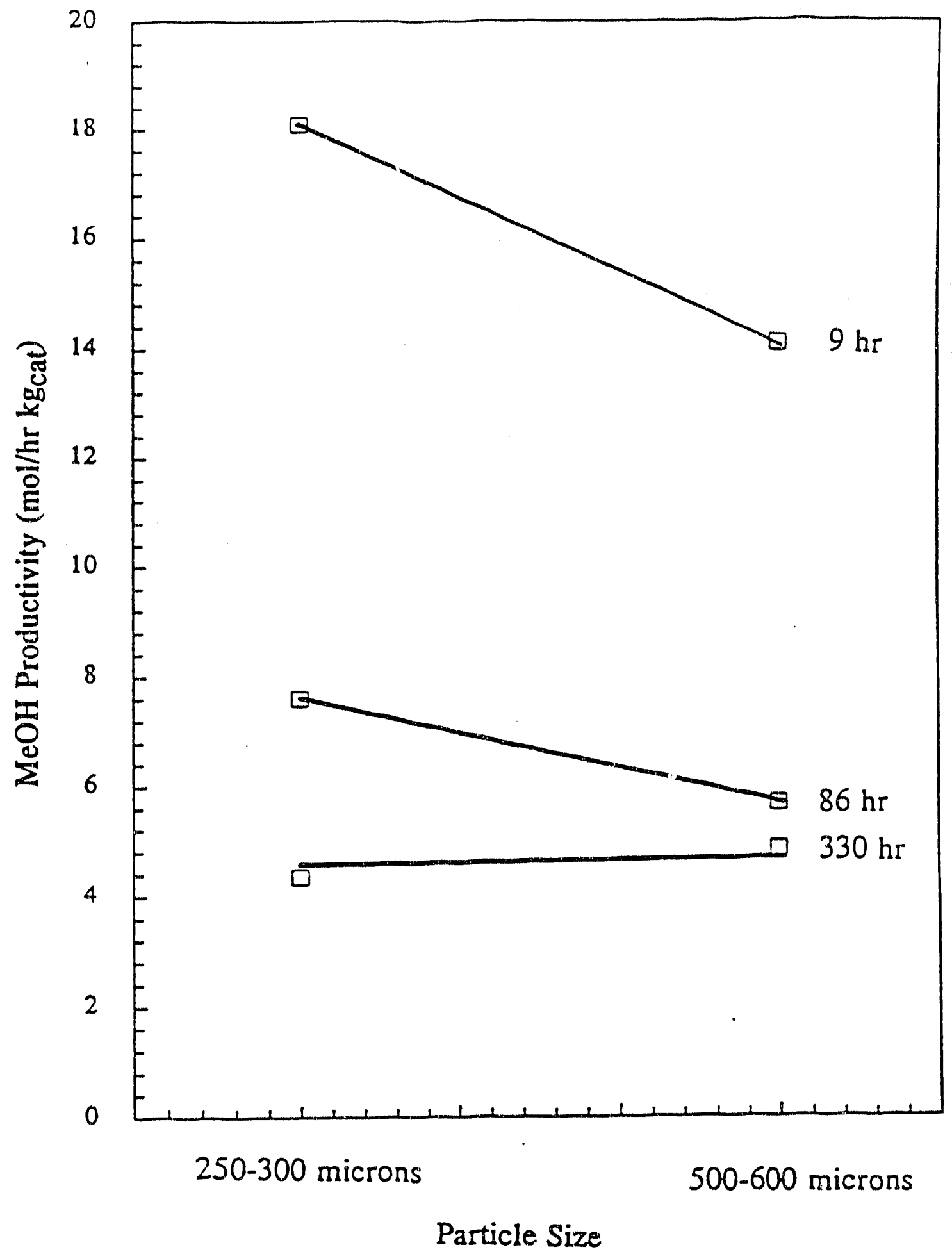

Figure 42. Effect of catalyst particle size on methanol production rate as a function of time on stream at $523 \mathrm{~K}, 5000 \mathrm{l} / \mathrm{hr} \mathrm{kgcat}$, and $\mathrm{H}_{2} /\left(\mathrm{CO}+\mathrm{CO}_{2}\right)=2$. 


\subsection{Equiliorium Calculations}

Equilibrium calculations were performed on the methanol synthesis reaction at $523 \mathrm{~K}$ and $5.2 \mathrm{MPa}$. The space velocity was varied in the range of 3000 to $13000 \mathrm{l} / \mathrm{hr} \mathrm{kg}_{\text {cat }}$. the oil molar flow rate was held at $14.15 \mathrm{~mol} / \mathrm{hr} \mathrm{kg}$ cat. The $\mathrm{H}_{2} /\left(\mathrm{CO}+\mathrm{CO}_{2}\right)$ ratio was set at 2,1 , and 0.5 . The two independent reactions considered are the carbon monoxide hydrogenation reaction and the reverse water gas shift reaction. The solution is assumed to be ideal and the liquid vapor equilibrium is governed by Henry's law. Henry's law constants for the components involved are determined using relations given by von Wedel, (1988). Thermodynamic equilibruim constants are calculated by assuming ideal gas behavior by the mixture. Based on these assumptions, the following set of equations are written:

Component mass balance:

$$
\begin{aligned}
& \mathrm{H}_{2}: \quad\left(V y_{1}\right)_{\text {out }}+\left(L x_{1}\right)_{\text {out }}+2 \zeta_{1}+\zeta_{2}=\left(V y_{1}\right)_{\text {in }}+\left(L x_{1}\right)_{\text {in }} \\
& \mathrm{CO}_{2}: \quad\left(V y_{2}\right)_{\text {out }}+\left(L x_{2}\right)_{\text {out }} \quad+\zeta_{2}=\left(V y_{2}\right)_{\text {in }}+\left(L x_{2}\right)_{\text {in }} \\
& \mathrm{CO}: \quad\left(V y_{3}\right)_{o u t}+\left(L x_{3}\right)_{o u t}+\zeta_{1}-\zeta_{2}=\left(V y_{3}\right)_{\text {in }}+\left(L x_{3}\right)_{\text {in }} \\
& \mathrm{CH}_{3} \mathrm{OH}: \quad\left(V y_{4}\right)_{\text {out }}+\left(L x_{4}\right)_{\text {out }}-\zeta_{1}=\left(V y_{4}\right)_{\text {in }}+\left(L x_{4}\right)_{\text {in }} \\
& \mathrm{H}_{2} \mathrm{O}: \quad\left(V y_{5}\right)_{\text {out }}+\left(L x_{5}\right)_{\text {out }} \quad-\zeta_{2}=\left(V y_{5}\right)_{\text {in }}+\left(L x_{5}\right)_{\text {in }} \\
& \text { Oil: } \quad\left(V y_{\sigma}\right)_{\text {out }}+\left(L x_{6}\right)_{\text {out }} \quad=\quad\left(L x_{6}\right)_{\text {in }}
\end{aligned}
$$

Over all mass balance:

$$
V_{\text {out }}+L_{\text {out }}+2 \zeta_{1}=V_{\text {out }}+L_{\text {out }}
$$

Henry's relations:

$$
\begin{array}{ll}
\mathrm{H}_{2}: & y_{1} / x_{1}=k 1 \\
\mathrm{CO}_{2}: & y_{2} / x_{2}=k_{2} \\
\mathrm{CO}: & y_{3} / x_{3}=k_{3}
\end{array}
$$




$$
\begin{array}{ll}
\mathrm{CH}_{3} \mathrm{OH}: & y_{4} / x_{4}=k_{4} \\
\mathrm{H}_{2} \mathrm{O}: & y_{5} / x_{5}=k_{5}
\end{array}
$$

Summation of components mole fractions in the liquid phase:

$$
x_{1}+x_{2}+x_{3}+x_{4}+x_{5}+x_{6}=1
$$

Reaction equilibrium constants:

$$
\begin{aligned}
& K_{1}=f_{\mathrm{CH}_{3} \mathrm{OH}} /\left(\left(f_{\mathrm{H}_{2}}\right)^{2} f_{\mathrm{CO}}\right) \\
& K_{2}=\left(f_{\mathrm{H}_{2} \mathrm{O}} f_{\mathrm{CO}} /\left(f_{\mathrm{H}_{2}} f_{\mathrm{CO} 2}\right)\right.
\end{aligned}
$$

Where the reactions involved are :

$$
\begin{array}{lll}
\mathrm{CO}+2 \mathrm{H}_{2} & \Leftrightarrow \mathrm{CH}_{3} \mathrm{OH} & \mathrm{K}_{1}, \zeta_{1} \\
\mathrm{H}_{2}+\mathrm{CO}_{2} \Leftrightarrow \mathrm{CO}+\mathrm{H}_{2} \mathrm{O} & \mathrm{K}_{2}, \zeta_{2}
\end{array}
$$

These fifteen equations in fifteen unknowns are solved using a IMSL library program utilizing a Levenberg-Marquardt algorithm and finite difference approximation to the Jacobian. The computer program is shown in appendix $B$. $f_{i}$ is the fugacity of component $\mathrm{i}$ and is set equal to $H_{i} C_{T} x_{i}$, where $\mathrm{H}_{\mathrm{i}}$ is Henry's constant for component $\mathrm{i}$ and $\mathrm{C}_{\mathrm{T}}$ is the total concentration which was set equal to Density oil $/ M W_{o i l}$.

Results obtained indicate that the experimental methanol production rate along with the experimental carbon monoxide and hydrogen \% conversions are about one tenth of those determined by equilibrium calculations. On the other hand, more water is produced experimentally than the amount determined by equilibrium calculations. These results are illustrated in tables 3 and 4. 
Table 3. Comparison between experimental methanol and water production rates with these obtained by equilibrium calculations

\begin{tabular}{|c|c|c|c|c|c|}
\hline & \multirow[t]{2}{*}{$\begin{array}{c}\text { Space Velocity } \\
\text { //hr kgcat }\end{array}$} & \multicolumn{2}{|c|}{$\begin{array}{l}\text { Methanol Production Rate } \\
\mathrm{mol} / \mathrm{hr} \mathrm{kg} \text { cat }\end{array}$} & \multicolumn{2}{|c|}{$\begin{array}{c}\text { Water Production Rate } \\
\mathrm{mol} / \mathrm{hr} \mathrm{kgcat}\end{array}$} \\
\hline & & Exp. & Equil. & Exp. & Equil. \\
\hline \multirow[t]{4}{*}{ Ratio=2 } & 3000 & 3.04 & 23.17 & 0.32 & 0.12 \\
\hline & 5000 & 4.76 & 38.28 & 0.58 & 0.20 \\
\hline & 7500 & 5.07 & 57.30 & 0.60 & 0.29 \\
\hline & 10000 & 5.71 & 76.26 & 0.76 & 0.38 \\
\hline \multirow[t]{4}{*}{ Ratio=1 } & 3000 & 2.44 & 19.33 & 0.94 & 0.52 \\
\hline & 5000 & 4.99 & 32.02 & 0.28 & 0.089 \\
\hline & 8000 & 6.2 & 48.21 & 0.40 & 0.12 \\
\hline & 13000 & 7.5 & 83.48 & 0.47 & 0.21 \\
\hline \multirow[t]{4}{*}{ Ratio $=0.5$} & 3000 & 1.99 & 12.60 & 0.15 & 0.027 \\
\hline & 5000 & 4.84 & 20.99 & 0.42 & 0.044 \\
\hline & 8000 & 5.74 & 33.66 & 0.47 & 0.069 \\
\hline & 13000 & 7.25 & 54.71 & 0.73 & 0.11 \\
\hline
\end{tabular}


Table 4. Comparison between experimental hydrogen and carbon monoxide \% conversions with these obtained by equilibrium calculations

\begin{tabular}{|c|c|c|c|c|c|}
\hline & \multirow[t]{2}{*}{$\begin{array}{c}\text { Space Velocity } \\
\text { 1/hr kgcat }\end{array}$} & \multicolumn{2}{|c|}{ Hydrogen $\%$ conversion } & \multicolumn{2}{|c|}{$\begin{array}{c}\text { Carbon monoxide \% } \\
\text { conversion }\end{array}$} \\
\hline & & Exp. & Equil. & Exp. & Equil. \\
\hline \multirow[t]{4}{*}{ Ratio $=2$} & 3000 & 11.16 & 52.07 & 4.34 & 57.01 \\
\hline & 5000 & 7.49 & 51.69 & 4.65 & 56.61 \\
\hline & 7500 & 2.60 & 51.50 & 5.24 & 56.41 \\
\hline & 10000 & 3.20 & 51.40 & 3.63 & 56.30 \\
\hline \multirow[t]{4}{*}{ Ratio=1 } & 3000 & 8.96 & 57.83 & 1.78 & 31.79 \\
\hline & 5000 & 8.65 & 57.58 & 1.67 & 31.85 \\
\hline & 8000 & 7.06 & 57.70 & 0.71 & 31.72 \\
\hline & 13000 & 4.58 & 57.66 & 0.071 & 31.70 \\
\hline \multirow[t]{4}{*}{ Ratio $=0.5$} & 3000 & 9.28 & 55.13 & 4.04 & 15.60 \\
\hline & 5000 & 7.86 & 55.20 & 5.29 & 15.20 \\
\hline & 8000 & 7.45 & 55.24 & 4.26 & 15.63 \\
\hline & 13000 & 6.00 & 55.27 & 4.27 & 15.64 \\
\hline
\end{tabular}




\subsection{Rate Equation Development}

On the basis of equilibrium calculations, it is concluded that the carbon monoxide and carbon dioxide hydrogenation reactions are far from equilibrium and low conversions were achieved. It is also noted that more water is produced than that predicted by equilibrium calculations. It is assumed that the reactor is isothermal, the carbon monoxide hydrogenation reaction is the rate controlling step, and the water gas shift reaction is at dynamic equilibrium, also the liquid and vapor phases in the reactor are in equilibrium and governed by Henry's law. Therefore an equation of the form shown below (equation(29)) is proposed as a kinetic model describing methanol synthesis at the industrial conditions of $5.2 \mathrm{MPa}$ and $523 \mathrm{~K}$.

$$
r_{\text {methanol }}=k p_{H_{2}}^{a} p_{C O}^{b} p_{C H S O H}^{c} p_{H_{2} \mathrm{O}}^{d} p_{C O 2}^{a}
$$

Where $\mathrm{k}$ is the rate constant. All six parameters are fit from experimental data collected at three different $\mathrm{H}_{2} /\left(\mathrm{CO}+\mathrm{CO}_{2}\right)$ ratios. Flash calculations are conducted on the tail gas leaving the reactor to determine component distribution in the gas and liquid phase by solving the following equation:

$$
1=\sum_{i=1}^{6} \frac{x_{i}}{\left[1-\left(\frac{V}{F}\right)\left(1-K_{i}\right)\right]}
$$

Where $x_{i}$ and $K_{i}$ are the outlet liquid mole fraction and equilibrium constant ( $K$ value) of component i respectively. $F$ is the inlet flow rate and $V$ is the outlet gas flow rate. Henry's law is used to find the gas phase composition:

$$
y_{i}=\frac{H_{i} C_{T}}{P} x_{i}
$$

Where $C_{T}$ is given by equation (32) and $\mathrm{p}_{\mathrm{i}}$ is given by equation (33). 


$$
\begin{gathered}
C_{T}=\frac{\rho_{\text {oil }}}{M W_{o i l}} \\
p_{i}=y_{i} P
\end{gathered}
$$

$\mathrm{H}_{\mathrm{i}}$ and $\mathrm{C}_{\mathrm{T}}$ are the Henry's constant for component $\mathrm{i}$ and the total concentration respectively. The oil vapor pressure is negligible. The calculated partial pressures are fitted to equation (29) yielding the following power law rate equation:

$$
r_{\text {methanol }}=0.066 \frac{p_{H_{2}}^{0.58} p_{C O}^{0.78}}{p_{C H, O H}^{0.38} p_{H_{2} O}^{0.064}}
$$

This equation is valid in the space velocity range of $5000-13000 \mathrm{l} / \mathrm{hr} \mathrm{kg}_{\text {cat }}$ at 5.2 $\mathrm{MPa}$ and $523 \mathrm{~K}$. A parity plot showing the validation of equation (35) is shown in figure 43. Methanol synthesis process simulation using equation (35) to describe methanol production rate at $523 \mathrm{~K}$ and $5.2 \mathrm{MPa}$ was conducted. The same set of equations used in equilibrium calculations was used excluding equation (27) which was replaced with equation (35). The computer process simulation results indicate the model developed has an absolute average error of 5.78. The computer program is shown in appendix C. A comparison of average error percent of models proposed by several researchers is shown in table 5 . Methanol production rates obtained by process simulation are compared to experimental production rates in table 6.

Table 5. Comparison of the average error percent of models proposed by several researchers

\begin{tabular}{|l|c|c|}
\hline \multicolumn{1}{|c|}{ Researcher } & Number of constants & Average error percent \\
\hline Natta et al. (1955) & 8 & 12.0 \\
\hline Leonov et al. (1973) & 2 & 20.6 \\
\hline Lee et al. (1984) & 2 & 20.8 \\
\hline Villa et al. (1985) & 8 & 11.3 \\
\hline von Wedel (1988) & 7 & 9.8 \\
\hline McNeil et al. (1989) & 6 & 18 \\
\hline This Study & 5 & 5.8 \\
\hline
\end{tabular}


Table 6. Comparison between methanol production rates obtained by process simulation and experimental methanol production rates

\begin{tabular}{|c|c|c|c|c|}
\hline & \multirow[t]{2}{*}{$\begin{array}{c}\text { Space Velocity } \\
\text { /hr kgcat }\end{array}$} & \multicolumn{2}{|c|}{$\begin{array}{l}\text { Methanol Production Rate } \\
\mathrm{mol} / \mathrm{hr} \mathrm{kg} \mathrm{cat}\end{array}$} & \multirow[t]{2}{*}{$\%$ error } \\
\hline & & Exp. & Predicted & \\
\hline \multirow[t]{3}{*}{ Ratio=2 } & 5000 & 4.76 & 4.86 & -2.10 \\
\hline & 7500 & 5.07 & 5.48 & -8.09 \\
\hline & 10000 & 5.71 & 5.96 & -4.38 \\
\hline \multirow[t]{3}{*}{ Ratio=1 } & 5000 & 4.99 & 5.43 & -8.82 \\
\hline & 8000 & 6.20 & 6.17 & 0.48 \\
\hline & 13000 & 7.50 & 7.24 & 3.33 \\
\hline \multirow[t]{3}{*}{ Ratio $=0.5$} & 5000 & 4.84 & 5.5 & -13.63 \\
\hline & 8000 & 5.74 & 6.36 & -10.8 \\
\hline & 13000 & 7.25 & 7.35 & 1.38 \\
\hline
\end{tabular}

Due to the low conversions and production rates attained, the reverse term of the rate equation has a negligible effect on the calculated methanol production rate, but at studies where high conversions are achieved it is highly advisable to use that term. Therefore, the final form of the rate equation developed is:

$$
\zeta_{1}=0.066 \frac{p_{H_{2}}^{0.58} p_{C O}^{0.78}}{p_{C H S O H}^{0.38} p_{H_{2 O}}^{0.06}}\left[1-\frac{p_{C H, O H}}{p_{H_{2}}^{2} p_{C O} K_{1}}\right]
$$

This equation can be used for methanol rate prediction and for performing design calculation at typical industrial conditions using a $\mathrm{CuO} / \mathrm{ZnO} / \mathrm{Al}_{2} \mathrm{O}_{3}$ catalyst. $\mathrm{K}_{1}$ is the thermodynamic equilibrium constant for the carbon monoxide hydrogenation reaction.

Equation (35) shows that methanol synthesis is a first order reaction in agreement with Weimer et al. (1987) who indicate that the reaction data exhilit an almost first order 


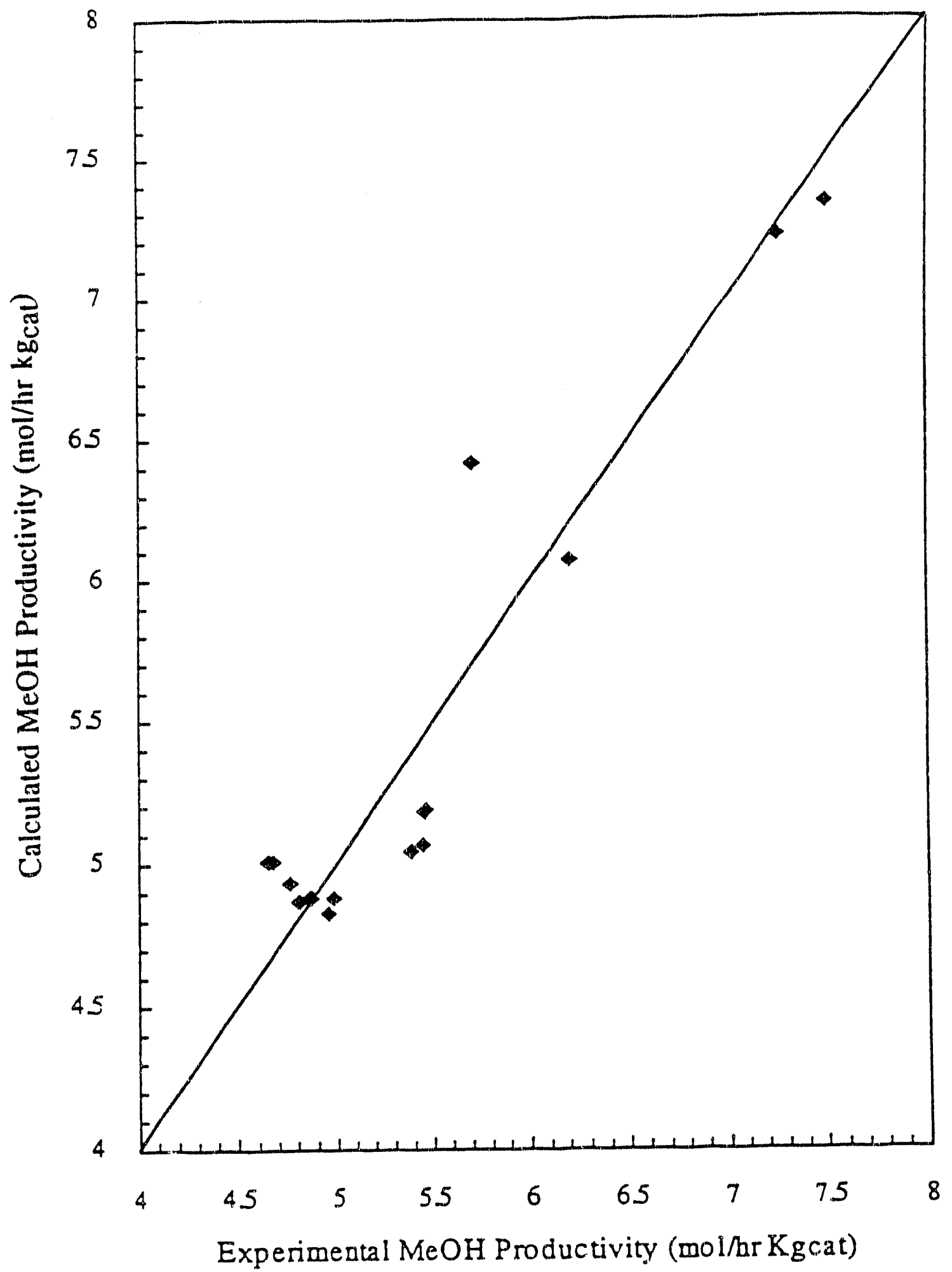

Figure 43. Scatter plot showing the validity of the rate equation developed in this study. 
behavior with respect to pressure. Also, the driving force term $\left(\mathrm{p}_{\mathrm{CO}}^{\mathrm{a}} \mathrm{p}_{\mathrm{H} 2}^{\mathrm{b}}\right)$ is in the numerator in agreement with many researchers' work.

Moreover, the Methanol partial pressure term is in the denominator, considered as a resistance, in agreement with Natta (1955), who indicates that methanol is strongly adsorbed, therefore inhibiting methanol synthesis. The witer partial pressure term, also considered as a resistance, is in the denominator in agreement with Liu et al. (1984), who indicate that water is competetively adsorbed and therefore inhibiting methanol production and the extent of inhibitition increases with increasing water partial pressure.

The main objective of this study is to deduce a kinetic model describing methanol synthesis. It was not intended in this study to investigate the role of carbon dioxide in methanol synthesis nor the catalyst pore diffusional kinetics, but some basic insight into the effect of these factors were achieved. Therefore, further in depth studies on both the role of carbon dioxide and diffusional kinetics in methanol synthesis reaction are recommended.

\subsection{Catalyst Characterization}

The catalyst surface area was measured before and after the reaction. The measured surface area for the fresh catalyst was $49 \mathrm{~m}^{2} / \mathrm{g}$, and that of the same catalyst after 660 hours of continuous operation was $32 \mathrm{~m}^{2} / \mathrm{g}$. The reduction in the surface area could be due to coke deposition, surface metal sintering, or due to the fact that the catalyst suffered irreversible deactivation when the reaction temperature was raised to $538 \mathrm{~K}$. Also, atomic adsorption was used to analyze for iron in the catalyst after the reaction and was found to be $0.2 \mathrm{wt}$. \% iron. The manufacturer did not report that the catalyst contains even trace of iron. 


\section{LITERATURE CITED}

Agny, R. M., and C. G. Takoudis," Synthesis of Methanol from Carbon Monoxide and Hydrogen over Copper Zinc Oxide Alumina Catalyst," , Ind. Eng. Chem. Prod. Res. Rev., 24, 50 (1985).

Aharoni,C., and H. Starer,"Adsorption and Desorption of Hydrogen, Carbon Monoxide, and their Products on a Catalyst for the Synthesis of Methanol," Can.J. of Chem., 52, 4044 (1978).

Berty, J. M., L. Sunggyu, V. Parekh, R. Gandi, and K. Sivagnanam,"Diffusional Kinetics of Low Pressure Methanol Synthesis," 'Third Pacific Chemical Engineering Congress, Seoul, Korea (1983).

Chinchen, G. C., P. J. Denny, D. G. Parker, M.S. Spencer, and D. A. Whan,"Mechanism of Methanol Synthesis from $\mathrm{CO}_{2} / \mathrm{CO} / \mathrm{H}_{2}$ Mixtures Over Copper/Zinc Oxide/Alumina Catalysts: Use of ${ }^{14}$ C-Labeled reactants," Applied Catalysis, 30, 333 (1987).

Chinchen, G. C., K. Mansfield, and M. S. Spencer," The Methanol Synthesis: How Does it Work?," Chem. Tech, 20, 692 (1990).

Crocco, J." Methanol : Yesterday, Today and Tomorrow," Chemistry and Industry, 4, 97 (1990).

Dybkjaer, I., P. E. H. Nielson, and J. B. Hansen, "Synthesis of Methanol on Cu-Based Catalyst," Symp. on Reaction Eng. for Methanol Synthesis," AICHE 74th Ann. Meet., New Orleans (1981).

Golden, T. C. , T. H. Hsiung, and Karen E. Snyder, "Removal of Trace Iron and Nickel Carbonyls by Adsorption," Ind. E.zg. Chem. Res., 30, 502 (1991).

Graaf, G. H., J. Stamhius, and A. A. C. M. Beenachers, "Kinetics of Low Pressure Methanol Synthesis," Chem. Eng. Sci., 43, 3185 (1988). 
Hill, C. G., An Introduction to Chemical Engineering Kinetics and Reactor Design, Second Edition, John Wiley \& Sons, New York, 1977.

Kelly, K. P., T. Tatsumi, T. Uematsu, D. J. Driscoll, and J. H. Lunsford,"Methanol Synthesis over Palladium Supported on Silica," J. Catal., 101, 396 (1986).

King, D. L., and J. H. Grate," Look What You Can Make From Methanol?," Chem. Tech, 15,244 (1985).

Klier, K., V. Chatikavanij, R. G. Herman, and G. W. Simmons, " Catalytic Synthesis of Methanol from $\mathrm{CO} / \mathrm{H}_{2}, " J$. Catal., 74, 343 (1982).

Lee, S., V. R. Parameswaran, I. Wender, and J Kulik," Role of Carbon Dioxide in Methanol Synthesis," Fuel Science and technology Int'l, 7, 1021 (1989).

Leonov, V. E., M. M. Karabaev, E. N. Tsybiana, and G. S. Petrishchova,"Study of Methanol Synthesis on a Low Temperature Catalyst," Kinet Katal, 14, 970 (1988).

Levenspiel, O., Chemical Reaction Engineering, Second Edition, John Wiley \& Sons, New York, 1983.

Liu, G., D. Willcox, M. Garland, and H.H. Kung,"Rate of Methanol Production on a Copper-Zinc Oxide Catalyst: The Dependence on the Feed Composition," J. Catal., 90,139 (1984).

Maj, J. ,C. A. Colmenares, and G. A. Somorjai,"Methanol Production f:nm Carbon Monoxide and Hydrogen on Thorium Dioxide," J. Catal., 95, 385 (1985).

McNeil, M. A., C. J. Schack, and R. G. Rinker," Methanol Synthesis from Hydrogen, Carbon Monoxide, and Carbon Dioxide Over a $\mathrm{Cu} / \mathrm{ZnO} / \mathrm{Al}_{2} \mathrm{O}_{3}$ Catalyst: II Development of a Phenomenological Rates Expression," Applied Catalysis, 50, 265 (1989).

Natta, G., " Synthesis of Methanol," in Catalysis, P. H. Emmett ed., Reinhold, New York, 349 (1955). 
Pass, G. G., A Kinetic Model for Methanol Synthesis on a Cu/Zn/Cr${ }_{2} \mathrm{O}_{3}$ Catalyst, Thesis, Texas A\&M University (1989).

Pass, G. G., C. Holzhauser, A. Akgerman, and R.G. Anthony,"Methanol Synthesis in a Trickle Bed Reactor,"AICHE J., 36, 1054, (1990).

Poutsma, M. L., L.F. Elek, P.A. Ibarbia, A. P. Risch, and J. A. Rabo,"Selective Formation of Methanol from Synthesis Gas over Palladium Catalysts," J. Catal. 52, 157 (1978).

Rase, H. F., Fixed Bed Reactor Design and Diagnostics, Butterworths, Stoneham, MA, 1990.

Sawani, A., M. K. KO, V. Paramesswaran, S. Lee, and C. J. Kulik,"In-situ Reduction of Methanol Synthesis Catalyst in a Three Phase Slurry Reactor," Fuel Science and Technology International, 5, 77 (1987).

Schack, C. J., M. A. McNeil, and G Rinker," Methanol Synthesis from Hydrogen, Carbon Monoxide, and Carbon Dioxide over a $\mathrm{Cu} / \mathrm{ZnO} / \mathrm{Al}_{2} \mathrm{O}_{3}$ Catalyst: I. Steady State Kinetics Experiments," Applied Catalysis, 50, 247 (1989).

Stiles, A., F. Chen, J. Harrison,"Catalytic Conversion of Synthesis Gas to Methanol and Other Oxygenated Products," Ind. Eng. Chem. Res., 30, 811 (1991).

Villa, P., P. Forzatti, G. Buzzi-Ferraris, G. Garone, and I. Pasquon,"Synthesis of Alcohol from Carbon Oxides and Hydrogen," Ind. Eng. Chem. Process Des. Dev., 24, 12 (1985).

von Wedel, W., S. Ledakowicz, and W. D. Deckewer," Kinetics of Methanol Synthesis in the Slurry Phase," Chem. Eng. Sci., 43, 2169 (1988).

Weimer , R. F., D. M. Terry, and D. Stepanoff," Laboratory Kinetics and Mass Transfer in the Liquid Phase Methanol Process," Paper 25d, AICHE Ann. Meet., New York (1987). 
Ledakowicz , S., and L. Nowlcki,"Solubilities of Synthesis Gas Components in a Paraffinic Oil under Methanol Synthesis Conditions," J. Chem. Eng., 32, 166 (1987). 
APPENDIX A

SUMMARY OF DATA 
Table A1. Effect of time on stream on condensate production rate and composition at $5000 \mathrm{Vhr} \mathrm{kg}_{\text {cat }}, 523 \mathrm{~K}$, and $\mathrm{H}_{2} /\left(\mathrm{CO}+\mathrm{CO}_{2}\right)=2$.

\begin{tabular}{lllllllll} 
Run * & Time(hr) & \multicolumn{2}{c}{ Comp. Prod. Rate(mol/hr Kg) } & \multicolumn{3}{l}{ comp. Fraction in condensate } \\
& & MeOH & Water & DME & MeOH & Water & DME \\
& & & & & & & & \\
1 & 8 & 14.129 & 0.1591 & 0.000118 & 0.98886 & 0.011132 & $8.27 \mathrm{E}-06$ \\
2 & 16 & 14.0965 & 0.161428 & 0.000135 & 0.988669 & 0.011322 & $9.45 \mathrm{E}-06$ \\
3 & 38 & 9.200244 & 0.143795 & $8.46 \mathrm{E}-05$ & 0.984602 & 0.015389 & $9.06 \mathrm{E}-06$ \\
4 & 65 & 9.728286 & 0.20505 & $8.50 \mathrm{E}-05$ & 0.979349 & 0.020642 & $8.64 \mathrm{E}-06$ \\
5 & 86 & 7.952188 & 0.195943 & $6.50 \mathrm{E}-06$ & 0.975945 & 0.024047 & $8.08 \mathrm{E}-06$ \\
6 & 106 & 7.088709 & 0.230868 & $1.24 \mathrm{E}-05$ & 0.968442 & 0.031541 & $1.69 \mathrm{E}-05$ \\
8 & 130 & 5.750382 & 0.165872 & $4.53 \mathrm{E}-05$ & 0.971956 & 0.028036 & $7.65 \mathrm{E}-06$ \\
10 & 157 & 4.953652 & 0.193407 & $3.91 \mathrm{E}-05$ & 0.962416 & 0.037576 & $7.91 \mathrm{E}-06$ \\
12 & 180 & 4.978227 & 0.205265 & $4.30 \mathrm{E}-05$ & 0.960392 & 0.039599 & $8.29 \mathrm{E}-06$ \\
20 & 328 & 4.860547 & 0.30336 & $4.35 \mathrm{E}-05$ & 0.941246 & 0.058746 & $8.43 \mathrm{E}-06$ \\
29 & 470 & 4.870703 & 0.452017 & $2.59 \mathrm{E}-05$ & 0.915073 & 0.084922 & $4.86 \mathrm{E}-06$ \\
31 & 493 & 4.643694 & 0.633291 & $5.54 \mathrm{E}-05$ & 0.879981 & 0.120009 & $1.05 \mathrm{E}-05$ \\
35 & 595 & 4.764352 & 0.581181 & 0.001728 & 0.890989 & 0.108688 & 0.000323 \\
41 & 660 & 4.671145 & 0.670652 & 0.009818 & 0.872848 & 0.125318 & 0.001835
\end{tabular}


Table A2. Effect of time on stream on conversions at $5000 \mathrm{lhr} \mathrm{kg}_{c a t}, 523 \mathrm{~K}$, and $\mathrm{H}_{2} /\left(\mathrm{CO}+\mathrm{CO}_{2}\right)=2$.

Run \# Tim:

\% Conversions

(hr) $\mathrm{H} 2 \mathrm{CO} 2 \mathrm{CO} \mathrm{CO}$ to Carbon $\mathrm{CO}$ to $\mathrm{C}$ to $\mathrm{H}$ to $\mathrm{CO} 2 \mathrm{MeOH} \mathrm{MeOH} \mathrm{MeOH}$

$\begin{array}{llllllllll}1 & 8 & 15.877 & 5.036 & 20.94 & -0.522 & 19.44 & 20.99 & 19.01 & 19.01\end{array}$

$\begin{array}{llllllllll}2 & 16 & 19.725 & 5.22 & 22.48 & -0.541 & 20.859 & 20.994 & 18.79 & 18.79\end{array}$

$\begin{array}{llllllllll}3 & 38 & 15.63 & 1.783 & 13.803 & -0.185 & 12.674 & 13.667 & 12.385 & 12.385\end{array}$

$\begin{array}{llllllllll}4 & 65 & 12.899 & 1.196 & 14.151 & -0.124 & 12.934 & 14.454 & 13.095 & 13.095\end{array}$

$\begin{array}{llllllllll}5 & 86 & 8.494 & 2.031 & 11.379 & -0.21 & 10.5 & 11.815 & 10.704 & 10.704\end{array}$

$\begin{array}{llllllllll}6 & 106 & 8.217 & 2.839 & 7.777 & -0.294 & 7.313 & 10.532 & 9.542 & 9.542\end{array}$

$\begin{array}{llllllllll}8 & 130 & 7.534 & 11.765 & 4.944 & -1.22 & 5.585 & 8.544 & 7.74 & 7.74\end{array}$

$\begin{array}{llllllllll}10 & 157 & 6.267 & 2.091 & 5.051 & -0.217 & 4.773 & 7.36 & 6.668 & 6.668\end{array}$

$\begin{array}{llllllllll}12 & 180 & 6.87 & 11.984 & 2.852 & -1.243 & 3.711 & 7.396 & 6.701 & 6.701\end{array}$

$\begin{array}{llllllllll}20 & 328 & 4.785 & 17.423 & 5.936 & -1.807 & 7.015 & 7.221 & 6.543 & 6.543\end{array}$

$\begin{array}{llllllllll}29 & 470 & 7.036 & 7.124 & 4.662 & -0.739 & 4.894 & 7.236 & 6.556 & 6.556\end{array}$

$\begin{array}{llllllllll}31 & 493 & 7.138 & 6.264 & 4.287 & -0.649 & 4.73 & 6.899 & 6.251 & 6.251\end{array}$

$\begin{array}{llllllllll}35 & 595 & 7.495 & 6.625 & 4.656 & -0.687 & 4.841 & 7.078 & 6.413 & 6.413\end{array}$

$\begin{array}{llllllllll}41 & 660 & 5.953 & 15.729 & 4.17 & -1.631 & 5.257 & 6.94 & 6.288 & 6.2688\end{array}$ 
Table A3. Effect of space velocity on condensate production rate and composition at $5.3 \mathrm{~K}$ and different $\mathrm{H}_{2} /\left(\mathrm{CO}+\mathrm{CO}_{2}\right)$ ratios.

S. V. Comp. Prad. Rate(mol/hr Kg) MeOH Water DME comp. Fraction in condensace $\mathrm{MeOH}$ Water DME

RATIO $=2 / 1$

$\begin{array}{ccccccc}3000 & 3.037 & 0.321 & 3.29 E-05 & 0.904 & 0.0958 & 9.79 \mathrm{E}-06 \\ 5000 & 4.764 & 0.581 & 0.001728 & 0.891 & 0.1086 & 0.000323 \\ 7500 & 5.07006 & 0.596 & 5.65 \mathrm{~F}-05 & 0.8947 & 0.1052 & 9.98 \mathrm{E}-06 \\ 10000 & 5.7099 & 0.763 & 0.01196 & 0.8805 & 0.1176 & 0.001844\end{array}$

RATIO $=1 / 1$

$\begin{array}{lllllll}3000 & 2.4399 & 0.0939 & 0.0053 & 0.96117 & 0.03674 & 0.00208 \\ 5000 & 4.989 & 0.2778 & 0.0076 & 0.94588 & 0.05267 & 0.001441 \\ 8000 & 6.2034 & 0.4021 & 0.0055 & 0.9383 & 0.06082 & 0.000836 \\ 13000 & 7.501 & 0.472 & 0.0318 & 0.937 & 0.05899 & 0.00398\end{array}$

RATIO $=0.5 / 1$

$\begin{array}{ccccccc}3000 & 1.991 & 0.1469 & 0.0138 & 0.9253 & 0.06829 & 0.006405 \\ 5000 & 4.8387 & 0.4218 & 0.0558 & 0.9101 & 0.07934 & 0.05582 \\ 8000 & 5.7423 & 0.4659 & 0.0404 & 0.9189 & 0.07456 & 0.00646 \\ 13000 & 7.25 & 0.7354 & 0.01568 & 0.90614 & 0.0919 & 0.00196\end{array}$


Table A4. Effect of space velocity on conversions at $523 \mathrm{~K}$ and different $\mathrm{H}_{2} /\left(\mathrm{CO}+\mathrm{CO}_{2}\right)$ ratios.

S. V.

varkeces $\mathrm{CO}$ CO CO to Carbon $\mathrm{CO}$ to $\mathrm{C}$ to $\mathrm{H}$ to

RATIO $=2 / 1$

3000

5000

7500

$10000 \quad 3.198$
$\mathrm{CO} 2$

$11.16 \quad-4.93$

7.49

6.625

8.048

8.048

$8.54 \quad 3.63$ $\begin{array}{lll}4.34 & 0.5118 & 3.469\end{array}$

4.65

$-0.687$

4.841

0.0835

$-0.885$
MeOH MeOH MEOH

$\begin{array}{lll}7.51 & 6.804 & 6.804\end{array}$

$\begin{array}{lll}7.079 & 6.413 & 6.413\end{array}$

$\begin{array}{lll}5.014 & 4.54 & 4.54\end{array}$

$\begin{array}{lll}4.235 & 3.837 & 3.837\end{array}$

$$
\begin{aligned}
& \text { RATIO }=1 / 1 \\
& \begin{array}{lllllllll}
3000 & 8.96 & 8.48 & 1.78 & -0.8805 & 2.416 & 4.021 & 3.643 & 7.287
\end{array} \\
& \begin{array}{lllllllll}
5000 & 8.653 & 13.525 & 1.67 & -1.403 & 2.789 & 4.941 & 4.477 & 8.955
\end{array} \\
& \begin{array}{lllllllll}
8000 & 7.06 & 16.47 & 0.705 & -1.71 & 2.188 & 4.09 & 3.705 & 7.411
\end{array} \\
& \begin{array}{lllllllll}
13000 & 4.58 & 24.54 & 0.079 & -2.54 & 2.37 & 2.85 & 2.58 & 5.17
\end{array}
\end{aligned}
$$

RATIO $=0.5 / 1$

$\begin{array}{ccccccccc}3000 & 9.28 & -10.73 & 4.04 & 1.003 & 2.776 & 2.47 & 2.258 & 8.701 \\ 5000 & 7.86 & -6.94 & 5.29 & 0.65 & 4.24 & 3.607 & 3.3 & 12.706 \\ 8000 & 7.455 & -5.68 & 4.264 & 0.5311 & 3.414 & 2.67 & 2.44 & 9.41 \\ 13000 & 5.998 & -6.62 & 4.27 & 0.619 & 3.338 & 2.077 & 1.898 & 7.314\end{array}$


Table A5. Effect of space velocity on condensate production rate and composition at different temperatures and at $\mathrm{H}_{2} /\left(\mathrm{CO}+\mathrm{CO}_{2}\right)=2$.

S. V. Comp. Prod. Rate(mol/hr $\mathrm{Kg}$ )

Ihr kgeat MeOH Water DME

$\mathrm{T}=523 \mathrm{~K}$

$\begin{array}{ccccccc}3000 & 3.037 & 0.321 & 3.29 \mathrm{E}-05 & 0.904 & 0.0958 & 9.79 \mathrm{E}-06 \\ 5000 & 4.764 & 0.581 & 0.001728 & 0.891 & 0.1086 & 0.000323 \\ 7500 & 5.07006 & 0.596 & 5.65 \mathrm{E}-05 & 0.8947 & 0.1052 & 9.98 \mathrm{E}-06 \\ 10000 & 5.7099 & 0.763 & 0.01196 & 0.8805 & 0.1176 & 0.001844\end{array}$

$\mathrm{T}=508 \mathrm{~K}$

comp. Fraction in condensate MeOH Water DME

10000

5.7099

$0.763 \quad 0.01196$

0.8805

$0.1176 \quad 0.001844$ 
Table A6. Effect of space velocity on conversions at different temperatures and at $\mathrm{H}_{2} /\left(\mathrm{CO}+\mathrm{CO}_{2}\right)=2$.

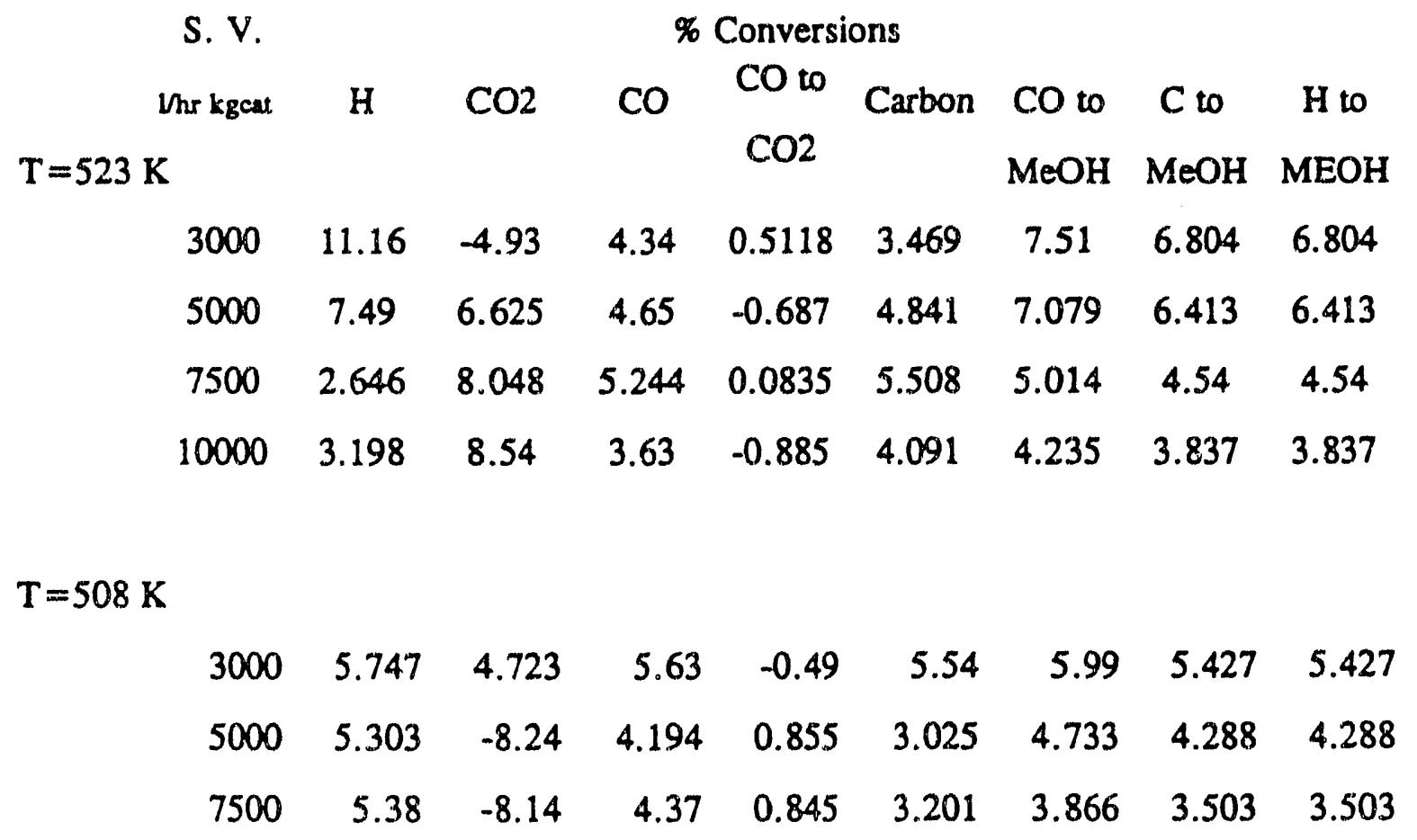


Table A7. Percent error of the proposed equation

$\begin{array}{ccccc} & \begin{array}{c}\text { S.V. } \\ \text { Vhr kgcat }\end{array} & \begin{array}{c}\text { Rmeoh } \\ \text { mol/hr kgcat }\end{array} & \begin{array}{c}\text { Rmeoh eq. } \\ \text { mol/hr kgcat }\end{array} & \text { \% error } \\ \text { Ratio=2 } & 5000 & 4.87 & 4.74 & -2.63 \\ & 10000 & 5.71 & 5.90 & 3.39 \\ & 5000 & 4.64 & 4.74 & 2.02 \\ & 5000 & 4.81 & 4.71 & -1.94 \\ & 5000 & 4.76 & 4.71 & -1.19 \\ & 5000 & 4.67 & 4.69 & 0.50 \\ & 5000 & 4.95 & 4.97 & 0.43 \\ & 5000 & 4.98 & 4.99 & 0.19 \\ \text { Ratio }=1 & 5000 & 5.46 & 5.49 & 0.58 \\ & 13000 & 7.50 & 7.35 & -1.98 \\ & 5000 & 5.45 & 5.55 & 1.85 \\ & 8000 & 6.20 & 6.21 & 0.12 \\ & 5000 & 4.86 & 4.82 & -0.82 \\ \text { Ratio }=0.5 & 5000 & 5.44 & 5.45 & 0.08 \\ & 5000 & 5.38 & 5.41 & 0.44 \\ & 13000 & 7.25 & 7.19 & -0.86\end{array}$

Absolute average error : $\quad 1.19$ 
APPENDIX B

EQUILIBRIUM CALCULATIONS PROGRAM 


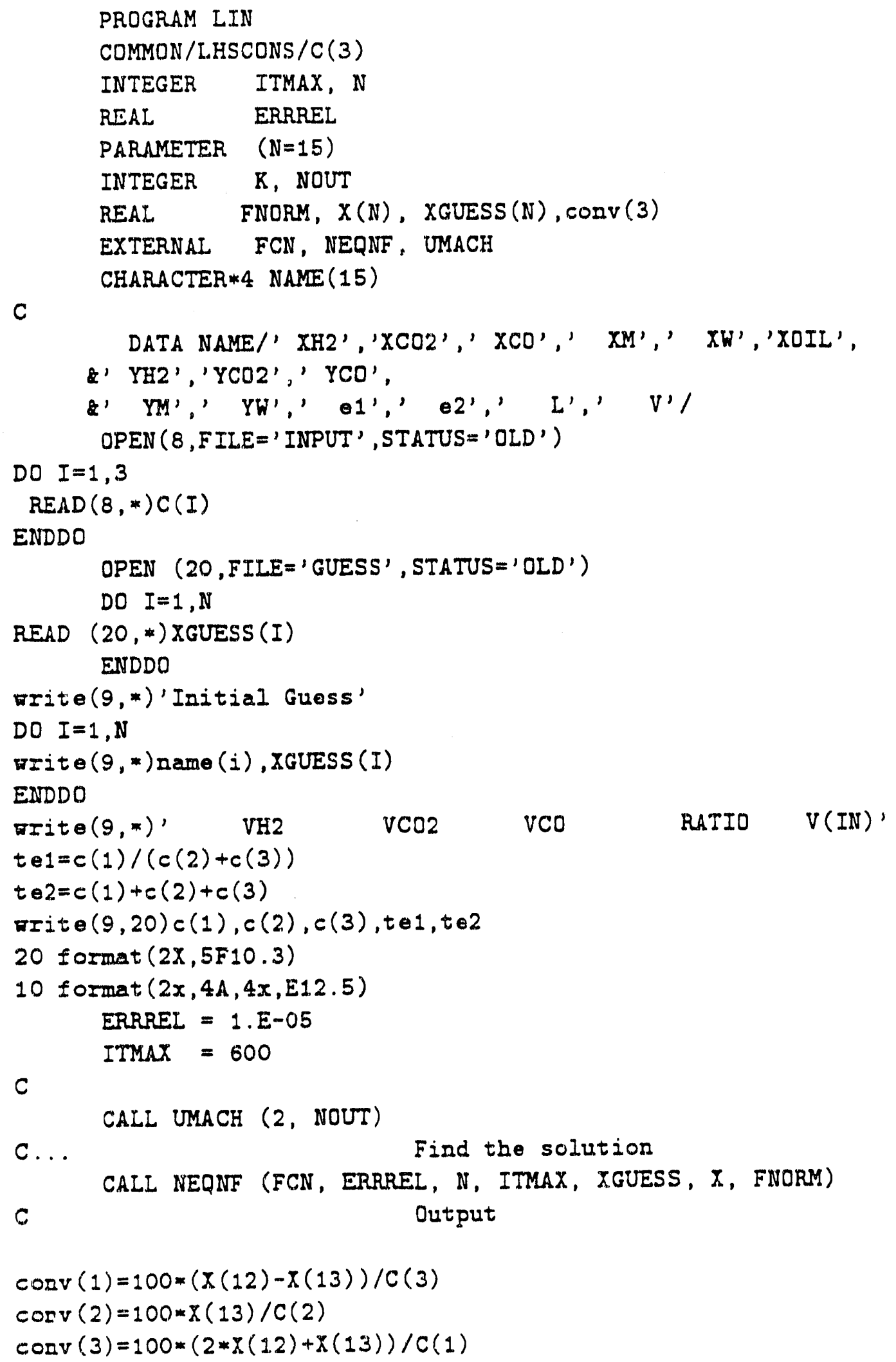


WRITE $(9, *)$ 'SOLUTION'

do $\mathrm{k}=1, \mathrm{n}$

$\operatorname{WRITE}(9, *)$ name $(k), X(K)$

endio

WRITE $(9, *)$ 'EITOI NORM'

WRITE $(9, *)$ FNORM

WRITE $(9, *)$ 'Stoping Criteria used'

WRITE $(9, *)$ ERRREL

WRITE $(9, *)$ ' \%CONVERS IONS :'

$\operatorname{WRITE}(9, *) ' \operatorname{CONV} C O=\prime, \operatorname{CONV}(1)$

$\operatorname{WRITE}(\theta, *) ' \operatorname{CONV} \operatorname{CO2}=\prime, \operatorname{CONV}(2)$

$\operatorname{WRITE}(9, *) ' \operatorname{CONV} \mathrm{H} 2=\prime, \operatorname{CONV}(3)$

END

C.

C. User-defined subroutine

SUBROUTINE FCN (X, F, N)

COMMON/LHSCONS/C ( 3 )

INTEGER N

REAL $\quad X(N), F(N)$

C

$$
\begin{aligned}
& F(1)=X(15) * X(7)+X(14) * X(1)+2 * X(12)+X(13)-C(1) \\
& F(2)=X(15) * X(8)+X(14) * X(2)+X(13)-C(2) \\
& F(3)=X(15) * X(9)+X(14) * X(3)+X(12)-X(13)-C(3) \\
& F(4)=X(15) * X(10)+X(14) * X(4)-X(12)-0.0 \\
& F(5)=X(15) * X(11)+X(14) * X(5)-X(13)-0.0 \\
& F(6)=X(14) * X(6)-6.0856 \\
& F(7)=X(14)+X(15)+2 * X(12)-(C(1)+C(2)+C(3)+6.0856) \\
& F(8)=X(1)+X(2)+X(3)+X(4)+X(5)+X(6)-1 . \\
& F(9)=X(7)-2.21 * X(1) \\
& F(10)=X(8)-91.8 * X(2) \\
& F(11)=X(9)-6.61 * X(3) \\
& F(12)=X(10)-1.92 * X(4) \\
& F(13)=X(11)-1.37 * X(5) \\
& F(14)=X(4)-88.17 * X(3) * X(1) * 2 \\
& F(15)=X(5) * X(3)-0.248785 * X(1) * X(2) \\
& \text { RETURN } \\
& \text { END }
\end{aligned}
$$


APPENDIX C

PROCESS SIMULATION PROGRAM 


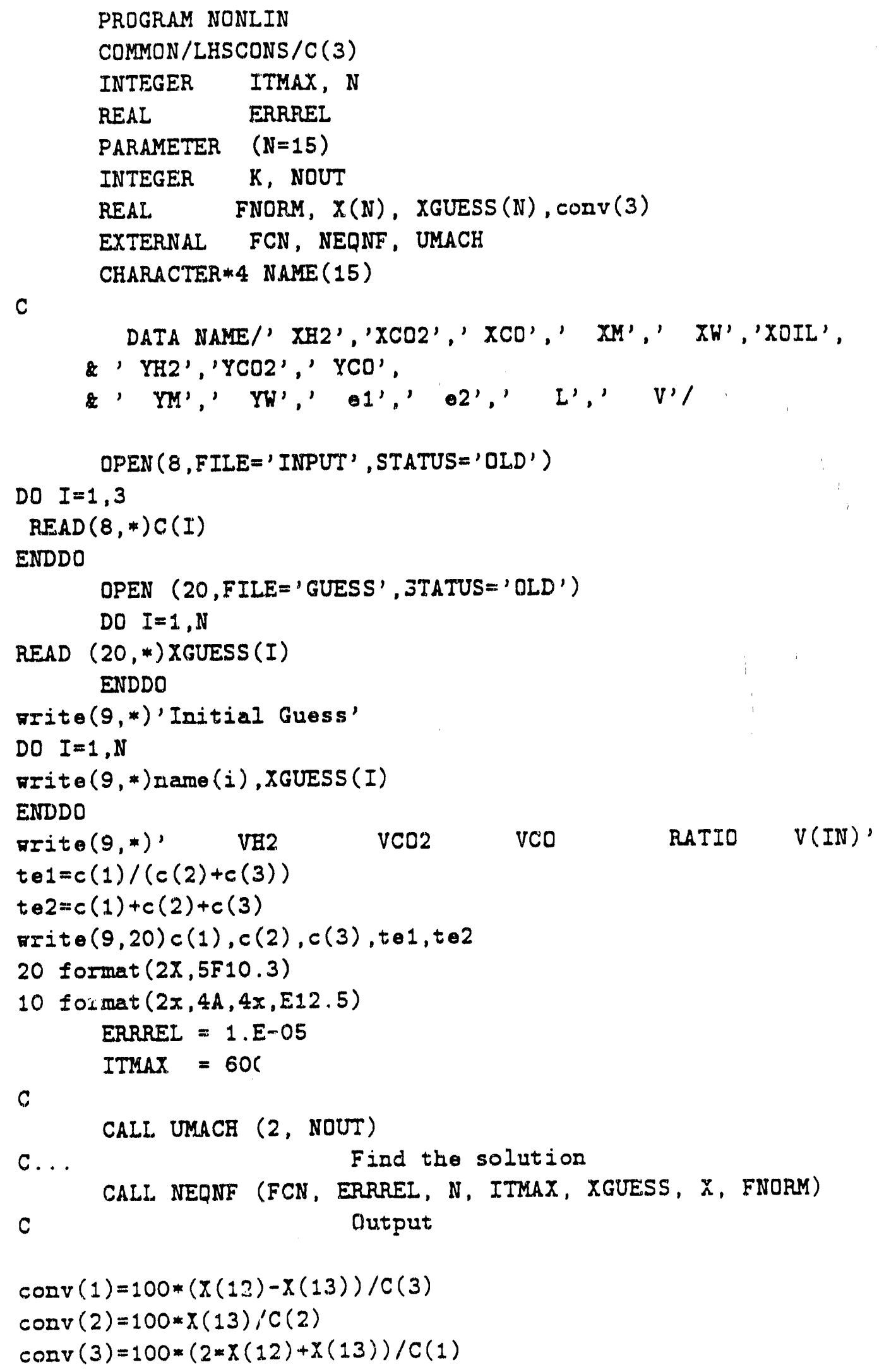


WRITE $(9, *)$ 'SOLUTION'

do $k=1, n$

WRITE $(9, *) \operatorname{name}(k), X(K)$

enddo

WRITE $(9, *)$ 'EIIOI NORM'

$\operatorname{WRITE}(9, *)$ FNORM

WRITE $(9, *)$ 'Stoping Criteria used'

WRITE $(9, *)$ ERRREI

WRITE $(9, *)$ ' $\%$ CONVERS IONS :'

$\operatorname{WRITE}(9, *), \operatorname{CONV} C O=\prime, \operatorname{CONV}(1)$

$\operatorname{WRITE}(9, *) \cdot \operatorname{CONV} \operatorname{CO} 2=\prime, \operatorname{CONV}(2)$

$\operatorname{WRITE}(9, *) ' \operatorname{CONV} \mathrm{H} 2=\prime, \operatorname{CONV}(3)$

C

END

C

User-defined subroutine

SUBROUTINE FCN $(X, F, N)$

COMMON/LESCONS/C ( 3 )

INTEGER N

REAL $X(\mathbb{N}), F(\mathbb{N})$

C

$$
\begin{aligned}
& F(1)=X(15) * X(7)+X(14) * X(1)+2 * X(12)+X(13)-C(1) \\
& F(2)=X(15) * X(8)+X(14) * X(2)+X(13)-C(2) \\
& F(3)=X(15) * X(9)+X(14) * X(3)+X(12)-X(13)-C(3) \\
& F(4)=X(15) * X(10)+X(14) * X(4)-X(12)-0.0 \\
& F(5)=X(15) * X(11)+X(14) * X(5)-X(13)-0.0 \\
& F(6)=X(14) * X(6)-14.15 \\
& F(7)=X(14)+X(15)+2 * X(12)-(C(1)+C(2)+C(3)+14.15) \\
& F(8)=X(1)+X(2)+X(3)+X(4)+X(5)+X(6)-1 . \\
& F(9)=X(7)-2.21 * X(1) \\
& F(10)=X(8)-91.8 * X(2) \\
& F(11)=X(9)-6.61 * X(3) \\
& F(12)=X(10)-1.92 * X(4) \\
& F(13)=X(11)-1.37 * X(5) \\
& F(14)=.853823+0.582 * \operatorname{LOG}(X(7))+0.779 * \operatorname{LOG}(X(9)) \\
& \&-I D G(X(12))-0.385 * \operatorname{LOG}(X(10))-0.0644 * \operatorname{LOG}(X(11)) \\
& F(15)=X(5) * X(3)-0.248785 * X(1) * X(2)
\end{aligned}
$$

RETURN

END 
Hamad A. Al-Adwani is an employee of Kuwait University where he was granted a scholarship to pursue both a M.S. and a Ph.D. degree in chemical engineering specializing in kinetics and catalysis. Following the completion of his academic requirements he will join the Chemical Engineering Department of Kuwait University as a faculty member.

The author's permanent address is

Hamad Abdulwahab Al-Adwani

Kuwait University

Chemical Engineering Department

P. O. Box $5969 \quad$ Safat

State of Kuwait $\quad 13060$ 

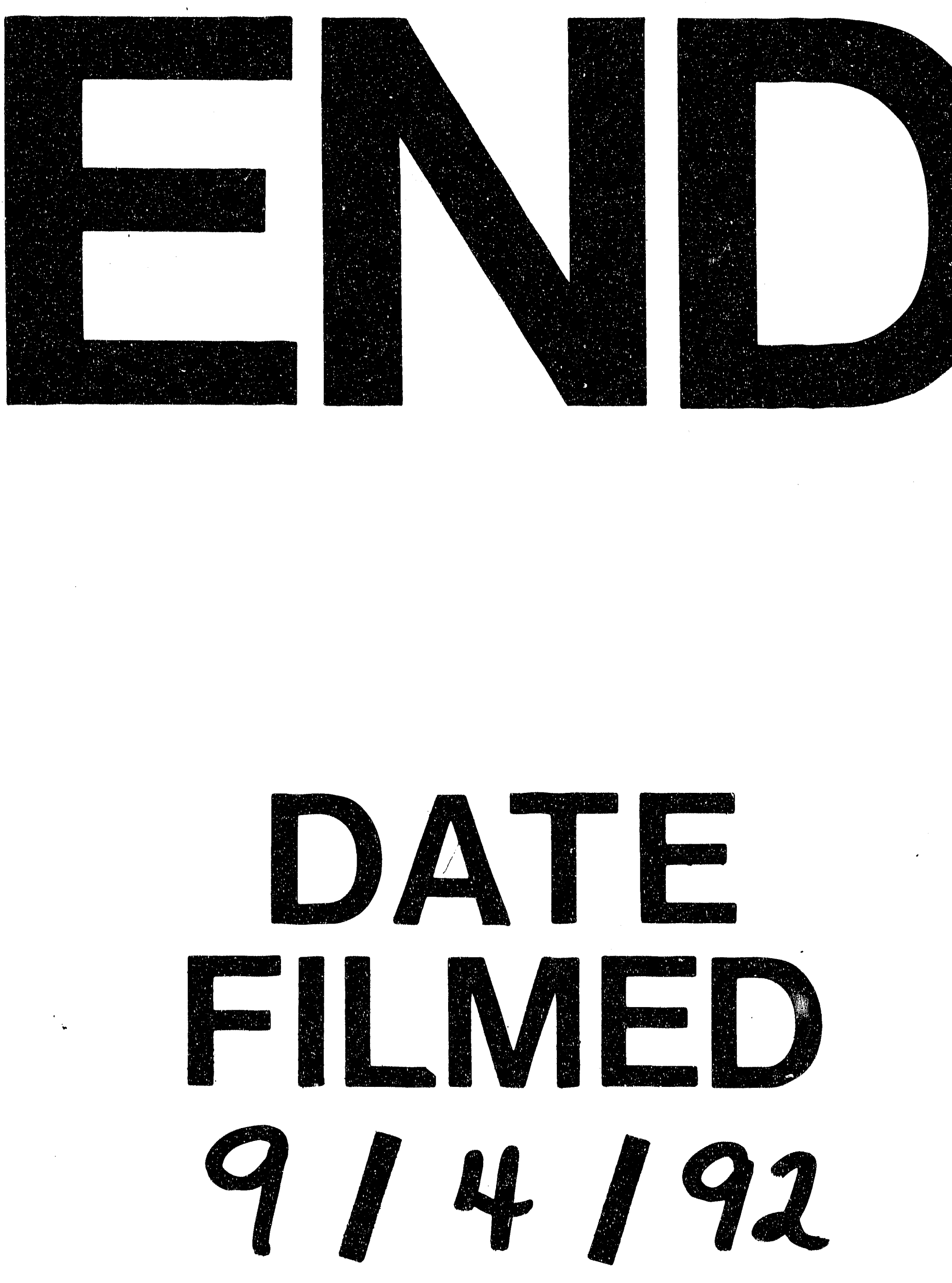


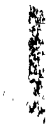

